

\section{Public JOURNAL OF Transportation}

Gary L. Brosch, Editor

Patricia Henderson Ball, Managing Editor

\section{Editorial Board}

Robert B. Cervero, Ph.D. University of California, Berkeley

Chester E. Colby MK Centennial

Gordon Fielding, Ph.D. University of California, Irvine David J. Forkenbrock, Ph.D. University of lowa José A. Gómez-Ibáñez, Ph.D. Harvard University
Naomi W. Ledé, Ph.D.

Texas Transportation Institute

William W. Millar American Public Transit Association

Steven E. Polzin, Ph.D., P.E. University of South Florida

Sandra Rosenbloom, Ph.D.

University of Arizona

Lawrence Schulman LS Associates

George Smerk, D.B.A.

Indiana University

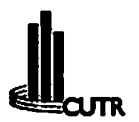

The Journal of Public Transportation (ISSN 1077-291X) is published quarterly by the Center for Urban Transportation Research (CUTR) in the College of Engineering at the University of South Florida. The contents of this document reflect the views of the authors, who are responsible for the facts and the accuracy of the information presented herein. This document is disseminated under the sponsorship of the U.S. Department of Transportation, University Research Institute Program, in the interest of information exchange. The U.S. Government assumes no liability for the contents or use thereof. Subscriptions are complimentary and may be obtained by contacting the Center for Urban Transportation Research, University of South Florida, 4202 E. Fowler Avenue, CUT 100, Tampa, FL 33620-5375, (813) 974-3120, e-mail: pball@cutr.eng.usf.edu. 


\section{Public \\ JOURNAL OF \\ Transportation}

Volume 3, No. 4, 2001

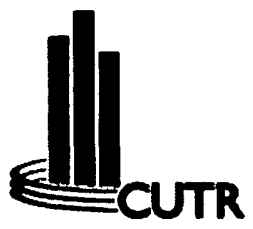

(C) 2001 Center for Urban Transportation Research

National Center for Transit Research

Center for Urban Transportation Research

College of Engineering - University of South Florida

4202 E. Fowler Avenue, CUT 100, Tampa, FL 33620-5375

(813) 974-3120 • Fax (813) 974-5168

E-mail: pball@cutr.eng.usf.edu

Web Site: http://www.cutr.eng.usf.edu 


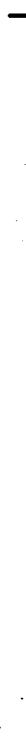




\section{Public \\ JOURNAL OF \\ Transportation}

Volume 3, No. 4, 2001

\section{Contents}

Walk-and-Ride: Factors Influencing Pedestrian Access to Transit

Robert Cervero

The Absence Consequences of Overtime in the Transit Industry

Yoram Shiftan and Nigel H. M. Wilson

Multicriteria Feasibility Evaluation for Rural Transit in Georgia

George D. Mazur, Karen K. Dixon, and Wayne A. Sarasua

Visualization of Transit Mobility and Performance

Anibal A. Galíndez and Ricardo Mireles-Córdova

Evaluation of Garden State Parkway Alternate Bus Routing

Field Operational Test

Kaan Ozbay, Tilanka Karunararatne, Trefor Williams,

Diogenes Feldhaus, and Mohsen Jafari

Our troubled planet can no longer afford the luxury of pursuits confined to an ivory tower. Scholarship has to prove its worth. not on its own terms, but by service to the nation and the world.

$\square$ Oscar Handlin 


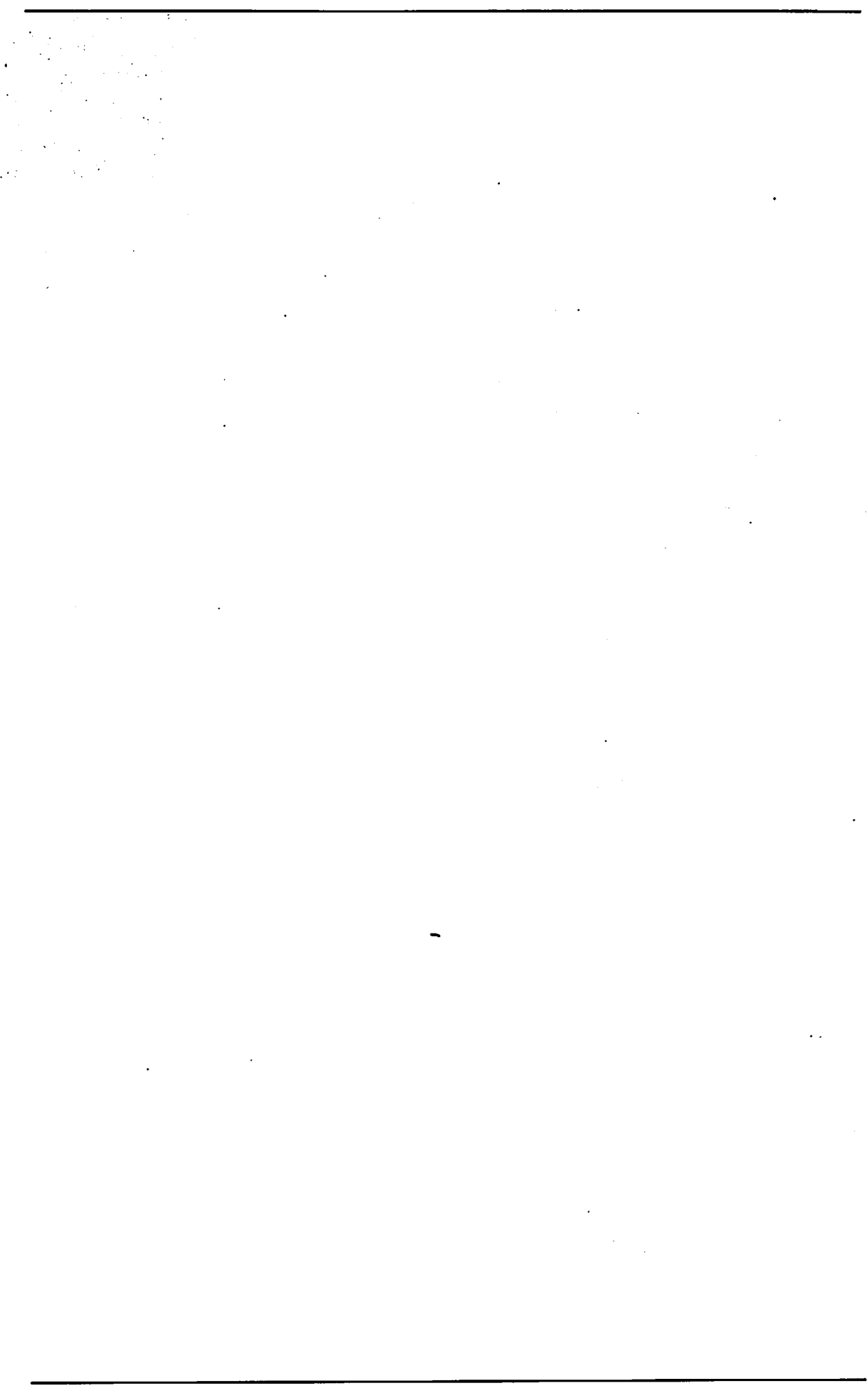




\title{
Walk-and-Ride: Factors Influencing Pedestrian Access to Transit
}

\author{
Robert Cervero \\ Univerity of Califoria, Berkeley
}

\begin{abstract}
$\overline{\text { Abstract }}$
The predominant means of reaching suburban rail stations in the United States is by private car. Transit villages strive, among other things, to convert larger shares of rail access trips to walk-and-ride, bike-and-ride, and bus-and-ride. Empirical evidence on how built environments influence walk-access to rail transit remains sketchy. In this article, analyses are carried out at two resolutions to address this question. Aggregate data from the San Francisco Bay Area reveal compact, mixed-use settings with minimal obstructions are conducive to walk-and-ride rail patronage. A disaggregate-level analysis of access trips to Washington Metrorail services by residents of Montgomery County, Maryland, shows that urban design, and particularly sidewalk provisions and street dimensions, significantly influence whether someone reaches a rail stop by foot or not. Elasticities are presented that summarize findings. The article concludes that conversion of park-and-ride lots to transit-oriented developments holds considerable promise for promoting walk-and-ride transit usage in years to come.
\end{abstract}

\section{Accessing Rail Transit}

In much of America, and particularly in the suburbs, the automobile has become the mobility standard for accessing rail transit systems. Consequently, transit stations encircled by a sea of parking have become a common feature of 
America's suburban landscape. Indeed, parking lots are the dominant "land uses" within a half-mile of most suburban rail stations in the United States.

In parts of the United States, efforts are underway to change this, converting parking lots and transforming station areas into "transit villages" (Cervero 1996a; Bernick and Cervero 1997). The transit village concept embraces many objectives, including neighborhood revitalization, improved transportation conditions, and enhancement of built and natural environments. While the chief environmental benefit of transit-oriented development comes from coaxing motorists over to mass transit, a secondary benefit is the inducement of more walk and bicycle access trips to and from transit.

Getting more rail transit users to walk-and-ride, bike-and-ride, or bus-andride rather than park-and-ride could yield a number of benefits. By reducing the need for parking lots, rail transit agencies could redirect investments and resources to improved mainline services. Less surface parking would also reduce the separation of land uses, effectively "de-scaling" suburban landscapes, and free up land for infill development. And encouraging nonmotorized forms of station access would yield transportation and environmental benefits by reducing vehicle-miles-traveled (and thus greenhouse gas emissions and energy consumption) as well as the traffic snarls and noise levels that often afflict neighborhoods located near rail stations. Research has shown that the "dis-amenity" of living near a park-and-ride lot can lower residential property values, all else being equal. In the case of the Santa Clara Light Rail Transit system, Landis et al. (1994, p. 28) found single-family homes within 800 feet of a light-rail station with a parking lot were worth about $\$ 31,000$ less than equivalent properties beyond the immediate impact zone of a station, controlling for other factors.

Perhaps the biggest environmental benefit from converting larger shares of rail access trips from park-and-ride to walk-and-ride and other means would be less air pollution. From an air quality standpoint, transit riding does little good if most people use their cars to reach stations. For a 3-mile automobile trip, the typical distance driven to access a suburban park-and-ride lot in the United States (Cervero 1995), 84 percent of hydrocarbon (HC) emissions and 54 per- 
cent of nitrogen oxide (NOx) emissions are due to cold starts (inefficient cold engines and catalytic converters during the first few minutes of driving) and hot evaporative soaks (Barry and Associates 1991). That is, a sizeable share of tailpipe emissions of the two main precursors to the formation of photochemical smog occur from turning the automobile engine on and driving a mile and turning it off. Drive-alone access trips to rail stations, regardless of how short they are, emit levels of pollutants that are not too much below those of the typical 10-mile solo commute. Thus, relying on a car to access a metropolitan rail service pretty much negates the air quality benefits of patronizing transit.

The three core dimensions, or " 3 D's," of built environments-density, diversity, and design-as defined by Cervero and Kockelman (1997) are thought to influence access trips to rail stops, along with parking provisions, though to what degree remains unclear since relatively little systematic work has been conducted to date on this question. In general, we know that, as densities fall and distances to downtowns increase, Americans increasingly rely on mechanized means to reach stations. In downtowns, most people reach transit stops by foot. Surveys of residents accessing downtown San Francisco stations to take BART (Bay Area Rapid Transit) to work reveal that two-thirds arrive by foot (Cervero 1995). As one leaves downtown stations and heads outwards, the share of walk-on trips falls precipitously, replaced by mechanized access trips-park-and-ride, kiss-and-ride (i.e., passenger drop-off), and bus-and-ride. At suburban BART stations, like Walnut Creek and Fremont, over 85 percent of access trips are by passenger car, and fewer than 5 percent are by foot or bicycle travel. Studies in greater Washington, D.C., metropolitan Toronto, and the San Francisco Bay Area show that beyond 1 mile of a suburban rail station, 60 to 80 percent of access trips are by automobile, with the share rising steadily as access distance increases (Stringham 1982; JHK and Associates 1987, 1989; Cervero 1994).

This article probes the influences of various factors, particularly those related to physical land-use patterns and built environments, which explain walk-and-ride forms of rail-transit usage. It is postulated that the three core dimensions of the built environment - density, diversity, and design-promote 
walk-and-ride access. Density does this mainly by bringing larger shares of residents within walking distances of rail stops. Diversity, reflecting the degree of land-use mixture, promotes walking by allowing pedestrians to efficiently consolidate trip ends - such as between a station, retail shop, and a residence, and without the need of a car-by bringing mixed activities closer together (Cervero 1988). And design matters, in that having a continuous and complete sidewalk network in place in addition to a visually stimulating environment enhances the walking experience. Research by Untermann (1984) shows the typical "maximum" acceptable suburban walking distance of one-quarter to a half-mile can be stretched considerably (perhaps as much as doubled) by creating pleasant and interesting urban spaces and corridors.

To test these propositions, two sets of analyses are carried out. The first analysis is conducted at an aggregate scale, using multiple regression to explain walk access market shares for 34 BART stations in the San Francisco Bay Area. The second analysis is disaggregate in scale, using binomial logit models to predict the probability that a resident of Montgomery County, Maryland, reached a Washington Metrorail station by foot versus private car. (Efforts to model bicycle-and-ride access as well were unsuccessful because sample sizes were too small in both case studies.) By shedding light on the link between built environments and walk-and-ride access, it is hoped this research can inform ongoing efforts to promote and design transit-oriented developments as well as provide insights into planning and design for station-area circulation.

\section{Aggregate Analysis: Walk-and-Ride Access to and Egress from Bart Stations}

This section presents regression models that predict the influences of land-use variables as well as other factors (e.g., parking supplies) on percentages of access and egress trips by walking. The distinction between the two is that access represents travel from one's residence to a rail stop whereas egress signifies movement from a rail stop to one's nonresidential destination, such as a workplace. BART's 34 stations and their surrounding one-half-mile areas served as cases for studying variation in walk access and walk egress modal splits. 


\section{Data Sources and Model Structure}

For purposes of estimating market shares of access trips by walking for each of BART's original 34 stations, data from on-board surveys of over 35,000 BART passengers compiled in late-1992 were used (Bay Area Rapid Transit District 1993). The effects of distance on access modes were plotted from these data (using GIS to measure the straight-line distance from the residence of each surveyed passenger to the nearest BART station portal). For distance intervals within a 3-mile access-shed, Figure 1 shows the dominant means of home-end access for commute trips were: walking, 5/8 mile or less; transit, 5/8 to 1 mile; and park-and-ride, beyond 1 mile. Clearly, concentrating housing near rail stops induces walk-and-ride trips. BART's 5/8-mile threshold for walk trips considerably exceeds the one-quarter mile threshold customarily used to define walking access to transit but is less than the 4,000-foot "walking impact zone" (wherein the majority of rail trips were by walk-ons) that Stringham (1982) found for rail stations in Toronto.

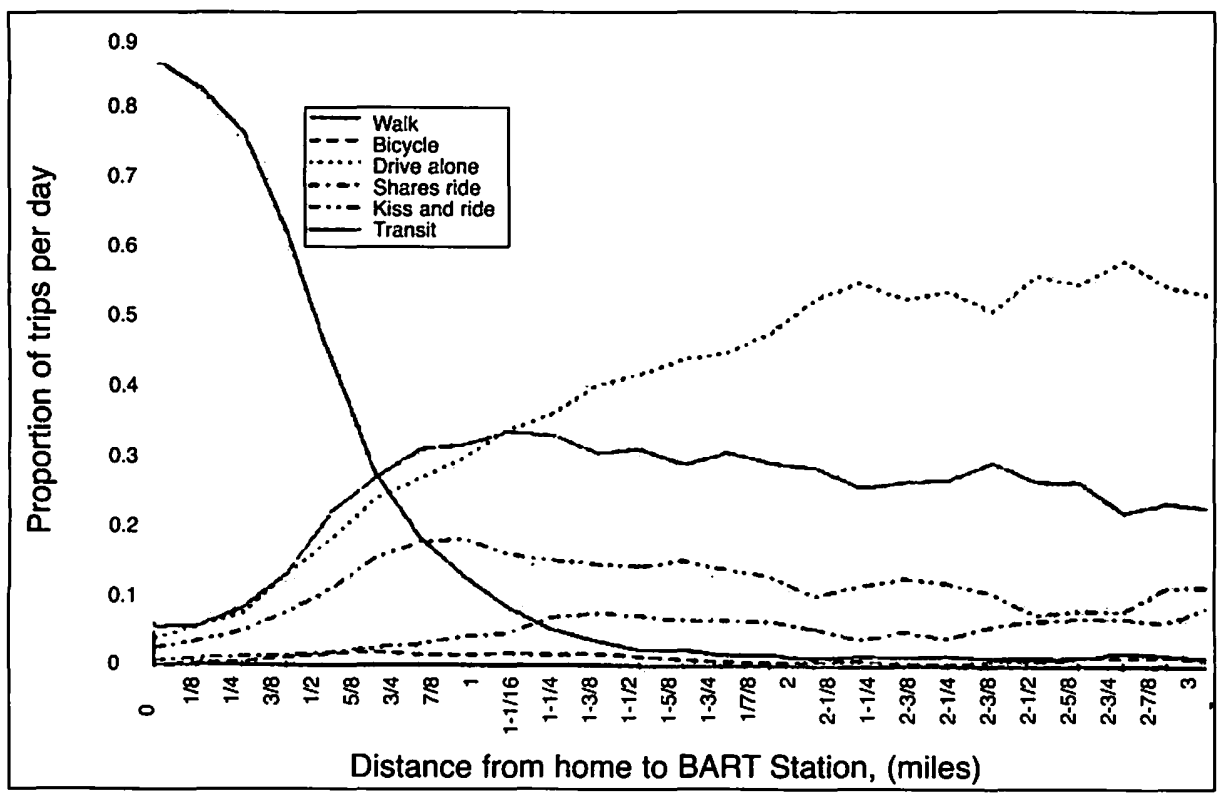

Figure 1. Distribution of means of access as a function of distance to BART station for journeys-to-work: 0- to 3-mile distance, derived for all BART stations 
The principal land-use data used in the analyses that follow were a digital inventory of dominant land uses within hectare grid cells $(100 \times 100$ meters), compiled by the Association of Bay Area Government (ABAG) for the entire San Francisco Bay Area. Using GIS, buffers were drawn to estimate the composition of land uses within a one-half-mile radius of each of the 34 stations. Residential and employment densities were estimated for block groups and census tracts surrounding each station, based on 1990 census data. Transit data, such as parking supplies at BART stations and feeder bus service levels in and around stations, were compiled from local transit agencies in the Bay Area including BART, AC Transit, and San Francisco Muni.

The regression models that follow explain walk-and-ride market shares mainly in terms of the land-use features (e.g., residential densities) and transportation provisions (e.g., supply of parking spaces) in and around BART stations. Only variables that were reasonably statistically significant and had interpretable results were included in the models. An ordinal variable that rated stations in terms of sidewalk provisions was a candidate for model entry but was statistically insignificant. Efforts were also made to introduce various control variables; however, none of these variables was significant enough to enter the model either. Median household incomes in the vicinity of stations, for instance, had no appreciable effect on whether BART users walked to stations once variables like density were controlled. Nor did factors like station function (e.g., whether a transfer station) or proximity of a station to freeways. Far more important were attributes of built environments-namely, densities and mixtures of land uses-as well as supply-side variables related to parking provisions, transit service levels, and station setting.

\section{Walk-and-Ride Access}

Table 1 presents a best-fitting regression model that explained 89 percent of the variation in walk-access modal splits for BART's 34 stations. Consistent with the hypotheses, the table shows that the share of BART access trips by foot increased sharply with densities (especially residential densities) and mixed-land uses around stations and fell as substitutes to walking (i.e., lots of parking and good transit connections) were more plentiful. According to the 
model, an increase in residential densities of 10 households per gross acre was associated with an 11.3 percentage point increase in the share of access trips by walking, controlling for parking supplies and other explanatory variables. Also, devoting large shares of station-area land to residential uses is a strong inducement to walk-and-ride. This finding supports the contention of transit

\begin{tabular}{|c|c|c|c|}
\hline \multirow[b]{3}{*}{ Variables } & $\begin{array}{l}\text { entage o } \\
\text { rip Purp }\end{array}$ & $\begin{array}{l}\text { Access TI } \\
\text { es, } 1992\end{array}$ & \\
\hline & \multicolumn{3}{|c|}{ Estimates: } \\
\hline & Coefficient & $\begin{array}{l}\text { Standard } \\
\text { Error }\end{array}$ & Probability \\
\hline \multicolumn{4}{|l|}{ Density } \\
\hline $\begin{array}{l}\text { Employment density: Workers per gross acre within one-half } \\
\text { mile of station }\end{array}$ & .330 & .057 & .000 \\
\hline $\begin{array}{l}\text { Residential density: Households per gross acre within one-half- } \\
\text { mile of station }\end{array}$ & 1.130 & .314 & .001 \\
\hline \multicolumn{4}{|l|}{ Land-Use Type and Diversity } \\
\hline $\begin{array}{l}\text { Residential orientation: Percent of land area within one-half mile } \\
\text { of station in residential use }\end{array}$ & .532 & .312 & .100 \\
\hline $\begin{array}{l}\text { Land-use diversity: Normalized entropy index of land-use } \\
\text { mixture within one-half mile of station }\end{array}$ & 55.746 & 35.308 & .127 \\
\hline \multicolumn{4}{|l|}{ Transit Provisions } \\
\hline Number of park-and-ride spaces at station & -0.020 & .004 & .000 \\
\hline $\begin{array}{l}\text { Transit service levels: Route miles per } 1,000 \text { households within } \\
\text { one-half mile of station }\end{array}$ & -3.121 & 1.099 & .009 \\
\hline Terminal or near-terminal station: $0=\mathrm{no}, 1=$ yes $^{\mathrm{c}}$ & 19.569 & 6.886 & .009 \\
\hline Constant & -18.664 & 42.474 & .664 \\
\hline \multicolumn{4}{|l|}{ Summary Statistics } \\
\hline Number of cases & & & 34 \\
\hline F Statistic (probability & & & $29.30(.000)$ \\
\hline $\mathrm{R}^{2}$ & & & \\
\hline \multicolumn{4}{|c|}{$\begin{array}{l}\text { 'Normalized entropy }=\left\{-\Sigma_{k}\left[\left(p_{i}\right)\left(\ln p_{i}\right)\right]\right\} /(\ln k) \text {, where: } p_{i}=\text { proportion of total land area devoted to dominant use } \\
\text { for land-use category } i \text { (where the } i \text { categories are residential, commercial, industrial/office, public, and other); and } \\
k=5 \text { (number of land-use categories). A } 0 \text { value signifies land devoted to a single use and } I \text { denotes land area } \\
\text { evenly spread among the five land-use categories. } \\
\text { 'Route miles of all surface transit modes, including bus transit, streetcar trams, light-rail transit, and cable car } \\
\text { services, within one-half mile of rail station, excluding BART services. } \\
\text { 'Near-terminal represents stations toward the end of the line that function like terminals because they are closer to } \\
\text { freeways than the actual terminals and thus tend to serve larger ridership catchments. BART's near-terminal } \\
\text { stations, El Cerrito del Norte and Pleasant Hill, have larger supplies of parking than terminal stations since they are } \\
\text { easier to reach by freeway. }\end{array}$} \\
\hline
\end{tabular}


village design that calls for a significant residential presence for purposes of invigorating station areas and providing "eyes on the community 24 hours a day" (Bernick and Cervero 1997, p. 10). This finding also likely reflects the dynamics of "residential sorting"-the tendency of those who have a proclivity to commute via transit and are drawn to the idea of not having to drive to work to conscientiously locate near a station when renting or buying a place to live (Voith 1991; Cervero 1994).

As expected, provisions for competitive means of station access worked against walking-and-riding. Plentiful parking spaces evidently prompted significant shares of BART users to drive instead of walk to stations, even when controlling for factors like residential densities and land-use mixes. Similarly, intensive transit services around stations encouraged bus-and-ride at the expense of pedestrian access. Interestingly, the table shows that, once parking supplies and other factors were controlled for, terminal and near-terminal stations tended to have higher levels of access trips by foot, despite their freeway and highway orientations. This finding largely reflects the presence of several large apartment complexes in the vicinity of two near-terminal stations, Pleasant Hill and El Cerrito del Norte, yielding high shares of walk-access trips to these two stations.

\section{Walk-and-Ride Egress}

To explore whether the influences of land-use variables on walking market shares were symmetrical at both ends of a transit trip, models were also estimated for egress trips (i.e., from a rail stop to the final trip destination). Table 2 shows that the relationships for explaining walk egress trips were very similar as those found for walk access trips, though land-use variables exerted even stronger influences in this model. Controlling for densities, parking supplies, and other factors, for instance, Table 2 indicates a station area that had a balanced mix of land uses averaged 73 percent more egress trips by walking than one surrounded by a single land use. Every 10 additional jobs per acre, the model suggests, were associated with a 3.33 percentage point increase in egress trips by foot, holding other factors constant. Working against walk egress trips were parking supplies, bus service levels, and interestingly, the 
presence of a freeway median. The results suggest that BART stations situated in freeway medians averaged around 7 percent fewer egress trips by foot, controlling for densities and other factors. This finding buttresses the argument that quality of walking environment matters. Freeway medians often form bar-

Table 2

\section{Regression Model for Predicting Percentage of Egress Trips from BART Stations by Walking, All Trip Purposes, 1992}

\begin{tabular}{|c|c|c|c|}
\hline \multirow[b]{2}{*}{ Variables } & \multicolumn{3}{|c|}{ Estimates: } \\
\hline & Coefficient & $\begin{array}{l}\text { Standard } \\
\text { Error }\end{array}$ & Probability \\
\hline \multicolumn{4}{|l|}{ Density } \\
\hline $\begin{array}{l}\text { Employment density: Workers per gross acre within one-half } \\
\text { mile of station }\end{array}$ & .338 & .050 & .000 \\
\hline $\begin{array}{l}\text { Residential density: Households per gross acre within one-half- } \\
\text { mile of station }\end{array}$ & 1.556 & .310 & .000 \\
\hline \multicolumn{4}{|l|}{ Land-Use Type and Diversity } \\
\hline $\begin{array}{l}\text { Residential orientation: Percent of land area within one-half mile } \\
\text { of station in residential use }\end{array}$ & .637 & .310 & .050 \\
\hline $\begin{array}{l}\text { Land-use diversity: Normalized entropy index of land-use } \\
\text { mixture within one-half mile of station }\end{array}$ & 73.577 & 37.090 & .058 \\
\hline \multicolumn{4}{|l|}{ Transit Provisions } \\
\hline Number of park-and-ride spaces at station & -0.012 & .003 & .000 \\
\hline $\begin{array}{l}\text { Transit service levels: Route miles per } 1,000 \text { households within } \\
\text { one-half mile of station }\end{array}$ & -3.629 & 1.054 & .002 \\
\hline Station located in freeway median: $0=$ no, layes & 19.569 & 6.886 & .009 \\
\hline Constant & -35.370 & 42.293 & .441 \\
\hline \multicolumn{4}{|l|}{ Summary Statistics } \\
\hline Number of cases & & & 34 \\
\hline F Statistic (probability & & & $28.91(.000)$ \\
\hline $\mathbf{R}^{2}$ & & & .886 \\
\hline
\end{tabular}

'Normalized entropy $=\left\{-\Sigma_{i}\left[\left(p_{i}\right)\left(\ln p_{i}\right)\right]\right\} /(\ln k)$, where: $p_{i}=$ proportion of total land area devoted to dominant use for land-use category $i$ (where the $i$ categories are residential, commercial, industrialoffice, public, and other); and $k=5$ (number of land-use categories). A 0 value signifies land devoted to a single use and 1 denotes land area evenly spread among the five land use categories.

${ }^{b}$ Route miles of all surface transit modes, including bus transit, streetcar trams, light-rail transit, and cable car services, within one-half mile of rail station, excluding BART services.

'Near-terminal represents stations toward the end of the line that function like terminals because they are closer to freeways than the actual terminals and thus tend to serve larger ridership catchments. BART's near-terminal stations, El Cerrito del Norte and Pleasant Hill, have larger supplies of parking than terminal stations since they are easier to reach bv freewav. 
riers to movement in many ways - physically, visually, psychologically, and symbolically. The vibrations caused by heavy freeway traffic, and shadows cast by elevated structures can also discourage foot travel.

\section{Synopsis: Elasticities}

While the regression results reveal the statistical significance of factors shaping walk-and-ride access, it is difficult to judge the relative importance of particular explanatory variables from model outputs. To shed light on the relative sensitivity of walk-access to land-use variables and other factors, results are best summarized in elasticity form. Table 3 presents midpoint elasticities imputed from the regression results, revealing the percentage of change in walk-and-ride market shares for every 1 percent increase in the mean value of each land-use variable.' The table shows that, in general, the relationship between built environments and walking-and-riding is fairly inelastic, though the influences of land-use variables are generally as strong as other predictors. Walk-access and walk-egress market shares were most influenced by concentrated development around stations. This lends credibility to the transit village concept for the results clearly reveal that compact residential development within a half-mile of a rail stop significantly induces travel to and from stations. Also, access and egress modal splits were more sensitive to residential densities than to employment densities. Land-use diversity also mattered: high mixed-use settings around rail stops encouraged walk-and-ride, ostensibly because residents can take care of personal needs, like picking up a few groceries after work, when retail shops and other services lie between stations and their homes. Loutzenheiser (1997) also showed the presence of retail near stations encouraged walk-access trips to BART. In a study of transit usage nationwide using the American Housing Survey, Cervero (1996b) similarly found mixed-land uses to be an inducement to transit riding for those living within several miles of a rail station.

In addition to land-use variables, Table 3 shows factors related to transit provisions also appreciably influenced walk-and-ride behavior. Notably, parkand-ride supplies were a significant deterrent to walk-access and walk-egress. 


\begin{tabular}{|l|c|}
\hline \multicolumn{3}{|c|}{ Table 3} \\
Mid-point Elasticities of Access and Egress Walk Trips \\
as Functions of Land-Use and Other Explanatory Variables
\end{tabular}

The physical characteristics of stations, such as being situated in the median of a freeway or at (or near) the end of a line, exerted relatively weak influences on whether BART patrons walked-and-rode, once factors like density and parking supplies were controlled for.

\section{Disaggregate Analysis: Walk-and-Ride Access to and Egress from Washington Metrorail Stations}

While the analysis of walk-and-ride behavior in the San Francisco Bay Area supported the core hypotheses of this research, the findings captured aggregate patterns of travel behavior. Because variables defining attributes of surveyed BART riders were sparse, disaggregate analyses could not be conducted. For this purpose, data were compiled on access trips among residents of Montgomery County, Maryland, who patronized the Washington Metrorail system.

Montgomery County, Maryland, a fairly affluent county of 850,000 inhabitants adjacent to the District of Columbia, provides a good setting to explore the research hypotheses in greater depth because the county planning department maintains fairly rich data on land-use characteristics of its 318 traffic analysis zones (TAZs). In particular, far more variables were available from Montgomery County to explore the effects of urban design factors on walk access. 


\section{Data Sources and Model Structure}

Trip records for 177 Montgomery County residents who made a trip aboard Washington Metrorail were drawn from the 1994 Household Travel Survey compiled for the Metropolitan Washington Council of Government (MWCOG) region. Added to these records were various land-use, activitylocation, urban design, and accessibility measures associated with the TAZ of the origin of each trip record, typically representing a person's place of residence. A number of additional variables (e.g., land-use diversity, gross densities) were created using input variables of each TAZ.

A binomial logit model, of the following form, was used to estimate the probability a Montgomery County resident patronizing Metrorail accessed the station by foot:

$\mathrm{P}_{\text {nio }}=\exp \left(\mathrm{V}_{\text {nio }}\right) /\left[\mathrm{L}_{\mathrm{j} \in \mathrm{C} \text { no }} \exp \left(\mathrm{V}_{\text {njo }}\right], \quad \forall \mathrm{V}_{\text {nio }}=f\left(\mathrm{~T}_{\mathrm{io}}, \mathrm{SE}_{\mathrm{n}}, \mathrm{BE}, \mathrm{BE}_{\mathrm{d}}\right)\right.$

where:

$\mathbf{P}_{\text {nio }}=$ probability of person $\mathrm{n}$ choosing means $\mathrm{i}$ for accessing the nearest Metrorail station from the person's residence at origin 0 ;

$\mathrm{C}_{\mathrm{nod}}=$ choice set of modes available to person $\mathrm{n}$ traveling from origin o to the nearest Metrorail station;

$\mathrm{V}_{\text {nio }}=$ utility function (systematic component) for person $\mathrm{n}$ traveling by mode $\mathrm{i}$ from origin $\mathrm{o}$ to the nearest Metrorail station;

$T_{i o}=$ trip characteristics for travel (e.g., time) by mode $i$ from origin o to the nearest Metrorail station;

$\mathrm{SE}_{\mathrm{n}}=$ socioeconomic characteristics of trip-maker $\mathrm{n}$ (e.g., income and vehicle availability); and

$\mathrm{BE}_{\mathrm{o}}=$ built environment vector for $\mathrm{TAZ}$ origin o, representing measures of land-use intensity, land-use mixture, and walking quality.

As with the analysis of access to BART, the aim was to estimate the bestfitting model that yielded significant and interpretable explanatory variables. A number of variables reflecting densities and land-use mixtures at trip origins were examined in terms of their ability to increase utility for walk-and-ride access; however, only a handful were found to be reasonably significant. 
Among the candidate variables considered for gauging walking quality, the ones that proved to be the best predictors included the ratio of sidewalk miles to road miles (as an index of sidewalk provisions) and intersection density (number of intersections per square mile, an indicator of degree of trafficstream conflict points and street connectivity).

The logit model was estimated only from records of Montgomery County residents who patronized Metrorail at stations where park-and-ride facilities were available. This meant park-and-ride as well as bus-and-ride and kiss-and-ride were bonafide alternatives for access a Metrorail station. Because the availability of park-and-ride was a control introduced in the analysis, the supply of parking spaces did not enter as a variable for predicting the probability of walk access.

\section{Walk-and-Ride Access}

The best-fitting binomial logit model, shown in Table 4, yielded a pseudo-R-squared (rho) statistic of 0.57 , indicating the model does a 57 percent better job than a simple flip of a coin at predicting whether a Montgomery County Metrorail patron accessed a station by walking or not. Land-use factors related to the " 3 D" core dimensions-proximity (a correlate of density), diversity, and design-significantly influenced the odds of a Montgomery County resident reaching a station by foot versus a motorized mode. Travel time to a station impeded walking whereas having large shares of housing near a station spurred it. As with BART, living near Metrorail was a strong inducement to walk-on access. This finding is consistent with research by JHK and Associates $(1987,1989)$ that revealed remarkably high rates of transit commuting among apartment and condominium dwellers who resided close to Washington Metrorail stations, with transit capturing over a 50 percent market share in the case of several apartment projects.

Similar to the findings of the aggregate analysis, more mixed-use environments also seemed to promote walking access, ostensibly because transit riders can chain trip ends by foot in more diverse settings (e.g., walk from a station to a nearby shop to one's residence when returning home from work via Metrorail in the evening). Diversity within a much larger 45-minute travel shed was likewise positively associated with walking access, suggesting subregional balance worked in favor of foot travel as well. 
Of particular note was the value of urban design factors in inducing pedestrian access. Montgomery residents were more likely to walk-and-ride than parkand-ride in settings with fairly complete sidewalk networks. Intersection density, a proxy for degree of road connectivity, also promoted walking access. A neighborhood with a fine grain mesh of intersections, it appears, provided more possibilities for conveniently connecting origins and destinations by foot.

\begin{tabular}{|c|c|c|c|}
\hline \multicolumn{4}{|c|}{$\begin{array}{c}\text { Table } 4 \\
\text { Binomial Logit Model } \\
\text { for Predicting Probability Montgomery County Resident Taking } \\
\text { Metrorail Accessed Station by Walking, All Trip Purposes, } 1994\end{array}$} \\
\hline \multirow[b]{2}{*}{ Variables } & \multicolumn{3}{|c|}{ Estimates } \\
\hline & Coefficient & $\begin{array}{l}\text { Standard } \\
\text { Error }\end{array}$ & Probability \\
\hline \multicolumn{4}{|l|}{ Nearness and Proximity } \\
\hline \multicolumn{4}{|l|}{$\begin{array}{l}\text { Time to nearest Metrorail station from residence, highway } \\
\text { network (minutes) }\end{array}$} \\
\hline $\begin{array}{l}\text { Proportion of households in TAZ of residence within one-half } \\
\text { mile of Metrorail Station }\end{array}$ & 2.758 & 1.656 & .096 \\
\hline \multicolumn{4}{|l|}{ Diversity } \\
\hline $\begin{array}{l}\text { Land-use diversity, TAZ of residence: Employment and } \\
\text { population relative to county ratio }\end{array}$ & 18.500 & 11.256 & .100 \\
\hline $\begin{array}{l}\text { Job accessibility, TAZ of residence: Number of jobs (in 1000s) } \\
\text { within 45-minute highway network travel time }\end{array}$ &. .005 & .002 & .036 \\
\hline \multicolumn{4}{|l|}{ Design } \\
\hline $\begin{array}{l}\text { Ratio of sidewalk miles to road miles, } \\
\text { TAZ of residence }\end{array}$ & 1.133 & .647 & .080 \\
\hline $\begin{array}{l}\text { Intersection density, TAZ of residence: Number of intersections } \\
\text { per square mile }\end{array}$ & .008 & .007 & .272 \\
\hline Constant & -1.059 & .220 & .040 \\
\hline \multicolumn{4}{|l|}{ Summary Statistics } \\
\hline Number of cases & & & 177 \\
\hline $\begin{array}{l}-2 L(c): \text { Log likelihood function value, } \\
\text { constant-only model }\end{array}$ & & & 99.768 \\
\hline $\begin{array}{l}-2 \mathrm{~L}(B): \mathrm{Log} \text { likelihood function value, } \\
\text { parameterized model }\end{array}$ & & & 58.283 \\
\hline $\begin{array}{l}\text { Model chi-square (probability): } \\
-2[L(c)-L(B)]\end{array}$ & & & $41.485(.0000)$ \\
\hline$\rho^{2}$ (Nagelkerke) & & & .574 \\
\hline \multicolumn{4}{|c|}{$\begin{array}{l}\text { - Diversity }=1-\{\text { ABS }[(b \text { * (population - employment)] } /[(b \text { • (population + employment)]\}, where } b= \\
\text { countywide ratio of employment to population, set at } 0.464 \text { for } 1994 \text { (based on data from County Business Patterns, } \\
\text { Montgomery County, Maryland, U.S. Department of Commerce, 1995). }\end{array}$} \\
\hline
\end{tabular}


Surprisingly, none of the socioeconomic control variables-including the person's age, gender, vehicle availability, and household income-entered the model as significant predictors. Evidently, walk-and-ride access, at least in Montgomery County, does not discriminate with respect to user demographics.

\section{Walk-and-Ride Egress}

A binomial logit model, shown in Table 5, was also estimated to predict the probability a Montgomery County resident who patronized Metrorail walked from the disembarking station to his or her trip destination. While

\begin{tabular}{|c|c|c|c|}
\hline \multicolumn{4}{|c|}{$\begin{array}{c}\text { Table } 5 \\
\text { Binomial Logit Model } \\
\text { for Predicting Probability Montgomery County Resident Taking } \\
\text { Metrorail Walked from Station to Destination, All Trip Purposes, } \\
1994 \text { Metrorail Accessed Station by Walking, All Trip Purposes, } 1994\end{array}$} \\
\hline \multirow[b]{2}{*}{ Variables } & \multicolumn{3}{|c|}{ Estimates } \\
\hline & Coefficient & $\begin{array}{l}\text { Standard } \\
\text { Error }\end{array}$ & Probability \\
\hline \multicolumn{4}{|l|}{ Nearness and Proximity } \\
\hline $\begin{array}{l}\text { Distance from Metrorail station to destination, highway network } \\
\text { (miles) }\end{array}$ & -3.518 & 1.28 & .006 \\
\hline \multicolumn{4}{|l|}{ Location } \\
\hline Washington, D.C. destination: $0=$ No, $1=$ Yes & .376 & .354 & .288 \\
\hline \multicolumn{4}{|l|}{ Design } \\
\hline $\begin{array}{l}\text { Ratio of sidewalk miles to road miles, } \\
\text { TAZ of destination" }\end{array}$ & .977 & .766 & .183 \\
\hline Median street width, TAZ of destination (feet) & -.058 & .032 & .066 \\
\hline Constant & 5.273 & 2.989 & .077 \\
\hline \multicolumn{4}{|l|}{ Summary Statistics } \\
\hline Number of cases & & & 177 \\
\hline $\begin{array}{l}-2 \mathrm{~L}(c) \text { : Log likelihood function value, } \\
\text { constamt-only model }\end{array}$ & & & 95.265 \\
\hline $\begin{array}{l}-2 L(B) \text { : Log likelihood function value, } \\
\text { parameterized model }\end{array}$ & & & 57.006 \\
\hline $\begin{array}{l}\text { Model chi-square (probability): } \\
-2[L(c)-L(B)]\end{array}$ & \multicolumn{3}{|c|}{$38.259(.0000)$} \\
\hline$\rho^{2}$ (Nagelkerke) & & & .745 \\
\hline
\end{tabular}


fewer predictor variables entered this model than the others, the model nonetheless had a good overall fit with a rho statistic of almost 0.75 .

The walk-egress model magnified the importance of urban design factors in encouraging people to walk upon disembarking a station. Controlling for the fact that walk egress eroded rapidly with distance from a station and was highest for egress trips from a station in the District of Columbia, the model reveals scale of streets and sidewalk provisions weighed in on the decision to walk (versus, say, take a bus or taxi). Notably, streetscapes with relatively narrow curb-to-curb widths and flanked by continuous and complete sidewalk networks were the most conducive to walk-egress travel.

\section{Synopsis: Elasticities}

As in the case of regression results, it is difficult to judge the relative importance of particular explanatory variables from logit model outputs. To do this, it is best to again translate and summarize logit results in elasticity form. Disaggregate elasticities represent the sensitivity of an individual's choice probability to a change in the value of some attribute (Ben-Akiva and Lerman 1985). They were imputed by systematically increasing one built-environment variable at a time by 1 percent and applying each of the models to measure the corresponding percentage change in mode-choice probabilities, setting values for all other variables in the utility function at their statistical means (in the case of ratio-scale variables) or modes (in the case of categorical-scale variables). ${ }^{2}$ Estimates represent mode-choice point elasticities for the "typical" Montgomery County traveler. Mathematically, the elasticity (E) of the probability of person $n$ choosing mode $i\left(P_{n i}\right)$ as a function of a change in the value of variable $X_{k}$ for person $n$ and mode $i\left(X_{k n i}\right)$, with all other variables set at their mean or modal values, equals:

$$
E_{X \mathrm{nni}}^{P_{n i}}=\left(\partial P_{n i} / \partial X_{k n i}\right)\left(X_{k n i} / P_{n i}\right) ; \forall V_{n i}=f\left(\bar{x}_{1 n i,} \bar{x}_{2 n i, \ldots,} \bar{x}_{k-1 n i,} \bar{x}_{k+1 n i, \ldots}\right.
$$

Table 6 presents imputed point elasticities. Overall, the disaggregate analysis reveals fairly inelastic, though still meaningful, relationships. Distance and time were the greatest impedances to Montgomery County residents walking-and-riding. Next in importance were urban design features, par- 


\section{Table 6}

Point Elasticity Estimates Imputed from Logit Models:

Percentage Change in Probability of Walk-and-Ride Travel with a 1-Percent Increase in Explanatory Variable

\begin{tabular}{|lcc|}
\hline Explanatory Variables & Walk Access & Walk Egress \\
\hline Time to Metrorail Station & -362 & - \\
\hline Distance from Metrorail Station & - & -.506 \\
\hline Sidewalk Ratio & .231 & .160 \\
\hline Intersection Density & .061 & - \\
Street Width & - & -.382 \\
Housing Proximity & .163 & \\
\hline Land-Use Diversity & .147 & - \\
\hline Job Accessibility & .211 & - \\
\hline
\end{tabular}

ticularly at the trip destination. Land-use diversity also worked in favor of walk access, though only marginally. In contrast to the aggregate analysis from the Bay Area, densities at either trip end exerted no discernible influences on the likelihood of walking-and-riding in the disaggregate analyses.

\section{Toward Walking-Friendly Transit Environments}

Walk-and-ride transit usage is one of the most sustainable forms of urban mobility. Giving up a car in favor of walking to a station can improve air quality by eliminating cold-start emissions associated with park-and-ride access. Converting parking lots to residential and commercial land uses can also help leverage transit village development and the environmental and transportation benefits associated with it (Calthorpe 1993; Bernick and Cervero 1997).

Based on a triangulated research design, drawing insights from two different metropolitan areas at two different grains of analyses, this research revealed that built environments exert significant influences on walk-and-ride access. Assuming they are within reasonable distance of a station, rail passengers are more likely to walk to and from a station in compact, mixed-use settings with ample sidewalk provisions and minimal physical obstructions. Concentrated development around stations likely stimulates walk-and-ride in 
many instances among those who purposefully opt to live within walking distance of rail transit for the very purpose of economizing on commuting.

The fact that these relationships were uncovered in two settings at two different grains analysis suggests that they are robust. In general, the analyses at both grains were fairly consistent and reinforcing. Whatever differences existed between the aggregate and disaggregate analyses could be due to contextual differences as much as differences in research resolutions. In a study of access trips to BART stations, Loutzenheiser (1997) similarly obtained somewhat different, though overall reinforcing, results depending on the scale of analysis.

All transit trips involve some degree of walking; however, this research makes clear that attending to the mobility and design needs of those who exclusively walk to and from stations is especially important. While many programs for enhancing station-area environments tend to focus on residential settings, facilitating pedestrian movements once passengers disembark at stations is equally important. Often, egress needs are neglected altogether. In the case of commuter rail services to Santa Clara County, California, quality of egress has deteriorated to the point where patrons are keeping a second car near their destination station to complete the final leg of their journeys to work. A recent article in the San Jose Mercury News (2000) reports:

Silicon Valley is spawning a new type of commuter: a hybrid who takes the train to escape the misery of the freeway but makes the final leg of the journey to work by car. In a trend that has taken planners by surprise, so many riders on the Altamont Commuter Express and Capital Corridor trains are keeping second cars in Santa Clara that the city is building a new lot for overnight parking.

The one trend that could go a long way toward promoting walk-and-ride transit usage is the conversion and adaptive reuse of park-and-ride lots. With time, surface parking lots that envelope rail stations across the United States are proving to be a blessing in disguise for they provide large swaths of preassembled land. Many were originally overbuilt, thanks to generous federal funding for rail transit development. As neighborhoods around rail stops have 
matured and land values have increased, market pressures are prompting some U.S. transit agencies to sell off at least portions of them as a means both to create a ridership base and to reap windfalls in the form of value capture. Often the profits earned are more than enough to cover the cost of replacement structured parking, freeing up land for infill development. Surface parking conversion, then, is a back-door form of land-banking, a strategy long used in Scandinavia to create transit villages (Cervero 1998).

An important event that has made the retrofitting and adaptive reuse of parking lots possible has been the Federal Transit Administration's revised policy on joint development. In the past, transit agencies that sold off parking lots to private developers had to return most of the proceeds to the U.S. Treasury since federal grant monies originally paid for the parking facilities (Bernick and Freilich 1998). Under the new ruling, transit agencies can retain all income as long as the resulting real estate project is transit-supportive in its design and tied to a specific plan aimed at station-area redevelopment. While well intentioned, this is hardly philanthropy on the federal government's part. Encouraging infill, station-area development is in the direct financial interest of the U.S. Department of Transportation since the addition of new riders will help reduce operating deficits, thus lessening the demand for federal transit operating subsidies.

One of the first places to take advantage of the new federal ruling on joint development is San Jose, California. The City and the Santa Clara Valley Transportation Authority (SCVTA) have joined forces in designing a mid-rise, mixed-use project on the park-and-ride lot at the Ohlone-Chynoweth light rail station (Figure 2). Historically, Santa Clara County's light-rail system has struggled to build a ridership base in large part because much of its service territory consists of a landscape of sprawling office campuses (including the Silicon Valley) and car-oriented shopping plazas. However, as the demand for affordable housing with good access to the Silicon Valley has intensified, local policy-makers have come to the realization that parking-lot infilling was too good an opportunity to pass up. At the time of project development, only 30 percent of the 1,140 original parking spaces at the Ohlone-Chynoweth station 


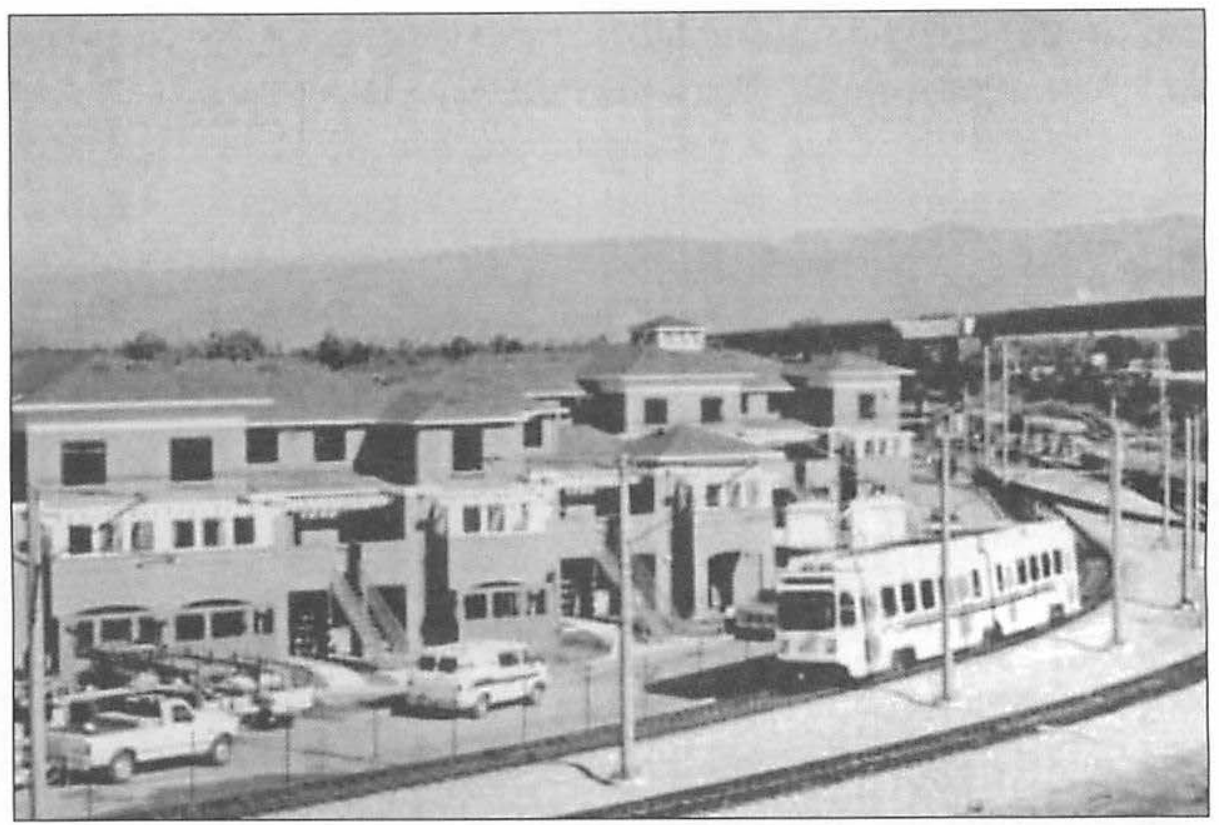

Figure 2. Adaptive reuse of a parking lot. Mixed housing-market and below-market rate units-on the former park-and-ride lot at the Ohlone-Chynoweth Station, San Jose, California

were used. Currently, 500 parking spaces are being converted to 195 units of two- and three-story town homes, a retail plaza, a child-care facility, and a community recreation center.

Whether the Ohlone-Chynoweth project is a bellwether for what is in store for station areas across the United States or just one more example of California as a "statistical outlier," only time will tell. Regardless, for both environmental and economic reasons, transit agencies and city planners need to seriously focus on strategies that will promote alternatives to park-and-ride access to rail transit. While there will always be a need for park-and-ride provisions, this need not be at the expense of overlooking the needs of pedestrians, bicyclists, and bus riders. As revealed by this research, creating built environments that attend to the needs of pedestrians and commingle activities within reasonable distances of each other can encourage more and more Americans to leave their cars at home and access rail stations by some other means. 


\section{Endnotes}

1. Midpoint elasticities are measured at the mean values of both the dependent and independent variable, using mean values for all other "control" variables in the equation as well.

2. The following mean values were used in calculating binomial probabilities: travel time $=9$; travel distance $=1$; land-use diversity (based on comparative population and employment ratios) $=0.34$; sidewalk ratio at residential end $=0.835$; sidewalk ratio at destination end $=0.958$; intersection density $=157$; median street width $=35$; proportion of housing within a half-mile of a rail station $=0.076$; and job access index $=1500$. For the computation of walk egress elasticities, the dummy variable for a Washington, D.C. location was set at the modal (most frequently occurring) value of 0 .

\section{References}

Barry and Associates. 1991. Air quality in California. Sacramento: California Air Resources Board.

Bay Area Rapid Transit District. 1993. BART passenger profile survey. Oakland: Bay Area Rapid Transit District, unpublished report.

Ben-Akiva, M., and S. Lerman. 1985. Discrete choice analysis: Theory and application to travel demand. Cambridge, MA: MIT Press.

Bernick, M., and R. Cervero. 1997. Transit villages for the twenty-first century. New York: McGraw-Hill.

Bernick, M., and A. Freilich. 1998. Transit villages and transit-based development: The rules are becoming more flexible. Urban Lawyer 30, 1: 1-31.

Calthorpe, P. 1993. The next American metropolis: Ecology, community and the American dream. New York: Princeton Architecture Press.

Cervero, R. 1988. Land-use mixing and suburban mobility. Transportation Quarterly 42: $429-446$.

Cervero, R. 1994. Transit-based housing in California: Evidence on ridership impacts. Transportation Policy 1, 3: 174-183.

Cervero, R. 1995. Rail access modes and catchment areas for the BART system. Berkeley: University of California, Institute of Urban and Regional Development, BART@20 Study. 
Cervero, R. 1996a. California's transit village movement. Journal of Public Transportation 1, 1: 103-130.

Cervero, R. 1996b. Mixed land-uses and commuting: Evidence from the American Housing Survey. Transportation Research A 30, 5: 361-377.

Cervero, R., and K. Kockelman. 1997. Travel demand and the 3 Ds: Density, diversity, and design. Transportation Research D 2, 3: 119-219.

Cervero, R. 1998. The transit metropolis: A global inquiry. Washington, DC: Island Press.

JHK and Associates, 1987. Development-related ridership survey I. Washington, DC: Washington Metropolitan Area Transit Authority.

JHK and Associates, 1989. Development-related ridership survey II. Washington, DC: Washington Metropolitan Area Transit Authority.

Landis, J., S. Guhathakurta, and M. Zhang. 1994. Capitalization of transit investments into single-family home prices: A comparative analysis of five California rail transit systems. Berkeley: University of California, Institute of Urban and Regional Development, Working Paper 619.

Loutzenheiser, D. 1997. Pedestrian access to transit. Transportation Research Record 1427.

San Jose Mercury News. 2000. Silicon Valley Redefines " $2^{\text {nd }}$ Car": More Workers Riding the Rails Then Taking Own Vehicle to Job. December 20: p. B-1.

Stringham, M. 1982. Travel behavior associated with land uses adjacent to rapid transit stations. ITE Journal 52, 4: 18-22.

Untermann. 1984. Accommodating the pedestrian: adapting towns and neighborhoods for walking and bicycling. New York: Van Nostrand Reinhold.

Voith, R. 1991. Transportation, sorting and house values. American Real Estate and Urban Economics Association 19, 2: 117-137.

\section{About the Author}

ROBERT CERvero (robertc@uclink.berkeley.edu) is a professor of city and regional planning at the University of California, Berkeley. $\mathrm{He}$ is the author of five books, including The Transit Metropolis (Island Press, 1998), Transit Villages for the 21st Century (McGraw-Hill, 1997), and Paratransit in America (Praeger, 1997). 
Dr. Cervero's current projects include a study of the informal transport sector for the United Nations, an evaluation of car-sharing, research on reverse-commuting trends, and an assessment of the land-market impacts of transit-oriented development. He is currently a Fellow with the Urban Land Institute and Lincoln Land Institute. 


\title{
The Absence Consequences of Overtime in the Transit Industry
}

Yoram Shiftan, Technion, Israel Institute of Technology Nigel H. M. Wilson, Massachusetts Institute of Technology.

\begin{abstract}
The transit industry relies on overtime to fill in for worker absence or to cover unexpected extra work. The purpose of this article is to study the absence consequences of overtime in the transit industry through a disaggregate model of absence. The model was estimated with panel data of transit operators to test the hypothesis that widespread availability of overtime may induce absence. This might occur for two reasons. Some employees may be more likely to be absent after reaching a threshold pay amount for a period, and this level will be reached after fewer hours on the job if overtime work is readily available. Other employees may be absent more because of the increased stress and fatigue associated with regularly working long hours including overtime. The results suggest that absence is more a habit than the result of a decision process based on past overtime worked.
\end{abstract}

\section{Introduction}

The transit industry relies on overtime to fill in for worker absence or to cover unexpected extra work. The importance of service reliability and the uncertainty about both the workforce available and the amount of work to be performed at a given time in the transit industry leads to the employment of more workers than those actually scheduled for work. Too large a workforce will result in low productivity, since some employees who do not have any useful work to perform must still be paid. Reducing the workforce size will require 
more overtime. Since it is common in the transit industry to provide substantial fringe benefits for employees but only small marginal benefits for working overtime (beyond the typical pay premium), it is not unusual for the total cost per hour of labor produced by an employee working overtime to be similar to that for an employee working regular time. This situation may lead to a policy of relying heavily on overtime to fill in for absent employees and to cover extra work requirements.

There are two reasons why this naive "cost-minimizing" solution might be inappropriate. First, frequently employees have the right to decline overtime work if they so choose, and the greater the reliance on overtime, the larger the number of situations in which no employees will be available and willing to work overtime, thus potentially significantly affecting service reliability. Second, if large amounts of overtime are worked, there may be an increase in levels of absence among the workforce. This might occur for two reasons. Some employees may be more likely to be absent after reaching a threshold pay amount for a period, and this level will be reached after fewer hours on the job if overtime work is readily available. Other employees may be absent more because of the increased stress and fatigue associated with regularly working long hours including overtime. In many properties, straight runs can be as long as 9 or 10 hours. The union contract usually requires that the longest duties go to regular operators who can also work overtime. This can result in operators working up to 13 or 14 hours per day and receiving up to 17 hours of equivalent straight-time pay. This has resulted in a great deal of stress on the operator in some properties.

Several papers have explored the general relationships between absence and overtime, some finding positive correlation between these two variables (Martin 1971; Gowler 1969), with others finding no such relationship (Buck and Shimmin 1959; Flanagan et al. 1974). Within the transit industry few studies found positive relationships between absence and overtime work including Perry (1983), Leahy, Sprague, and Schlegel (1979), Brown (1981) (as cited by Perry 1983), and Perin (1984); one study (Smith et al. 1980) found no such relationships. Considering that all these studies used either aggregate or weak mea- 
sures of absence or overtime, or small samples, further study is required to resolve the relationship between overtime availability and absence.

This article examines the absence consequences of overtime in the transit industry. If reliance on overtime creates more absence, then the direct cost of the employee working overtime will be less than the full cost of the overtime. Understanding the full cost of overtime is essential to the decision on workforce sizing as shown by strategic workforce planning models (Koutsopoulos and Wilson 1987; Hickman et al.1988; and Shiftan and Wilson 1994). This issue is of special interest today because many industries are aggressively downsizing their workforce.

This article presents a case study based on the Massachusetts Bay Transportation Authority (MBTA) to study this problem. The cost structure in which an hour of overtime costs the agency less than an hour of an extra operator is true for the MBTA because the high cost of fringe benefits that apply to employees working regular time outweighs the 50 percent pay premium for overtime work. The researchers test the hypothesis that widespread overtime availability may induce absence versus the alternative hypothesis that absence is more a result of individual characteristics through a disaggregate model of employee absence. The next section presents the development of a theoretical framework for exploring the relationship between overtime and absence, assuming absence results from a decision process using the income-leisure trade-off model.

\section{The Income-Leisure Trade-off Model}

Subjective cost/benefit or income/leisure evaluation by the employee is known as the income-leisure trade-off in workforce participation. Under this theory, the employee evaluates the economic and social benefits of work attendance versus leisure time and acts accordingly. Holding work schedule flexibility constant, the researchers analyze the work attendance decision within the conventional labor-leisure choice framework. Workers maximize a utility function containing consumption $(\mathrm{X})$ and leisure $(\mathrm{L})$ :

$$
\mathrm{U}=\mathrm{U}(\mathrm{X}, \mathrm{L})
$$


The worker faces two constraints, a time constraint and a budget constraint. Including both absence and overtime as decision variables, the time constraint can be written as:

$$
t-t^{c}-t^{t}-t^{0}=0
$$

where:

$t$ represents the total time in the period under consideration,

$t^{c}$ is the contracted number of work hours,

$t^{t}$ is leisure hours not including absence hours $\left(L=t^{t}+t^{2}\right.$ where $t^{a}$ is absence hours), and

$t^{0}$ is the amount of overtime worked. The budget constraint is:

$$
R+w\left(t^{\mathrm{c}}-t^{\mathrm{a}}\right)+w^{*} t^{\mathrm{o}}-D\left(t^{\mathrm{a}}\right)-\mathrm{X}=0
$$

where:

$R$ is income from sources other than work,

$w$ is the wage rate,

$w^{*}$ is the overtime pay rate, and

$D$ is a lump sum penalty for absence.

In practice, this penalty will be observed as a decreased probability of receiving a promotion or merit wage increase and an increased likelihood of being suspended or dismissed. The assumption is that the worker is not paid for absence hours. Substitution of Equations 2 and 3 into Equation 1 and differentiation with respect to $t$ and $t$ produce the following first-order equilibrium conditions:

$$
\begin{gathered}
\mathrm{U}_{\mathrm{L}}-(w+D) \mathrm{U}_{\mathrm{X}}=0 \\
-\mathrm{U}_{\mathrm{L}}+\mathrm{U}_{\mathrm{X}} w^{*}=0
\end{gathered}
$$

where:

$U_{\mathrm{k}}$ indicates the partial derivative of $\mathrm{U}$ with respect to $k=\mathrm{L}, \mathrm{X}$. 
The first condition indicates that a worker will be absent on any given day if the extra leisure is more valuable than the sum of the wages he or she would have earned that day and the associated loss in future earnings. This means that the shadow price of leisure time for absent workers is greater than the contracted wage. The second condition indicates that an employee is willing to work overtime as long as the overtime wage is more valuable than the extra leisure.

If the value of extra leisure is less than the overtime wage but more than the sum of the regular wage and the resultant loss in future earnings, then the employee would be willing both to take absence and to work overtime. The value of leisure may vary from day to day, resulting in employees opting for both overtime and absence over some period.

This analysis suggests that the absence model should include overtime $o$ and the overtime wage rate $w^{*}$ and can be written as:

$$
a=a\left(w, r, f^{c}, D, f, o, w^{*}\right)
$$

where:

$f$ is the schedule flexibility permitted.

The focus of this model is on voluntary absence that is a function of the worker's motivation to attend work, as opposed to involuntary absence that results from inability, rather than unwillingness, to attend work. Voluntary absence may also be a function of involuntary absence in prior periods. Even if the operator has other duties or was injured and had an involuntary absence, he or she still had a break from the routine of the job and the attendant stress and might be less inclined to take a voluntary absence in the following periods.

Overtime and absence over a period together define the individual tradeoff between leisure and income. If the worker has been absent too much in one period, in the sense that he or she ends the period "underemployed," the individual may tend to be absent less in the next period to recoup lost income. If on the other hand, the worker is "overemployed" in one period because of working overtime, he or she may tend to be absent in the following period to gain more leisure. This is consistent with Fichman's (1984) dynamic model of 
attendance, in which absence is one observable consequence of changing the allocation of time and effort from work to nonwork activity, and suggests that absences should be modeled dynamically, by letting the absence in period $t$ be a function of absence and overtime in prior periods. Each individual has his or her own target point in terms of the income-leisure trade-off. Assuming that each individual has a constant target point over time, this unobserved characteristic can be modeled by the individual history of absence and overtime over a relatively long period. In addition, differences in operator characteristics can be captured by operator-specific dummy variables that should be significant if absence is a habit. Finally, temporal variation can be accounted for by seasonal dummy variables that can test, for example, if there are higher absence rates in the summer when leisure time may have a higher value. All these effects and variables in the model can be written as:

$$
a_{\mathrm{tv}}=a\left(w, r, t^{\mathrm{c}}, d, f, o, w^{*}, A a_{\mathrm{i}}, A a_{\mathrm{v}}, O a, a_{\mathrm{t}-1, \mathrm{i}}, a_{\mathrm{t}-1, \mathrm{v}}, o_{\mathrm{t}-1}, a_{\mathrm{t}-2, \mathrm{l}}, a_{\mathrm{t}-2, \mathrm{v}}, o_{\mathrm{t}-2}, \ldots,\right.
$$

$$
\text { oper } \left._{\mathrm{i}}, \ldots, \text { season }_{1}, \text { season }_{2}, \ldots\right)
$$

where:

$a_{\mathrm{t}, \mathrm{v}}=$ voluntary absence in period $t$,

$a_{\mathrm{t}-\mathrm{k}, \mathrm{i}}=$ involuntary absence in period $t-k$,

$A a_{\mathrm{i}}=$ mean amount of past involuntary absence per period,

$A a_{\mathrm{v}}=$ mean amount of past voluntary absence per period,

$O a=$ average overtime over the $n$ periods before $t$,

$A a=$ average absence over the $n$ periods before $t$,

oper $_{\mathrm{i}}=$ dummy variables equal 1 for operator $i$ and 0 for all other operators, season $_{\mathrm{i}}=$ dummy variables equal 1 for season $i$, and 0 for any other season.

\section{The Income-Leisure Theory in the Transit Industry}

Several factors may make the income-leisure theory more significant in the transit industry than in some other industries:

1) Widespread availability of overtime may allow some employees to quickly recoup wages lost to absence, diminishing the economic benefits of regular work attendance. 
2) Scheduling inflexibility reduces the operator's opportunity to take time off when needed or desired. Some operators may then use sick leave as a means to obtain time off.

3)Management's inability to schedule personnel effectively results in an endless cycle in which operators work overtime and then take time off to compensate, resulting in more absence, and thus in more overtime work, etc.

4) The extraboard encourages employee absence because employees are aware that replacements are available for them. This problem may be exacerbated or perpetuated by the common practice of basing the current size of the extraboard on past levels of employee absence.

5) Occupational stress associated with working long and irregular hours may also induce absence. Occupational stress is not included as a separate variable in this model because it is very difficult to measure. However, stress is included in the model implicitly under the assumption that working overtime may increase stress.

\section{The MBTA Case Study}

In this section, the absence model is applied using data from the MBTA. The sample consists of 274 operators from all bus and trolley garages. The data include number of absence hours each day for each operator, the category of each absence, and the weekly payment for overtime worked during a period of one year.

The absences are classified into three groups:

1) voluntary absences (unauthorized absence) which are not paid;

2) involuntary absences (death in the family, industrial accident, military or jury duty, and excused) which are paid; and

3) sick absences which are not paid for the first day of the absence but are paid for any subsequent day.

Sick absences are a separate category because while it includes real sickness that should be considered involuntary, it may also be a way for an operator to take a voluntary absence. Overtime payment is on a daily basis for any time worked above 8 hours. This means that an operator can receive overtime 
compensation without working 40 hours a week and that an operator can both receive overtime compensation and be absent in the same week. The overtime pay rate is 1.5 times the base wage rate, but there are no fringe benefits charged to overtime.

Table 1 summarizes the absence and overtime variables, including the number of zero values for one of the seven MBTA garages. In this dataset, each observation corresponds to an operator weekly record.

\begin{tabular}{|lccc|}
\hline \multicolumn{4}{|c|}{$\begin{array}{c}\text { Table 1 } \\
\text { Summary of Absence and Overtime Data }\end{array}$} \\
\hline & $\stackrel{M}{S}$ & $\underline{S D}$ & $\%$ of observed \\
$(\mathrm{hr} / w k)$ & $(\mathrm{hr} / w k)$ & values $=0$ \\
\hline Absence & & & \\
Voluntary & 0.12 & 1.90 & 99.3 \\
Involuntary & 0.59 & 3.86 & 95.5 \\
Sick & 1.50 & 5.90 & 89.5 \\
Total & 2.20 & 7.27 & 84.9 \\
Overtime & 0.65 & 1.86 & 79.5 \\
\hline
\end{tabular}

As seen from Table 1, the occurrence of voluntary absence is very lowless than 10 percent of all absences. To explore whether some sick absences might be better classified as voluntary absences, Table 2 shows the duration of sick absences for a sample garage.

In light of the very high percentage of one-day sick absences and to model voluntary absences more realistically, the researchers defined new absence variables as follows:

- Short: any voluntary absence plus any single-day sick absence.

- Long: any sick absence that consists of at least two consecutive days. 


\begin{tabular}{|ccc|}
\hline \multicolumn{4}{|c|}{ Table 2} \\
& Frequencies of Sick Absences \\
\hline Days & Frequency & Percent \\
\hline 1 & 279 & 62.3 \\
2 & 55 & 12.3 \\
3 & 26 & 5.8 \\
4 & 48 & 10.7 \\
5 & 40 & 8.9 \\
\hline
\end{tabular}

The assumption is that most long sick absences are genuine and most short sick absences are really voluntary. Clearly, some short absences will really be involuntary, while some long absences may be voluntary, but there is no more reliable way to distinguish between the two. These categories are also consistent with the payment category: Long absences are paid (except the first day) while short ones are not. A model for short absence is consistent with the theoretical model, which assumes that absences are not paid.

In this study, duration rather than frequency was used as the absence measure because it is more consistent with the theoretical model. It is the duration of an absence rather than frequency that determines income. The researchers used a time unit of one week because they do not expect the hypothesized relationships to exist on a daily level, and analyzing longer periods may cause loss of important information. Wages at the MBTA are paid weekly, which also suggests that a week is an appropriate period for analysis, as this is the shortest period of perceived income for the operator. The model was estimated using the tobit model developed for censored data (Maddala 1983), as in this case clearly no employee can be absent a negative number of hours.

\section{Model Estimation Results}

The researchers estimated separate models for each garage because, even though absence and overtime policies are the same across all garages, their 
enforcement and application may vary. Classifying absence into the different categories may vary, as may the relationship between supervisors and operators.

Three different time-based explanatory variables were used for each absence category as well as for overtime. The definitions below are for the long variable but similar definitions hold for the short, the involuntary (invol), and overtime (ot) variables:

- Long_l is the amount of long absence in the immediately preceding week.

- Long_234 is the average long absence during preceding weeks 2 through 4.

- Long_past is the average long absence during preceding weeks 5 through 16.

- Winter, Spring, and Summer are seasonal dummy variables.

- Oper_i,i=1,2, . n are operator-specific dummy variables.

Table 3 shows the estimation results for each garage including the dummy variables for the first 16 operators in each garage, which are representative of the remaining results.

The main conclusions from the estimation are:

- Most of the explanatory power is due to the operator-specific dummy variables, for which virtually all coefficients were significant (only 9 out of the 274 dummy operator coefficients were not significant) with $t$-statistics between -1.9 and -5.5 . To test the hypotheses that the constant is not generic, the researchers ran a nested hypothesis test comparing this model to a restricted model. The results showed that for all garages the test statistic (with values in the range of 64-100) was larger than the chi square at 1 percent significance (with values between 60 and 63) and therefore the null hypothesis that the operator-specific dummy coefficients are equal can be rejected.

- The lagged overtime variables are all insignificant and most are negative, suggesting that those who tend to work overtime tend not to be absent.

- Short_l always has a positive coefficient which is generally significant. This is because some short absences in any week are continuations of absence in the preceding week. The long_l variable also has a significant positive coefficient for the same reason. 


\begin{tabular}{|c|c|c|c|c|c|c|c|}
\hline \multicolumn{8}{|c|}{$\begin{array}{c}\text { Table } 3 \\
\text { The Short Absence Model }\end{array}$} \\
\hline & $\begin{array}{c}\text { Garage } \\
122\end{array}$ & $\begin{array}{c}\text { Garage } \\
123\end{array}$ & $\begin{array}{c}\text { Garage } \\
125\end{array}$ & $\begin{array}{c}\text { Garage } \\
126\end{array}$ & $\begin{array}{c}\text { Garage } \\
128\end{array}$ & $\begin{array}{c}\text { Garage } \\
129\end{array}$ & $\begin{array}{c}\text { Garage } \\
132\end{array}$ \\
\hline short[-1] & $\begin{array}{r}0.689 \\
(4.21) \\
\end{array}$ & $\begin{array}{r}0.610 \\
(4.48) \\
\end{array}$ & $\begin{array}{r}0.331 \\
(1.54) \\
\end{array}$ & $\begin{array}{l}0.475 \\
(2.77) \\
\end{array}$ & $\begin{array}{r}0.787 \\
(5.66) \\
\end{array}$ & $\begin{array}{l}0.408 \\
(2.85) \\
\end{array}$ & $\begin{array}{r}0.707 \\
(4.26) \\
\end{array}$ \\
\hline short_234 & $\begin{array}{r}-1.074 \\
(-2.82) \\
\end{array}$ & $\begin{array}{r}-0.383 \\
(-1.66) \\
\end{array}$ & $\begin{array}{r}-0.454 \\
(-0.90) \\
\end{array}$ & $\begin{array}{r}0.007 \\
(0.03)\end{array}$ & $\begin{array}{r}0.165 \\
(0.84) \\
\end{array}$ & $\begin{array}{c}0.242 \\
(1.10) \\
\end{array}$ & $\begin{array}{r}0.211 \\
(0.96 \\
\end{array}$ \\
\hline short_past & $\begin{array}{c}-4.321 \\
(-3.93) \\
\end{array}$ & $\begin{array}{c}-1.410 \\
(-2.56) \\
\end{array}$ & $\begin{array}{l}-3.202 \\
(-2.55) \\
\end{array}$ & $\begin{array}{c}-1.230 \\
(-2.12) \\
\end{array}$ & $\begin{array}{r}-1.324 \\
(-2.85) \\
\end{array}$ & $\begin{array}{r}-2.458 \\
(-4.12) \\
\end{array}$ & $\begin{array}{r}-0.949 \\
(-2.14) \\
\end{array}$ \\
\hline Long[-1] & $\begin{array}{c}0.154 \\
(1.79) \\
\end{array}$ & $\begin{array}{c}0.446 \\
(5.90) \\
\end{array}$ & $\begin{array}{c}0.461 \\
(3.36) \\
\end{array}$ & $\begin{array}{r}0.475 \\
(5.65) \\
\end{array}$ & $\begin{array}{r}0.323 \\
(3.70) \\
\end{array}$ & $\begin{array}{r}0.336 \\
(3.12) \\
\end{array}$ & $\begin{array}{r}0.149 \\
(1.42) \\
\end{array}$ \\
\hline Long_234 & $\begin{array}{r}-0.093 \\
(-0.70) \\
\end{array}$ & $\begin{array}{c}-0.152 \\
(-1.28) \\
\end{array}$ & $\begin{array}{c}-1.343 \\
(-2.42) \\
\end{array}$ & $\begin{array}{r}0.030 \\
(0.21) \\
\end{array}$ & $\begin{array}{c}-0.239 \\
(-1.63) \\
\end{array}$ & $\begin{array}{r}0.320 \\
(1.99) \\
\end{array}$ & $\begin{array}{r}-0.299 \\
(-1.87) \\
\end{array}$ \\
\hline Long_past & $\begin{array}{c}0.218 \\
(0.80) \\
\end{array}$ & $\begin{array}{c}0.275 \\
(1.36) \\
\end{array}$ & $\begin{array}{c}-2.040 \\
(-2.32) \\
\end{array}$ & $\begin{array}{c}-0.279 \\
(-1.07) \\
\end{array}$ & $\begin{array}{c}0.255 \\
(1.25) \\
\end{array}$ & $\begin{array}{r}-0.212 \\
(-0.94) \\
\end{array}$ & $\begin{array}{r}-0.224 \\
(-1.35) \\
\end{array}$ \\
\hline invol[-1] & $\begin{array}{r}-0.306 \\
(-2.29) \\
\end{array}$ & $\begin{array}{c}0.136 \\
(1.26) \\
\end{array}$ & $\begin{array}{c}0.399 \\
(2.21) \\
\end{array}$ & $\begin{array}{c}-0.012 \\
(-0.07) \\
\end{array}$ & $\begin{array}{r}-0.145 \\
(-0.82) \\
\end{array}$ & $\begin{array}{r}-0.299 \\
(-1.37) \\
\end{array}$ & $\begin{array}{r}-0.222 \\
(-1.89) \\
\end{array}$ \\
\hline invol_234 & $\begin{array}{c}-0.041 \\
(-0.30) \\
\end{array}$ & $\begin{array}{c}-0.242 \\
(-1.68) \\
\end{array}$ & $\begin{array}{c}-0.463 \\
(-1.57) \\
\end{array}$ & $\begin{array}{c}0.088 \\
(0.46) \\
\end{array}$ & $\begin{array}{c}0.149 \\
(0.86) \\
\end{array}$ & $\begin{array}{c}-0.152 \\
(-0.76) \\
\end{array}$ & $\begin{array}{r}-0.081 \\
(-0.62) \\
\end{array}$ \\
\hline invol_past & $\begin{array}{c}0.124 \\
(0.53) \\
\end{array}$ & $\begin{array}{c}-0.239 \\
(-1.43) \\
\end{array}$ & $\begin{array}{c}0.621 \\
(1.63) \\
\end{array}$ & $\begin{array}{c}-0.035 \\
(-0.11) \\
\end{array}$ & $\begin{array}{c}0.298 \\
(1.26) \\
\end{array}$ & $\begin{array}{c}0.315 \\
(1.78) \\
\end{array}$ & $\begin{array}{r}-0.436 \\
(-2.50) \\
\end{array}$ \\
\hline $\mathbf{O t}$ & $\begin{array}{c}-0.010 \\
(-0.94) \\
\end{array}$ & $\begin{array}{c}-0.014 \\
(-1.15) \\
\end{array}$ & $\begin{array}{c}-0.018 \\
(-1.09) \\
\end{array}$ & $\begin{array}{r}-0.005 \\
(-0.43) \\
\end{array}$ & $\begin{array}{r}-0.029 \\
(-1.66) \\
\end{array}$ & $\begin{array}{r}0.012 \\
(1.20) \\
\end{array}$ & $\begin{array}{r}-0.009 \\
(-0.84) \\
\end{array}$ \\
\hline ot [-1] & $\begin{array}{c}-0.014 \\
(-1.29) \\
\end{array}$ & $\begin{array}{c}-0.001 \\
(-0.11) \\
\end{array}$ & $\begin{array}{r}-0.011 \\
(-0.65) \\
\end{array}$ & $\begin{array}{c}0.018 \\
(1.45) \\
\end{array}$ & $\begin{array}{r}-0.003 \\
(-0.16) \\
\end{array}$ & $\begin{array}{c}-0.014 \\
(-1.03) \\
\end{array}$ & $\begin{array}{r}-0.001 \\
(-0.16) \\
\end{array}$ \\
\hline ot_234 & $\begin{array}{c}-0.014 \\
(-0.95) \\
\end{array}$ & $\begin{array}{c}0.009 \\
(0.63) \\
\end{array}$ & $\begin{array}{l}-0.0045 \\
(-0.20)\end{array}$ & $\begin{array}{r}-0.023 \\
(-1.09) \\
\end{array}$ & $\begin{array}{r}-0.045 \\
(-1.64) \\
\end{array}$ & $\begin{array}{c}0.0088 \\
(0.51) \\
\end{array}$ & $\begin{array}{c}0.003 \\
(0.22) \\
\end{array}$ \\
\hline ot_past & $\begin{array}{r}-0.013 \\
(-0.44) \\
\end{array}$ & $\begin{array}{c}-0.042 \\
(-1.55) \\
\end{array}$ & $\begin{array}{c}0.0008 \\
(0.02)\end{array}$ & $\begin{array}{r}-0.047 \\
(-1.19) \\
\end{array}$ & $\begin{array}{c}-0.087 \\
(-1.59)\end{array}$ & $\begin{array}{c}-0.032 \\
(-0.82) \\
\end{array}$ & $\begin{array}{c}0.011 \\
(0.56) \\
\end{array}$ \\
\hline Winter90 & $\begin{array}{c}1.778 \\
(0.96) \\
\end{array}$ & $\begin{array}{c}-2.408 \\
(-1.36) \\
\end{array}$ & $\begin{array}{c}-3.193 \\
(-1.47) \\
\end{array}$ & $\begin{array}{c}-0.538 \\
(-0.30) \\
\end{array}$ & $\begin{array}{c}-2.462 \\
(-1.47) \\
\end{array}$ & $\begin{array}{c}0.316 \\
(0.16) \\
\end{array}$ & $\begin{array}{r}1.150 \\
(0.58) \\
\end{array}$ \\
\hline Spring90 & $\begin{array}{c}1.419 \\
(0.86) \\
\end{array}$ & $\begin{array}{r}-0.567 \\
(-0.38) \\
\end{array}$ & $\begin{array}{c}-0.758 \\
(-0.42) \\
\end{array}$ & $\begin{array}{c}-0.387 \\
(-0.26) \\
\end{array}$ & $\begin{array}{r}-1.981 \\
(-1.40) \\
\end{array}$ & $\begin{array}{c}-0.732 \\
(-0.42) \\
\end{array}$ & $\begin{array}{r}4.565 \\
(2.53) \\
\end{array}$ \\
\hline Summer90 & $\begin{array}{c}5.738 \\
(3.03) \\
\end{array}$ & $\begin{array}{r}-2.015 \\
(-1.24)\end{array}$ & $\begin{array}{c}3.292 \\
(1.74) \\
\end{array}$ & $\begin{array}{r}-0.457 \\
(-0.28) \\
\end{array}$ & $\begin{array}{c}-2.026 \\
(-1.35) \\
\end{array}$ & $\begin{array}{r}-1.223 \\
(-0.63) \\
\end{array}$ & $\begin{array}{c}4.892 \\
(2.54) \\
\end{array}$ \\
\hline Oper 1 & -20.841 & -15.788 & -25.782 & -24.073 & -23.830 & -16.085 & -24.780 \\
\hline
\end{tabular}




\begin{tabular}{|c|c|c|c|c|c|c|c|}
\hline & $(-3.17)$ & $(-4.41)$ & $(-3.80)$ & $(-4.93)$ & $(-4.41)$ & $(-3.96)$ & $(-4.50)$ \\
\hline Oper_2 & $\begin{array}{r}-9.892 \\
(-2.93) \\
\end{array}$ & $\begin{array}{r}-19.352 \\
(-4.80)\end{array}$ & $\begin{array}{r}-22.197 \\
(-4.93)\end{array}$ & $\begin{array}{r}-12.493 \\
(-3.92)\end{array}$ & $\begin{array}{r}-15.469 \\
(-3.94)\end{array}$ & $\begin{array}{r}-12.361 \\
(-3.51)\end{array}$ & $\begin{array}{l}-30.827 \\
(-4.35)\end{array}$ \\
\hline Oper_3 & $\begin{array}{c}-23.776 \\
(-3.75)\end{array}$ & $\begin{array}{c}-9.134 \\
(-2.99) \\
\end{array}$ & $\begin{array}{c}-11.449 \\
(-3.19) \\
\end{array}$ & $\begin{array}{c}-19.005 \\
(-4.38)\end{array}$ & $\begin{array}{c}-24.075 \\
(-4.47)\end{array}$ & $\begin{array}{c}-27.970 \\
(-4.49)\end{array}$ & $\begin{array}{l}-27.583 \\
(-4.81) \\
\end{array}$ \\
\hline Oper_4 & $\begin{array}{r}-12.199 \\
(-3.04) \\
\end{array}$ & $\begin{array}{c}-18.496 \\
(-4.61) \\
\end{array}$ & $\begin{array}{l}-24.791 \\
(-4.84) \\
\end{array}$ & $\begin{array}{r}-15.137 \\
(-4.15) \\
\end{array}$ & $\begin{array}{c}-15.949 \\
(-4.06)\end{array}$ & $\begin{array}{c}-23: 063 \\
(-4.48)\end{array}$ & $\begin{array}{l}-29.624 \\
(-5.08) \\
\end{array}$ \\
\hline Oper_5 & $\begin{array}{c}-16.650 \\
(-4.44)\end{array}$ & $\begin{array}{c}-25.333 \\
(-4.38) \\
\end{array}$ & $\begin{array}{l}-24.460 \\
(-3.63) \\
\end{array}$ & $\begin{array}{c}-24.386 \\
(-4.53)\end{array}$ & $\begin{array}{c}-15.130 \\
(-4.36)\end{array}$ & $\begin{array}{c}-27.732 \\
(-4.86)\end{array}$ & $\begin{array}{l}-30.420 \\
(-4.10)\end{array}$ \\
\hline Oper_6 & $\begin{array}{c}-21.194 \\
(-4.74) \\
\end{array}$ & $\begin{array}{r}-17.057 \\
(-4.33) \\
\end{array}$ & $\begin{array}{c}-21.628 \\
(-4.19)\end{array}$ & $\begin{array}{r}-18.909 \\
(-4.77)\end{array}$ & $\begin{array}{r}-18.233 \\
(-4.68) \\
\end{array}$ & $\begin{array}{c}-21.323 \\
(-4.77) \\
\end{array}$ & $\begin{array}{l}-30.716 \\
(-4.81) \\
\end{array}$ \\
\hline Oper_7 & $\begin{array}{l}-27.895 \\
(-4.79) \\
\end{array}$ & $\begin{array}{r}-14.724 \\
(-4.14) \\
\end{array}$ & $\begin{array}{r}-17.843 \\
(-4.08) \\
\end{array}$ & $\begin{array}{r}-24.953 \\
(-4.63) \\
\end{array}$ & $\begin{array}{c}-9.789 \\
(-3.40) \\
\end{array}$ & $\begin{array}{c}-10.219 \\
(-2.86)\end{array}$ & $\begin{array}{c}-19.518 \\
(-3.72) \\
\end{array}$ \\
\hline Oper_8 & $\begin{array}{r}-12.595 \\
(-2.83) \\
\end{array}$ & $\begin{array}{r}-15.391 \\
(-4.38) \\
\end{array}$ & $\begin{array}{r}-13.467 \\
(-3.09) \\
\end{array}$ & $\begin{array}{r}-11.512 \\
(-2.08)\end{array}$ & $\begin{array}{c}-21.460 \\
(-4.78)\end{array}$ & $\begin{array}{r}-17.053 \\
(-3.73) \\
\end{array}$ & $\begin{array}{l}-21.738 \\
(-5.41)\end{array}$ \\
\hline Oper_9 & $\begin{array}{c}3.832 \\
(0.86) \\
\end{array}$ & $\begin{array}{c}-16.959 \\
(-3.52) \\
\end{array}$ & $\begin{array}{c}-19.008 \\
(-3.86)\end{array}$ & $\begin{array}{c}-24.165 \\
(-4.42)\end{array}$ & $\begin{array}{c}-12.679 \\
(-4.06)\end{array}$ & $\begin{array}{c}-28.139 \\
(-4.40)\end{array}$ & $\begin{array}{l}-29.323 \\
(-4.86) \\
\end{array}$ \\
\hline Oper_10 & $\begin{array}{c}-10.974 \\
(-3.44)\end{array}$ & $\begin{array}{c}-12.532 \\
(-1.44)\end{array}$ & $\begin{array}{c}-14.820 \\
(-3.97)\end{array}$ & $\begin{array}{c}-19.860 \\
(-4.66)\end{array}$ & $\begin{array}{c}-12.158 \\
(-3.99)\end{array}$ & $\begin{array}{c}-12.060 \\
(-3.06)\end{array}$ & $\begin{array}{l}-28.990 \\
(-4.86)\end{array}$ \\
\hline Oper_11 & $\begin{array}{l}-29.602 \\
(-4.90)\end{array}$ & $\begin{array}{c}-18.236 \\
(-4.81) \\
\end{array}$ & $\begin{array}{r}-8.112 \\
(-2.12) \\
\end{array}$ & $\begin{array}{r}-11.735 \\
(-3.82) \\
\end{array}$ & $\begin{array}{c}-12.332 \\
(-3.78) \\
\end{array}$ & $\begin{array}{c}-20.753 \\
(-4.73) \\
\end{array}$ & $\begin{array}{l}-20.704 \\
(-5.44) \\
\end{array}$ \\
\hline Oper_12 & $\begin{array}{l}-27.457 \\
(-4.62)\end{array}$ & $\begin{array}{r}-10.271 \\
(-3.42) \\
\end{array}$ & $\begin{array}{r}-20.315 \\
(-4.43)\end{array}$ & $\begin{array}{c}-19.392 \\
(-4.60) \\
\end{array}$ & $\begin{array}{c}-19.921 \\
(-3.32)\end{array}$ & $\begin{array}{c}-12.358 \\
(-3.22)\end{array}$ & $\begin{array}{c}7.604 \\
(1.25) \\
\end{array}$ \\
\hline Oper_13 & $\begin{array}{c}-18.172 \\
(-4.66)\end{array}$ & $\begin{array}{l}-23.044 \\
(-3.88) \\
\end{array}$ & $\begin{array}{c}-26.395 \\
(-4.27)\end{array}$ & $\begin{array}{r}-10.643 \\
(-3.74)\end{array}$ & $\begin{array}{c}-10.140 \\
(-2.75)\end{array}$ & $\begin{array}{c}-28.356 \\
(-4.56)\end{array}$ & $\begin{array}{c}-30.378 \\
(-5.03) \\
\end{array}$ \\
\hline Oper_14 & $\begin{array}{c}-22.479 \\
(-4.95) \\
\end{array}$ & $\begin{array}{c}-16.786 \\
(-4.38) \\
\end{array}$ & $\begin{array}{r}-9.439 \\
(-2.83) \\
\end{array}$ & $\begin{array}{c}-22.994 \\
(-4.34) \\
\end{array}$ & $\begin{array}{r}-12.631 \\
(-3.90) \\
\end{array}$ & $\begin{array}{c}-14.449 \\
(-3.98) \\
\end{array}$ & $\begin{array}{r}-18.242 \\
(-5.13) \\
\end{array}$ \\
\hline Oper_15 & $\begin{array}{c}-17.498 \\
(-4.88) \\
\end{array}$ & $\begin{array}{r}-20.109 \\
(-4.49) \\
\end{array}$ & $\begin{array}{c}-14.466 \\
(-3.79) \\
\end{array}$ & $\begin{array}{c}-20.213 \\
(-4.81) \\
\end{array}$ & $\begin{array}{r}-8.557 \\
(-2.32) \\
\end{array}$ & $\begin{array}{c}-14.907 \\
(-3.99) \\
\end{array}$ & $\begin{array}{r}-8.851 \\
(-2.71) \\
\end{array}$ \\
\hline Oper_16 & $\begin{array}{c}-29.611 \\
(-4.90)\end{array}$ & $\begin{array}{r}-3.440 \\
(-1.09) \\
\end{array}$ & $\begin{array}{c}-28.000 \\
(-4.52)\end{array}$ & $\begin{array}{r}-20.197 \\
(-4.53) \\
\end{array}$ & $\begin{array}{c}-23.879 \\
(-4.31) \\
\end{array}$ & $\begin{array}{c}-23.291 \\
(-4.60) \\
\end{array}$ & $\begin{array}{l}-23.632 \\
(-3.13)\end{array}$ \\
\hline sigma**2 & $\begin{array}{c}159.836 \\
(7.38) \\
\end{array}$ & $\begin{array}{r}169.321 \\
(8.12) \\
\end{array}$ & $\begin{array}{c}199.089 \\
(6.90) \\
\end{array}$ & $\begin{array}{r}148.029 \\
(7.12) \\
\end{array}$ & $\begin{array}{c}160.942 \\
(8.28) \\
\end{array}$ & $\begin{array}{c}200.423 \\
(7.56) \\
\end{array}$ & $\begin{array}{c}169322 \\
(7.30) \\
\end{array}$ \\
\hline $\begin{array}{l}\log \\
\text { likelihood }\end{array}$ & -955.13 & -1105.5 & -907.69 & -904.73 & 1159.1 & -98729 & -94226 \\
\hline $\mathbf{N}$ & 1911 & 1960 & 2009 & 1862 & 1862 & 1862 & 1960 \\
\hline
\end{tabular}


- The negative and significant coefficients of the short past absence variable may be due to the disciplinary policy that limits the total amount of absence that can be taken without having a significant effect on the employee's career in the agency.

- The winter and spring dummy variables are not significant (except the spring in area 132), suggesting that absence in these seasons is not significantly different from absence in the fall. However, the summer dummy variable is positive and significant in three out of the seven garages, suggesting that in these garages operators tend to be absent more in the summer.

\section{Conclusions}

These estimation results suggest that absence is best interpreted as a habit, operators differ in their absence rates, and those who tend to be absent do so independent of whether or not they recently worked overtime. If there is some relationship, then those who tend to work overtime tend to be absent less.

However, studies of absence are very complicated and the data that were available for this study do not resolve all of the potential problems. For example, although the researchers classified absences into several categories, it is difficult to classify every absence correctly as either voluntary or involuntary. The researchers are also missing many potentially important data in the model such as nonlabor income and personal and family characteristics, especially financial needs and responsibilities. In addition, many operators (particularly junior ones) will not have the option of working overtime. As runs are chosen according to seniority, junior operators are more exposed to stress than senior operators. Senior operators have overtime available, but they are not exposed to the same level of stress as junior operators. Another explanation might be that, because of the relatively high operator wage rate at the MBTA, the income effect is stronger than the substitution effect and employees can afford to buy more leisure time independent of the overtime premium.

If the hypothesis that absence is more a habit than the result of a decision process based on past overtime worked is accepted, then reducing overtime will not necessarily reduce absence, and the key to reducing absence is to develop a monitoring system that can identify employees who tend to be 
absent. However, further research is recommended in this area, which should be based on more extensive data and more agencies.

\section{References}

Brown, B. 1981. Building an operator availability program: San Francisco Municipal Railway. Paper presented at the Annual Meeting of the American Public Transit Association, Chicago, IL, October.

Buck, L., and S. Shimmin. 1959. Overtime and financial responsibility. Occupational Psychology 33:137-148.

Fichman, M. 1984. A theoretical approach to understanding employee absence. In P. S. Goodman and R. S. Atkin (Eds), Absence: New approach to understanding, measuring and managing employee absence.. San Francisco: Jossey-Bass, 158-193

Flanagan, R. J., G. Strauss, and L. Ulman. 1974. Worker discontent and workplace behavior. Industrial Relations 13:101-123.

Gowler, D. 1969. Determinants of the supply of labour to the firm. Journal of Management Studies 6:73-95.

Hickman, M. D., H. N. Koutsopoulos, and N. H. M. Wilson. 1988. Strategic model for operator workforce planning in the transit industry. Transportation Research Record 1165:60-68.

Koutsopoulos, H. N., and N. H. M. Wilson. 1987. Operator workforce planning in the transit industry. Transportation Research 21A, 2, 127-38.

Leahy, A., C. Sprague, and L. Schlegel. 1979. Bus operator absenteeism: Some causes and cures. Transit Journal Fall, 29-38.

Maddala, G. S. 1983. Limited dependent and qualitative variables in econometrics. Cambridge [Cambridgeshire]; New York: Cambridge University Press.

Martin, J. 1971. Some aspects of absence in a light engineering factory. Occupational Psychology 45:77-91.

Perin, C. 1984. The dynamics of vehicle operator absenteeism. Transportation Research Record 1002:1-7.

Perry, L. J. 1983. A study of extraboard scheduling, workers' compensation and operator stress in California public transit. Institute of Transportation Studies, University of California, Irvine.

Shiftan, Y., and N. H. M. Wilson. 1994. Absence, overtime and reliability relationships in transit workforce planning. Transportation Research, Part A, 28:245-258. 
Smith, J., D. L. Kiffe, and D. L. Lee. 1980. An approach to ideal manpower planning. Transit Journal Fall.

\section{About the Authors}

YoRam SHIFTAN (shiftan@tx.technion.ac.il) is a senior lecturer in the Department of Civil Engineering at the Technion, Israel Institute of Technology. His research and teaching are focused on travel behavior, demand modeling, transport economics, and transportation and air quality. Dr. Shiftan received his $\mathrm{Ph.D}$. in transportation systems from Massachusetts Institute of Technology and his master's degree in transportation engineering from the Technion. Prior to joining the Technion, Dr. Shiftan was a senior associate at Cambridge Systematics Inc.

Nigel Wilson (nhmw@mit.edu) is a professor of civil and environmental engineering at M.I.T. and the leader of the Engineering Systems Group, one of the three main organizational units in the Department of Civil and Environmental Engineering. His research and teaching are focused on urban public transportation, including topics related to the operation, analysis, planning, and management of transit systems. Prof. Wilson received his master's and doctoral degrees in civil engineering and transportation systems from M.I.T. 


\section{Multicriteria Feasibility Evaluation for Rural Transit in Georgia}

George D. Mazur, Cambridge Systematics, Inc. Karen K. Dixon, Georgia Institute of Technology

Wayne A. Sarasua, Clemson University

\section{Abstract}

This article describes transit feasibility analysis features of the Georgia Department of Transportation's (GDOT's) Multimodal Transportation Planning Tool (MTPT). Using open databases that are available agencywide, the MTPT can provide a system-level analysis of transportation requirements of rural areas, identify potential implementation constraints early in the planning process, and develop a prioritized project list by mode for an analysis region. In addition to demand-responsive transit, the MTPT addresses intercity bus, intercity passenger rail, commuter rail, highways, aviation, and bicycle modes. This article focuses on the demand-responsive transit component of the MTPT, and provides an overview of how the MTPT can help automate system-level transit planning for the general public in rural Georgia.

The MTPT transit analysis assesses service feasibility for nonurbanized areas that do not currently have local transit service for the general public. In the MTPT, transit service feasibility considers the existence of human service transit providers in the county; the percentage of population in certain "target" populations; and estimates of potential ridership, vehicle requirements, capital costs, operating costs, and economic benefits. The first factor indicates if opportunities may exist to coordinate service with existing providers, and helps to address funding issues. The second factor assesses market characteristics of the target area as one determinant of potential service need. The third factor provides a range of potential values for key operating and 
financial statistics at a system-planning level of analysis. The intent of the analysis is to identify those locations where it makes sense to more seriously analyze new demandresponsive services.

This article should be helpful for transportation planners with responsibility for developing system-level transportation plans and programs at the county, region, and state levels. It will also be helpful for decision-makers who are trying to match transit funding to areas with high service needs.

\section{Introduction}

The passage of the Intermodal Surface Transportation Efficiency Act (ISTEA) and the Transportation Equity Act for the 21st Century (TEA-21) brought greater emphasis to congestion mitigation and multimodal planning in transportation. At the outset of the "ISTEA era," state departments of transportation (DOTs) committed significant resources to those metropolitan areas and rapidly developing fringe regions where congestion and intermodal problems were most prevalent. DOTs placed relatively less planning emphasis and resources on rural transportation issues, particularly for nonauto transportation modes such as transit services. Further, while statewide planning issues have garnered increasing research funds, few DOTs have undertaken research efforts to develop new ways to assist planners in identifying and prioritizing systemlevel needs in rural areas (Federal Highway Administration 1995).

System-level evaluation of transit needs and opportunities have traditionally presented challenges to transportation planners. Many of the available techniques have been refined for corridor- or route-level planning. Current system-level approaches to transit and multimodal planning borrow strategies from traditional highway planning with heavy emphasis on demand forecasting. However, considerations such as market characteristics and the unique financing structure of transit capital and operations suggest that a broader approach to system-level transit planning may be suitable. This broader approach is particularly warranted for statewide or rural applications, where local transit can be dominated by demand-responsive services that do not lend themselves to evaluation by techniques more suited for fixed-guideway or fixed-route bus services. 
Since passage of the Statewide Transportation Plan in 1994, the GDOT has been committed to achieving "a new vision for transportation in Georgia" that supports economic development, provides mobility options, enhances the quality of life, and allows full participation in the planning process (GDOT 1994). One primary recommendation from the statewide plan was to reorient the planning processes throughout the State to facilitate multimodal planning, programming, and decision making.

In the fall of 1994, GDOT's Office of Planning initiated development of a computer-based planning tool to aid in evaluating the multimodal transportation requirements of rural areas, including needs related to demand-responsive transit. This article reviews the application of GDOT's MTPT for system-level analysis of rural transit needs for the general public (i.e., "nonprogram" transit services). The article begins with a brief overview of MTPT capabilities. It then discusses various planning options for rural transit, as well as their integration into the MTPT. Finally, the article highlights steps taken to validate the analysis modules and potential steps for further enhancement.

\section{The Multimodal Transportation Planning Tool}

The MTPT is a comprehensive system- and project-level planning tool that can be used to identify needs and project priorities for nonurbanized areas in Georgia (Dixon et al. 2000; Mazur and Sarasua 1997; Mazur et al. 1996). The MTPT integrates a series of analytical routines into a Geographic Information System (GIS) platform, allowing an assessment of passenger travel on essentially all surface transportation modes.

At the system level, the tool can assess various metrics of current and future operational and physical performance, and identify those modal elements that fail to meet threshold values or that have been previously identified as modal needs. At the project level, the tool can perform a more detailed safety, operational, and physical analysis of roadway corridors, including those targeted for statewide bicycle routes. The MTPT can produce results at various aggregation levels including individual corridors, cities, counties, and GDOT administrative districts. In a typical session, an MTPT user identifies the geographic area to analyze, identifies modes to analyze, enters any user-specified parameters, conducts baseline and sensitivity analyses, and displays the results. 
The MTPT operates through an interface with several existing GDOT databases, allowing for querying and analysis of up-to-date physical and operational attributes. For demand-responsive transit, the MTPT relies on several internal databases that describe rural transit services in Georgia:

1)a county-level socioeconomic database containing detailed 1990 census data, population totals for 1960 to 1990 , and land area;

2)two service provider databases that list existing "program" and "nonprogram" rural transit providers; and

3)an urbanized county database that lists counties that are wholly or partially urbanized.

These databases provide the information needed to run routines developed specifically for the MTPT. The transit databases, together with a road characteristic database, GIS road maps, modal project data, supplemental databases (crash history, bicycle routes, etc.), and the system software, are written to a single compact disk, allowing the program to be easily shared with agencies throughout the State. This functionality is expanded by the MTPT's development for use with multiple operating systems on a personal computer.

\section{Rural Transit Services}

As with urban transit services, system-level planning for rural transit generally involves considerations of market feasibility, service need, potential usage, cost, and finance issues. However, the relative priority of the issues, methods used to assess the issues, and underlying scale of investment are typically different in urban and rural areas. While large-scale computerized travel-demand models are typically a central planning feature for large urban transit investments, use of data-intensive modeling efforts has historically not been an option for rural transit services.

In the past, several authors have suggested that comprehensive, longrange planning with travel-demand models be deemphasized in rural areas in favor of short-range corridor- and project-level planning (Fleet 1978; Golenburg 1978; Litz 1980; Smith 1982; Stover 1978). With more recent advances in computing technology, areas have begun to develop broad-scale modeling applications for rural transit (Black 1993; Attaluri et al. 1997). 
Nonetheless, the scope of these rural models needs to be sensitive to both the level of problems typically encountered in these areas and the quantity and quality of data that are generally available (Burkhardt et al. 1995; National Association of County Engineers 1995; King 1998).

Smerk (1978) suggests that sketch-planning techniques are highly appropriate for rural transit planning. These planning methods help analysts identify where multimodal opportunities exist, and pinpoint locations for more detailed study. Several sketch techniques or rules of thumb are available to perform this initial evaluation with minimal data requirements. Atkinson (1978) and Corradino (1978) present techniques for assessing the merits of local transit service in smaller communities. Both authors suggest use of the techniques to determine if threshold criteria are met and if further study is justified.

The Guidebook for Planning Small Urban and Rural Transportation Programs (U.S. DOT 1990) suggests that system-planning efforts for transit should focus on identifying need (number of people for which a service is targeted) rather than demand (number of anticipated trips by people in a market segment). In rural areas, the targeted market segments typically include elderly, handicapped, school-age children, and commuters to major job sites. The guidebook further suggests that service inventory and identification of service coordination opportunities should be part of the system-planning effort.

One of the more recent research efforts for estimating demand for rural passenger transportation was undertaken by Spielberg, Shaw, and McGetrick (1995) as part of the Transit Cooperative Research Program (TCRP) Project B-3. The authors reviewed dozens of previous transit-demand models as well as functional concepts for approaching demand estimation for both "program" and "nonprogram" demand-responsive transit services. Three consensus conclusions emerged from that work to guide development of a rural transit demand model:

1) The model should include variables for both market size and quantity of transit service to be made available.

2) The market for rural transit throughout the United States is largely composed of elderly, handicapped, and impoverished segments of the overall population. Rural transit is used by these segments largely for lifeline segments including work, medical care, and shopping trips. 
3) The model form should be based on the concept of decreasing returns to scale. In other words, while the per-person trip rate should increase with additional transit service, the rate of increase in the trip rate should decline as the amount of transit service continues to increase.

After careful comparison to existing rural transit operations in Georgia, the basic arguments of all these researchers were followed in developing an analysis process for the MTPT that would be suitable for system-level applications and would operate as a decision support, rather than decision-making, tool. Importantly, the arguments were adapted in a process that recognized the exclusive use of county-level, demand-responsive transit services in rural areas of Georgia.

\section{Transit Evaluation in the MTPT}

The basic focus of the MTPT transit analysis is to assess the feasibility for demand-responsive transit services. The tool was developed for application to new service rather than expansion or modification of existing services. The MTPT does not perform service planning, but rather assesses which counties merit consideration for initiating rural transit service. As such, the MTPT transit analysis is a decision-support tool that is intended to focus subsequent detailed service-planning efforts. Importantly, the MTPT transit analysis does not reach a conclusion about service feasibility; instead, it provides information that an analyst can use in reaching this decision.

In the MTPT, transit service feasibility considers three primary factors:

1) existence of human service transit providers in the county;

2) percentage of population in certain "target" populations; and

3)estimate of potential ridership, vehicle requirements, capital costs, operating costs, and economic benefits.

The first human service transit provider factor essentially notifies the analyst that opportunities may exist to coordinate service with existing providers, helping to address, in part, issues of funding for the operation of rural transit.

The second "target" population factor helps the analyst assess market characteristics of a geographic area through a comparison of county population statistics with both overall rural statewide averages for rural counties and 
statewide averages for counties with existing rural transit service. Ten key categories were consistently cited in the literature as major determinants of potential service need as opposed to demand.

The third "operational" factor provides a range of potential values for key operating and financial statistics. Based on user-selected values for level of service (operating hours and wait times) and type of transit vehicle, the MTPT estimates a range of values for the statistics using "off-the-shelf" analysis routines that have been customized for application to rural Georgia transit services.

The transit analysis is only functional in rural areas of the state (defined using the U.S. Census Bureau definition for nonurbanized areas). As mentioned earlier, the MTPT includes an urbanized county database of fully or partially urbanized counties. If a nonqualifying county is selected for analysis, the program returns error messages and truncates the transit analysis.

The MTPT includes a service provider database that identifies counties with existing transit services operated by a Federal Transit Administration (FTA) Section 5311-funded provider. The tool is not intended for use in analyzing service expansion or modification. Hence, if a county with current rural transit service is selected for analysis, the software will return an error message and cease subsequent evaluation. As can be seen, several avenues were followed to discourage inappropriate application of the transit routines.

\section{Service Coordination}

The MTPT first determines if rural transit in the analysis county is currently operated by a "human service" provider funded in whole or in part through the State of Georgia or FTA Section 5310 program. These human service providers operate transportation services for select groups of individuals who meet specific eligibility requirements (e.g., elderly). The services provided differ from general public transit services under FTA Section 5311. While nearly all human service transit providers in Georgia receive funding through the State of Georgia and FTA Section 5310, human service transit in other locations may be funded through other non-State and non-FTA sources.

In Georgia, a concerted effort is under way to find alternate means for providing transit services to these groups rather than having each human service 
provider purchase and operate its own vehicles. It is believed that alternate means of service provision, such as purchase of service from a regular rural transit agency, are cost efficient for the human service agency while providing an additional revenue stream to the regular rural transit provider. Hence, by identifying human service providers, a planner is notified that opportunities may exist to coordinate more extensive transit services that could have a more sustainable funding arrangement.

The service provider database included with the MTPT indicates counties in which these services are operated, service provider name, city where the provider is located, and funding source. If a human service provider is identified in the analysis area, a message is placed in the MTPT results report showing the name of the service provider and steps that an analyst should take to investigate the potential for service coordination.

\section{Service Need}

The second feasibility assessment category in the MTPT relates to service need. For the purposes of the analysis, service need is loosely defined as the number of people in different market segments for which a service is targeted. During MTPT development, an extensive literature review and outreach effort to rural transit planners and operators in Georgia identified 10 population segments that typically comprise the vast majority of the Georgia rural transit market:

- total persons age 60 and over;

- total persons living below poverty level;

- persons age 16 to 64 with mobility limitations;

- total persons with mobility limitations;

- employed persons with mobility limitations;

- persons enrolled in grade school;

- persons enrolled in high school;

- total households with no vehicles;

- persons using bus, walk, or bicycle modes to work; and

- persons using carpool to work.

These market segments are clearly not mutually exclusive. However, the service need analysis does not consider the absolute number of people in these 
different market segments, but rather their relative representation in the overall population of an analysis area. The MTPT provides the analyst with an estimate of the percentage of population in each market segment. The MTPT also provides two benchmark values for each market segment that allows the analyst to assess market characteristics of the target area:

- an average value for all Georgia rural counties; and

- an average value for all Georgia rural counties with existing public transit service.

The MTPT performs the service need assessment by querying an internal socioeconomic database that was developed from 1990 census data. While a variety of data sources were considered for this database, the Census Transportation Planning Package (CTPP) CD-ROM provides the data in the most accessible format. The poverty data were the only items that required estimation because the CTPP does not have a direct tabulation of impoverished households or individuals. The poverty estimation was generated using CTPP tables to estimate the number of households below the 1990 U.S. government poverty threshold and the number of persons per household. Population data are stored as raw numbers, and the MTPT calculates market percentages by dividing each socioeconomic category with total 1990 county population.

The socioeconomic database also includes land area and historical county population information. The historical data are used by the MTPT to estimate future values for total county population and portions of the market segments that are used to forecast service demand in subsequent analysis modules. Currently, the MTPT assumes that the relative percentage of total county population in each market segment does not change in the future. As part of an ongoing development of Georgia's statewide transportation plan, detailed countylevel population forecasts are being prepared that will include age and income estimates. It is anticipated that these population forecasts will be incorporated in the MTPT to enhance the service need and service demand components.

\section{Service Demand, Cost, and Benefits}

In the third part of the feasibility assessment, the MTPT estimates a range of potential values for key usage, equipment need, and cost statistics. Based on 
user-selected values for level of service (operating hours and wait times) and vehicle type, the MTPT provides estimates of annual ridership, fleet size, capital cost, annual operating cost, and annual economic benefit. The MTPT relies on "off-the-shelf" routines, including locally validated ridership equations, cost experience from Georgia operators, fleet estimation equations from other states, and a rural transit cost-benefit model developed for the GDOT. While many rural areas find that both social service (i.e., "program") and general public (i.e., "nonprogram") transit services are important, the MTPT only estimates demand, cost, and benefits for nonprogram services since the GDOT does not have funding and decision-making authority for program services.

Annual Ridership. The ridership routine provides an estimate of the annual number of transit trips per person based on the number of those individuals who are:

- age 60 and over,

- living in a household with annual wages below the poverty level, and

- age 16 to 64 and have a mobility limitation.

This transit rate per person is then multiplied by the population in these subgroups to arrive at an annual ridership estimate for the county. Estimates are provided for 2000 and 2010 using demographic data taken from the MTPT socioeconomic database that is used for the service need assessment. The MTPT provides a point estimate and range of likely values using the following equations:

Point Estimate: $Y=0.8983 * X^{0.822}$

Low Range: $\quad\left(-0.1073+(0.822 * \operatorname{LN}(X))-0.646 *\left[1.004+\left(\frac{(\operatorname{LN}(X)-1.17)^{2}}{359}\right)^{1 / 2}\right]\right)$

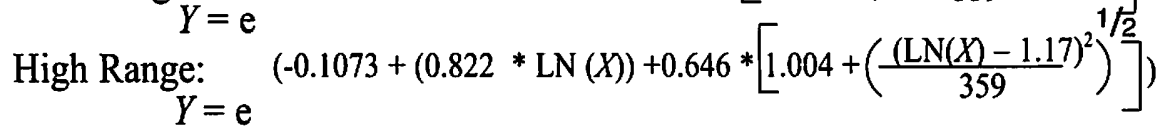

where:

$Y=$ annual trips per person within all targeted market segments (elderly, mobility limited, persons in poverty).

$X=$ annual transit revenue vehicle miles per capita.... 
In developing the ridership estimate, the MTPT user is allowed to select one of three typical levels of transit service corresponding to low (two revenue-vehicle miles [RVM] per capita), medium (five RVM per capita), and high (nine RVM per capita) service levels. These levels were identified based on current rural transit operations in Georgia. The service hours and availability that typically correspond to these levels are displayed in the MTPT dialogue box in Figure 1.

The ridership estimate is based on a methodology presented in TCRP Report 3 (Spielberg et al. 1995). This TCRP methodology was recalibrated for Georgia conditions to account for the exclusive use of county-based, demandresponsive service for general public transit in rural Georgia, and to improve overall model fit. The recalibration process is described in a subsequent section.

Fleet Size Requirements. Two separate equations, both taken from a rural transit analysis methodology developed for Florida (Corradino 1978), are used to estimate fleet size requirements. The first equation relies on the annual ridership previously described. The second equation relies on base RVM that are estimated by multiplying the service level selected above by total county population. Interestingly, both equations rely exclusively on operational parameters rather than vehicle size. The two estimates are averaged to arrive at a point

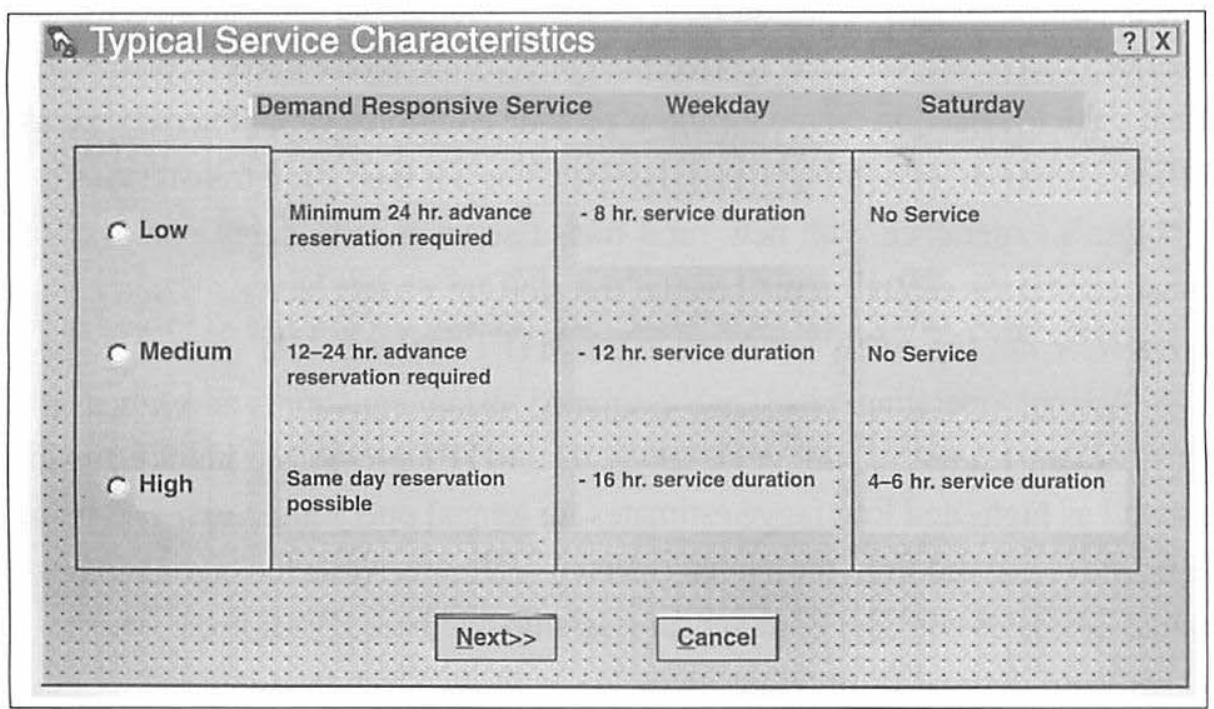

Figure 1. MTPT service-level dialogue box 
estimate for fleet size. A detailed test of these equations using recent operating data for Georgia's rural transit operators showed that an averaging of results from the two equations produced usable system-planning results. The specific equations used are:

$$
\begin{aligned}
& \text { Number of Vehicles }=\left(\frac{\text { Annual Demand }}{6,000}\right)^{\left(\frac{1}{1.8}\right)} \\
& \text { and } \\
& \text { Number of Vehicles }=\left(\frac{1.6 * \text { Base RVM }}{8,000}\right)^{\left(\frac{1}{1.7}\right)}
\end{aligned}
$$

Capital and Operating Costs. Capital costs are estimated in the MTPT by applying a unit cost to the fleet size estimate. Unit costs are based on recent GDOT acquisition experience for small and large buses, minibuses, and shutthe buses. Since these numbers are based on actual Georgia conditions, the values did not need additional adjustment. An MTPT user has the option of selecting different vehicle sizes in developing capital costs, as shown in the MTPT dialogue box example in Figure 2. In recent years, the GDOT has almost exclusively purchased small vans for rural transit. Although the user can select vehicles of other sizes, detailed service planning would likely need to justify the final vehicle selection. Some locations provide additional capital items such as office equipment or computer-based dispatching for their rural transit systems. Georgia's experience with new rural transit services is to delay purchase of most additional capital items beyond the start-up phase; hence, these capital costs were not separately tabulated in the MTPT analysis.

Annual operating costs are estimated using equations developed for TCRP Report 6 (Burkhardt et al. 1995). The MTPT provides a point estimate as well as high- and low-range estimates for annual operating costs. The point estimate is derived from the annual ridership estimate, while the high- and lowrange estimates consider both annual ridership and base RVM; these cost variables were derived in previous steps. As with the fleet size and capital cost methodologies, reviews of initial operating cost results using Georgia's recent 


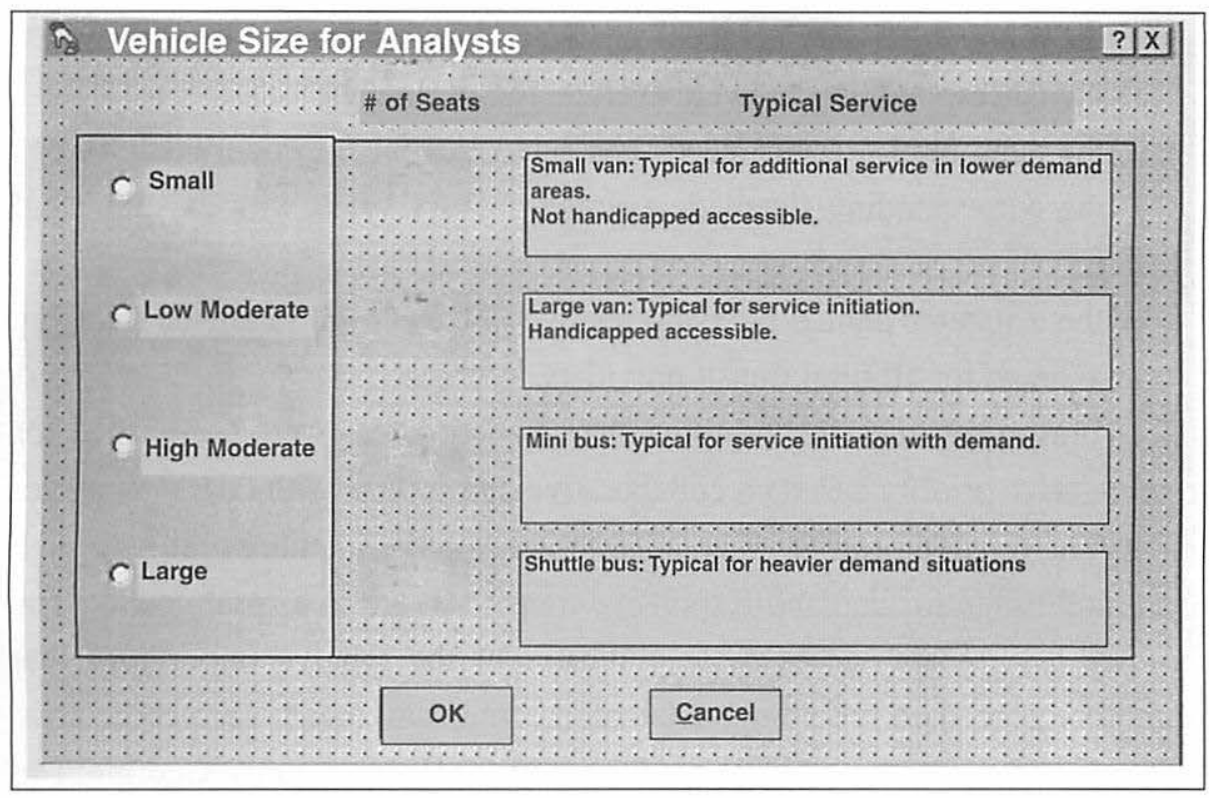

Figure 2. MTPT vehicle selection dialogue box

rural transit data showed a reasonable match between the estimated and actual costs for system-planning purposes.

Economic Benefits. The MTPT provides estimates of local economic impact and local government revenue impact based on the estimated average annual operating cost. The economic benefit estimate is based on relationships developed by the GDOT in the mid-1990s specifically for demand-responsive transit service in Georgia (Nelson and Peng 1998).

\section{Evaluation and Priority}

The MTPT was specifically structured so that the analyst will largely perform the evaluation and interpretation of the transit feasibility data. This structure was considered very important to discourage generic "black-box" applications of the system-level analysis. However, the MTPT does include a basic prioritization routine in the transit analysis to provide guidance to the user in interpreting the multiple data items estimated by the model.

The MTPT assigns a relative priority of either potential opportunity, moderate potential opportunity, high potential opportunity, or highest potential opportunity based on estimated characteristics in three areas: 
1) the number of "service-need" characteristics for the county that exceed the corresponding statewide average for all rural areas;

2) the number of "service-need" characteristics for the county that exceed the corresponding statewide average for rural areas with existing rural transit service; and

3)the estimated annual ridership relative to the current statewide ridership average for all rural transit providers.

Threshold values for the three characteristic areas were established for each relative priority based on collaborative discussions with GDOT management. The relative priority is intended to indicate the likelihood of both high need and usage for demand-responsive transit service in a rural county. The priority assignment serves as an indicator of the relative importance that should be placed on follow-up, detailed planning activities for a specific area. Figure 3 shows a sample MTPT results report for Bacon County, Georgia. The MTPT prioritized this rural county as having moderate potential opportunity for transit improvements based on demographic characteristics and estimated demand.

\section{Reestimation of Ridership Forecasting Routine}

The routine for forecasting rural transit ridership was adapted from TCRP Report 3. This method relies on RVM estimates and the number of people either with mobility impairments, living in poverty, or over age 60 , and was initially calibrated for the TCRP using a nationwide sample. Based on guidance in TCRP Report 3, the recommended level of application of this method was the county level for areas outside of Metropolitan Statistical Areas (MSAs) and with population densities under 1,000 persons per square mile. However, the authors expanded application of this method to all non-MSA counties in Georgia because a suitable estimation routine for demand-responsive service in higher-density areas could not be located.

Initial tests of this methodology on actual data from current rural transit providers in Georgia showed a large variation between predicted and actual ridership. When applied to Georgia, the TCRP method consistently overestimated ridership when transit service provision was low, and underestimated 


\section{TRANSIT MODE ANALYSIS}

The Program has determined that transit services in Bacon County are operated by the following social service transportation providers:

ALMA -- BACON COUNTY MR SERVICE PROVIDER

Comparison of Socioeconomic Characteristics For Bacon County

Column $A$ is the average for Bacon county

Column $B$ is the average of all rural counties

Column $C$ is the average of all rural counties with transit service

Data Category

Total Persons aged 60 and over

Total Persons living below poverty level

Persons aged 16 to 64 with mobility limitations

Persons enrolled in grade school

Persons enrolled in high school

Total persons with mobility limitations

Employed persons with mobility limitations

Total households with no vehicles

Persons using bus, walk or cycle modes to work

Persons using carpool to work
A

$\begin{array}{lll}16.97 & 16.14 & 16.13 \\ 09.94 & 17.04 & 18.40 \\ 08.22 & 01.90 & 01.98 \\ 15.08 & 14.24 & 14.02 \\ 05.49 & 04.27 & 04.44 \\ 11.16 & 04.68 & 04.73 \\ 00.41 & 00.31 & 00.31 \\ 11.20 & 09.60 & 09.08 \\ 00.95 & 01.31 & 01.20 \\ 08.46 & 08.24 & 08.50\end{array}$

*** Values are expressed as percent of total population. ***

Based on the selected characteristics summarized above, the following values have been estimated for transit service in Bacon county:

* Annual demand may be between 2,740 and 10,370 with a mean value of 5,330 for 1990.

* Annual demand may be between 2,870 and 10,850 with a mean value of 5,580 for 2000.

* Annual demand may be between 3,000 and 11,350 with a mean value of 5,830 for 2010.

* Vehicle requirements are estimated between 2 and 3 for full start-up.

* Capital costs are of the magnitude of (1997) $\$ 467,500$ for full start-up.

* Annual operating costs in the range of (1997) $\$ 8,600$ to (1997) $\$ 96,420$ with a mean value of (1997) $\$ 33,780$.

* The annual local economic impact from operating transit service is estimated to be in the range:

1. Local Economic Impact: $\$ 939,460$ to $\$ 1,699,550$

2. Local Government Revenue Impact: $\$ 11,820$ to $\$ 71,610$

* Bacon County is classified as a county with a priority classification as Moderate Potential Opportunity for Transit Improvements.

Figure 3. Sample MTPT transit output 
ridership when transit service provision was moderate. It was thought that these estimation problems could have arisen from: (1) a preponderance of demand-responsive service in Georgia as compared to other states, (2) overall lower levels of transit service levels as compared to other states, or (3) expansion of the methodology into locations beyond the intended area of application.

Therefore, the model was recalibrated using data only for Georgia's rural public transit operators.

The discussion earlier in this article of rural transit planning noted that the model form for ridership forecasts should be based on the concept of decreasing returns to scale. In other words, while the per-person trip rate should increase with additional transit service, the rate of increase in the trip rate should decline as the amount of transit service continues to increase. This essentially means that the model should be asymptotic toward a fixed-trip rate. However, investigation of the actual equations provided in TCRP Report 3 indicated that this model form was not used. Instead, the equations exhibited an increasing returns to scale rather than a decreasing returns to scale. Further analysis suggested that this model form (i.e., increasing returns to scale) accounted for much of the prediction error for Georgia conditions.

The ridership equations were reestimated using calibration and validation datasets developed from eight years of operating statistics for Georgia's rural transit operators and the MTPT socioeconomic database. An initial analysis of census data suggested that use of the "static" MTPT socioeconomic database was acceptable since changes in the rural population subsegments tended to occur very slowly, and overall growth rates in rural regions are very low. Other initial tests on different model forms also indicated that a "decreasing returns to scale" model form using RVM (rather than other operational variables) would produce the best statistical results.

The recalibrated model was then evaluated with the validation dataset. Three key statistics (average absolute mean difference, correlation coefficient, and $r$-squared) were calculated for the observed and predicted values of the validation dataset. Overall, the validation statistics, as shown in Table 1, indicated that the reestimated model performed reasonably well in predicting trip 
rates, but resulting confidence intervals might still be somewhat larger than desired due to the remaining spread in observed trip rates in both the calibration and validation datasets.

\begin{tabular}{|l|c|}
\hline \multicolumn{2}{|c|}{ Table 1 } \\
\multicolumn{2}{|c|}{ Validation Test Results for Recalibrated Model } \\
\hline Average annual observed trip rate for market segments & Value \\
Average absolute mean difference in trip rate & 3.66 \\
$R$-square (validation dataset using calibrated model) & 1.59 \\
$R$-square (calibration datset) & 0.65 \\
Correlation coefficient (observed versus predicted for validation dataset) & 0.70 \\
\end{tabular}

The effect of this spread was reviewed to establish appropriate prediction intervals for the newly calibrated model. Several potential confidence levels were evaluated to determine an acceptable level of confidence. In general, the selection of a specific percentile value for a confidence or prediction interval is guided by the decision-making need that the resulting information is intended to serve. Less sensitive decisions, such as those of a preliminary nature used to guide further studies, can be based on information in which less confidence exists. Since the MTPT transit results are intended as an initial assessment of potential transit suitability, a 70 percent confidence level was identified as adequate.

\section{Potential Enhancements}

The previous sections have described a process for initially analyzing the suitability of rural counties for demand-responsive transit service. The entire MTPT tool, including the transit analysis, is still undergoing a comprehensive evaluation by transportation planners at state and local agencies throughout Georgia. It is expected that this review will uncover ways to improve the MTPT in terms of both functionality and user-friendliness. The authors have identified a preliminary list of areas in which the MTPT transit analysis routine could be enhanced in the coming years:

- Revise the entire socioeconomic database upon receipt of results from the year 2000 U.S. census. 
- Test the effect of different service characteristics on model form. This test would involve providing a more precise statistical match between service characteristics (days and hours of operation, advance reservation requirements, etc.) and the RVM/capita input to the demand model. This option would require stratifying the input dataset based on these service characteristics.

- Test if the three market segments (elderly, impoverished, and handicapped) are individually significant for the ridership model or if there is significant overlap in the population groups; the three market segments are considered collectively in the current model. This option could require collection of detailed ridership data in some test locations.

- Test if other market segments, such as junior and senior high school populations, and special generators, such as colleges or resort areas, could be significant predictors of transit demand in Georgia.

- Test if more complex model forms, such as a logit model, would produce significantly better ridership forecasts.

- Revalidate the fleet size equations to test if service area is a significant factor in determining fleet size requirements.

- Provide increased MTPT user flexibility by permitting the program user to override default vehicle costs currently assigned within the program.

\section{Summary and Conclusions}

The ability for a governing agency to perform a wide-scale analysis for rural transit using a robust computer analysis tool affords policymakers the benefit of impartially identifying prospective regions where rural transit implementation will conceivably afford the greatest benefits. The MTPT transit module is such a tool and serves as an initial indicator for helping analysts with decisions regarding the type and extent of rural transit service needs. The balance of transit service coordination, need, and demand offered by the MTPT supports all initial aspects of rural transit analysis. The methods used by the tool incorporate nationally accepted standards that are modified to adapt to conditions unique to the State of Georgia. The tool filters nonqualifying regions from analysis, and prioritizes prospective transit services for qualifying rural areas. 
Though a single analysis tool should not be used to justify final policy and implementation decisions, the MTPT transit module serves as a solid foundation for the ultimate rural transit analysis and decision structure for the State of Georgia.

\section{References}

Atkinson, Wallace. 1978. Estimating transit demand, fleet size and costs for small communities. NCHRP Special Report 187: 29-33.

Attaluri, P., M. Javid, and P. N. Seneviratne. 1997. Modeling demand for public transit services in rural areas. Journal of Transportation Engineering 123 (3).

Black W. R. 1993. Development of IDEAL model for identification of rural public transit needs. Transportation Research Record 1402: 107-109.

Burkhardt, J. E., B. Hamby, and A. T. McGavock. 1995. Users manual for assessing service-delivery systems for rural passenger transportation. Transit Cooperative Research Program Report 6.

Corradino, Joseph. 1978. Forecasting transit ridership in smaller communities. NCHRP Special Report 187: 24-29.

Dixon, Karen K., Wayne Sarasua, Janice Daniel, and George D. Mazur. 2000. A tool for rural and statewide multimodal transportation planning. Journal of Computing in Civil Engineering. Forthcoming.

Federal Highway Administration (FHWA). 1995. General observations on statewide transportation planning. Unpublished agency memorandum. Washington, DC.

Fleet, Christopher. 1978. Achieving a balance between long-range and short-range planning at an appropriate level of effort. NCHRP Special Report 187: 11-16.

Georgia Department of Transportation (GDOT). 1994. Draft statewide transportation plan. Atlanta, GA.

Golenburg, Marvin. 1978. Procedure for analysis of system sufficiency and deficiency (abridgment). NCHRP Special Report 187: 85.

King, D. 1998. What are the "best practices" of rural subarea planning? Report FHWA-AZ-98-469. Washington, DC: Federal Highway Administration.

Litz, Leon E. 1980. Measuring highway improvement needs and priority analysis. Federal Highway Administration. Washington, DC.

Mazur, George, and Wayne Sarasua. 1997. Georgia's rural transportation planning tool: Something old, something new.... Presented at the Sixth TRB Conference on the Application of Transportation Planning Methods. Dearborn, MI.

Mazur, George, Wayne Sarasua, and Janice Daniel. 1996. A multimodal transportation planning tool for rural areas in Georgia. Transportation Research Record 1552: $48-56$. 
National Association of County Engineers. 1995. Rural transportation planning, 1995 Edition, NACE Action Guide. Washington, DC: Federal Highway Administration. Nelson, A. C., and Z. Peng. 1998. Rural transit service: A local economic and fiscal impact analysis. Transportation Research Record 1623: 57-62.

Smerk, George. 1978. Transportation and transit planning for small- and mediumsized urban areas. NCHRP Special Report 187: 18-21.

Smith, J. D. 1982. The choice of appraisal techniques when resources are limited-A case study of the rural roads programme in peninsular Malaysia. Highway Development in Developing Countries. Proceedings of the Conference on Criteria for Planning Highway Investment in Developing Countries: 71-77.

Spielberg, Frank, Gordon Shaw, and Christie McGetrick. 1995. Workbook for estimating demand for rural passenger transportation. Transit Cooperative Research Program Report 3.

Stover, Vergil. 1978. Appropriate level of effort for planning for small- and mediumsized communities. NCHRP Special Report 187: 9-11.

U.S. Department of Transportation. 1990. Guidebook for planning small urban and rural transportation programs-Volume 1. Washington, DC: New Mexico State Highway and Transportation Department.

\section{About the Authors}

George Mazur (gdm@camsys.com) is an associate with Cambridge Systematics, based out of the CS Oakland, California, office. He has 12 years of experience in transportation planning and policy, environmental analysis, and analytical tool development and application. He has civil engineering degrees from Purdue University and the University of California at Berkeley. Mr. Mazur is a registered Professional Engineer in California and Georgia.

DR. KaREN Dixon, P.E. (karen.dixon@ce.gatech.edu), is an assistant professor in the School of Civil and Environmental Engineering at the Georgia Institute of Technology. She received civil engineering degrees from North Carolina State University and Texas A\&M University. Dr. Dixon focuses her research in the areas of transportation design, operations, and safety.

DR. WAYNe A. SARASUa (sarasua@clemson.edu) is an assistant professor in the Department of Civil Engineering at Clemson University. Dr. Sarasua's research and teaching interests center on the application of geographic information system technologies to transportation. 


\title{
Visualization of Transit Mobility and Performance
}

\author{
Anibal A. Galindez, Los Angeles County \\ Metropolitan Transportation Authority \\ Ricardo Mireles-Córdova, Los Angeles Unified School District
}

\begin{abstract}
The visualization of a transit mobility model is presented in this article. The method described shows transit system capacity and utilization by area and time of day using ride-check data as a proxy for real-time information. It indicates how public transportation resources can be used in a more efficient and effective manner.

The visualization process requires the creation of a time/location data matrix of the variable to be analyzed and the linking of the performance measure to spatial data. This creates a temporal Geographic Information System (GIS) platform for the entire transit system or systems at the regional level. The GIS is "animated" to show snapshots of the system in sequence for the entire day. It serves as a powerful tool to evaluate bus route performance.

The visual display of transit system utilization facilitates the assessment of where, when, and what type of resources should be allocated to maximize transit utilization at the lowest possible cost. It also can serve as a graphical tool to inform the public and policy-makers about transit system performance. Different demand markets for transit (rail, bus fixed-route, shuttles, community circulators, vanpools, etc.) can be appraised and the effectiveness of current transit in serving these markets can be visualized. The method can be used to show where service can be allocated, thus enhancing the mobility of transit systems.
\end{abstract}


This article seeks to visualize the utilization of transit resources. Ideally, the mechanics of transportation system design and supply would be subject to continuous evaluation and refinement using an integrated scheme of automatic vehicle locators (AVLs), automatic passenger counters, and automated fare collection equipment. Currently, most transit agencies do not have this technology and rely instead on manual or semiautomated ride checks collected periodically. In lieu of real-time data, it is generally agreed that a ride check provides the most comprehensive set of data for operational and transit planning purposes. The methodology proposed in this article uses the ride check to visualize transit system performance by time of day and geographic area.

\section{Introduction}

A GIS has been defined as:

the organized activity by which people: (1) measure aspects of geographic phenomena and processes; (2) represent these measurements, usually in the form of a computer database, to emphasize spatial themes, entities, and relationships; (3) operate upon these representations to produce more measurements and to discover new relationships by integrating disparate sources; and (4) transform these representations to conform to other frameworks of entities and relationships. (Chrisman 1997)

A comprehensive treatment of GIS, an emerging multidisciplinary technology, is beyond the scope of this article. An understanding of GIS requires, at a minimum, knowledge about attribute and spatial measurement and the representation of this measurement; different kinds of operations and transformations that can be applied to spatial entities and attributes; and the evaluation and implementation of the GIS within social and institutional contexts. An account of these particulars can be found in Chrisman and the references cited therein.

Geographic information is commonly broken into the components of time, space, and attribute (when, where, and what.) Most GIS is organized with time held constant. Experience shows that attributes change with time. For example, overcrowding on a transit line is usually a temporal phenomenon. This condition is dynamic and occurs at certain locations and time periods. A static GIS does not allow the viewer to see these changes and their interactions within the transportation system. 
A temporal GIS, by storing information that changes with time, is able to answer questions such as where and when do the attributes or spatial objects change, what patterns may be observed, and what might be the underlying causes of these changes. Temporal GIS data can be visualized by "animating" the attribute information within a user-controlled, time-period sequence. The analysis can be done from a customer, transit agency, and/or regional perspective.

The GIS allows for the analysis of contiguous areas instead of discrete transit routes. It also serves as the basis for the creation of a street centerline GIS dataset that incorporates the transit route information as a network. This system would be amenable to network analysis questions such as assignment of routes to garages to minimize deadhead time. Current GIS software has the capability of performing network operations that can be used to evaluate service coverage and the minimization of aggregate walking time to transit stops. Another application would be efficient schedule adjustments for multiple time transfers.

The GIS serves as an aid in the design of transit systems. A system redesign should incorporate origin and destination surveys, trip diaries, and other forms of customer information. This allows explicit demand-side elements to be incorporated in the analysis. As an example, the survey data could be visualized and the system investigated for areas where passenger demand justifies nonexistent direct connectivity between travel points to minimize travel time.

\section{Methodology}

In the transit mobility model visualization, the ride-check data must be formatted as time/location matrices of the variables to be analyzed. These matrices are then imported into a GIS. A temporal GIS is created by sequentially displaying the map snapshots through animation software.

The method requires that the ride-check data have geocoded bus stops. The weekday ride-check data used were collected between December 1995 and August 1998. The data were organized by route and the ridership attribute information such as boardings, alightings, load ratios, schedule adherence, etc. summarized by stop and time period. This procedure creates a time of day/tran- 
sit stop location matrix of the variable of interest. The matrix can be generated through relational database, statistical, or mathematical software packages, or in-house computer programming.

Activity at a bus stop is what is known in GIS terminology as an "event." The process of geocoding takes an event's locational reference and matches it to a map that contains a spatial representation of the location. The reference to a location could be one of several types: a x, y (and z) coordinate, an address, or a measure along a route. A layer of geographic information is a collection of geographic features such as rail tracks, roads, transit routes, bus stops, municipalities, etc. The same type of shape-either points (bus stops), lines (routes), or polygons (cities)-represents these features. The geocoded bus stop data provide the link that ties the ridership information to the GIS platform. The $x, y$ coordinates of the bus stops can be linked in the database to attribute information about the bus stop such as transfer possibilities, landmarks, amenities, etc.

Graphic files with the variables and information of interest for particular time periods are generated in the GIS. These "snapshots" of the area are shown within a user-controlled time window sequence to produce the computer "animations." Passenger flow volumes on streets served by multiple routes can be depicted through three-dimensional graphics. The "animation" can be done as a slide show in a presentation software program, with "dynamic graphic engine" software or graphical simulation software packages.

The model is useful for presenting and analyzing complex bus route and transit system information. Among the advantages of using a GIS platform is the ability to tie the model information to other transit-related databases. This permits the overlay of geographic (schools, hospitals, shopping centers, etc.) and census-tract or block-level demographic features (income, auto availability, likelihood of transit dependency, etc.) to the ridership data on a map as well as operational peculiarities of the different transit routes.

The data can be aggregated to compute selected summary statistics by areas such as demographics, percentage of overcrowded bus stops and of impacted patronage, and economic/productivity numbers. GIS methods for statistical work permit the detailed treatment of statistical information using cus- 
tom designed polygons. The interactions between transit lines and the synergies of the transit system are assessed through the spatial-temporal variability of the attributes at the bus stop, route, and area polygon level.

Aerial photography can aid in the visualization of land-use patterns and in the construction of a typology of transit markets based on geographic/demographic factors. The GIS shows the relationships between different phenomena that affect transit supply and demand. An innovation of the methodology lies in allowing the visualization of multiple evaluation criteria simultaneously. In the following section, the methodology is applied to the service region of the Los Angeles County Metropolitan Transportation Authority (MTA).

\section{Visualization Model}

Los Angeles County is one of the nation's largest counties with 4,083 square miles $\left(11,077 \mathrm{~km}^{2}\right)$, of which $1,421 \mathrm{mi}^{2}\left(3,855 \mathrm{~km}^{2}\right)$ are incorporated areas. These areas represent 88 cities. The county is larger in population than 42 states in the nation, with more than 9.8 million people as of January 2000 , of which all but 1 million live in the cities. However, it has the lowest density of the 20 largest population centers of the world (World Almanac and Book of Facts 1995). This urban sprawl yielded an estimated 85.8 percent drive-alone and carpool weekday worktrips with a 6.5 percent transit share in Los Angeles County, according to the 1990 census.

The Los Angeles County MTA is the regional light rail, heavy rail, and largest bus operator, providing 1,440 square miles $\left(3,907 \mathrm{~km}^{2}\right)$ of service coverage in almost all of the cities and noncontiguous portions of unincorporated Los Angeles County. The agency is the second largest bus operator in North America in terms of unlinked passenger trips (American Public Transit Association 2000). Ninety-one percent of MTA boardings are made in the bus system.'

Boardings take place on 127 transit lines that have an average length of 24 miles (40 kilometers). The lines carry approximately 300,000 customers that generate about 1.1 million boardings on an average weekday. Trip lengths vary by line and type of service, but the systemwide average trip length is 3.7 miles (6 kilometers). A high transfer rate is a by-product of the system's grid 
design. The central business district (CBD) of Los Angeles is the transit center where lines connect for regional travel. The CBD of Los Angeles generates only 6 percent of the employment in the county (City of Los Angeles Planning Department 1995).

The agency directly operates or contracts 1,930 peak vehicles on a typical weekday. These vehicles are scheduled to deliver 20,400 revenue hours that cover 252,000 revenue miles (405,458 revenue kilometers). Directly-operated service represents 93 percent of the revenue hours and peak vehicles. Almost all MTA buses are 43-seat vehicles. In addition to the MTA, there are 12 regionally significant municipal bus operators and several local paratransit providers whose service coverage overlaps the MTA's in certain areas. The MTA carries approximately 80 percent, or 4 out of 5 , of the annual unlinked bus passenger trips.

The MTA ride-check database was summarized by census tract for the entire day. The census tract is a polygon containing all the transit attribute information of the bus stops within it in addition to demographic data. The population and employment densities of Los Angeles County are presented in Figures 1 and 2. The Central Limit Theorem of statistics allows us to do this based on the large number of census tracts $(1,642)$ involved (Draper and Smith 1981). Areas where the standard deviation is one or more above the mean represent areas where the population and employment are highly concentrated.

These maps closely mimic the location of households below the county's median income. The GIS can be used to pair the locations where a high concentration of jobs exists and the residences of likely jobholders. The system can be assessed to see how well it connects these markets and whether some routes can be restructured to better serve these clients.

The areas where boarding density (bus boardings/square mile) are the highest are shown in Figure 3 . The top 45 lines carry 85 percent of the boardings and the top 20 lines carry about half the weekday boardings. The Gaussian distribution, as shown in Figure 3, closely represents this fact. It shows areas where high-capacity transit could be currently implemented to improve bus service for the greatest number of customers. 


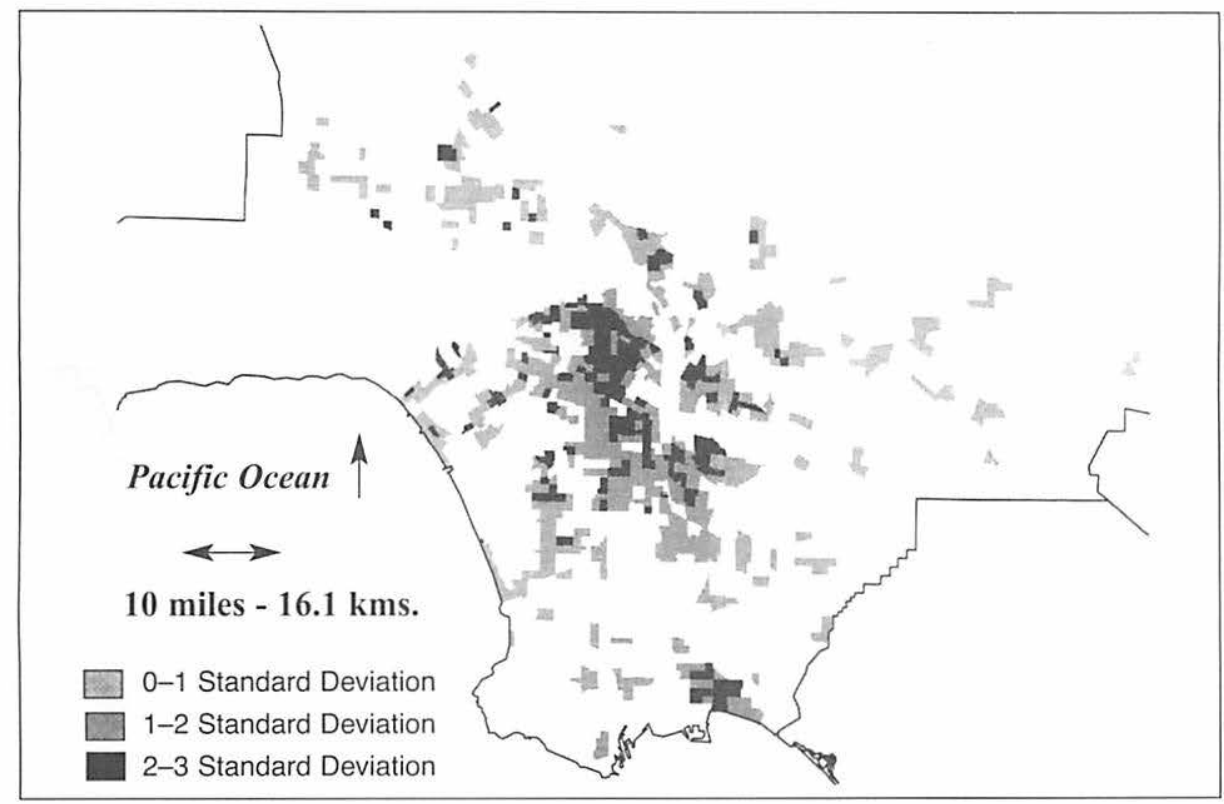

Source: 1990 Census STF3 File.

Figure 1. Los Angeles County population density

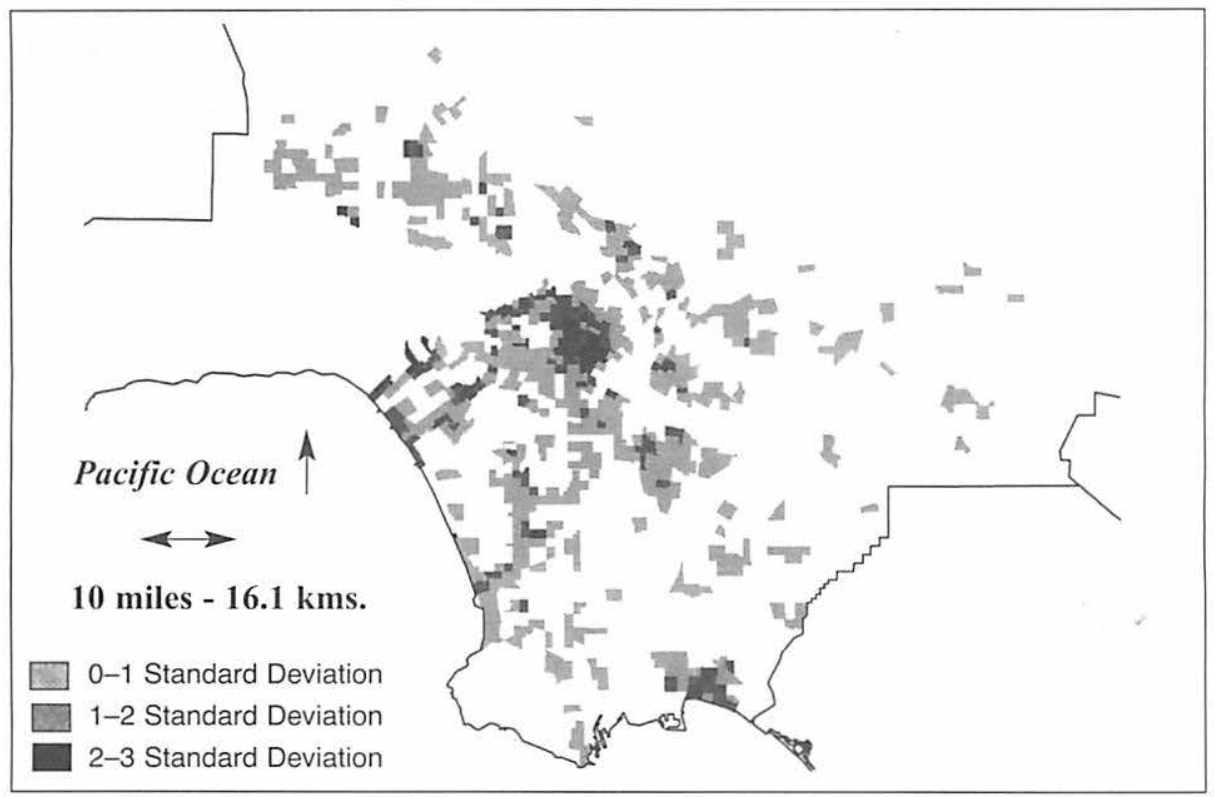

Source: 1990 Census STF3 File.

Figure 2. Los Angeles County employment density 


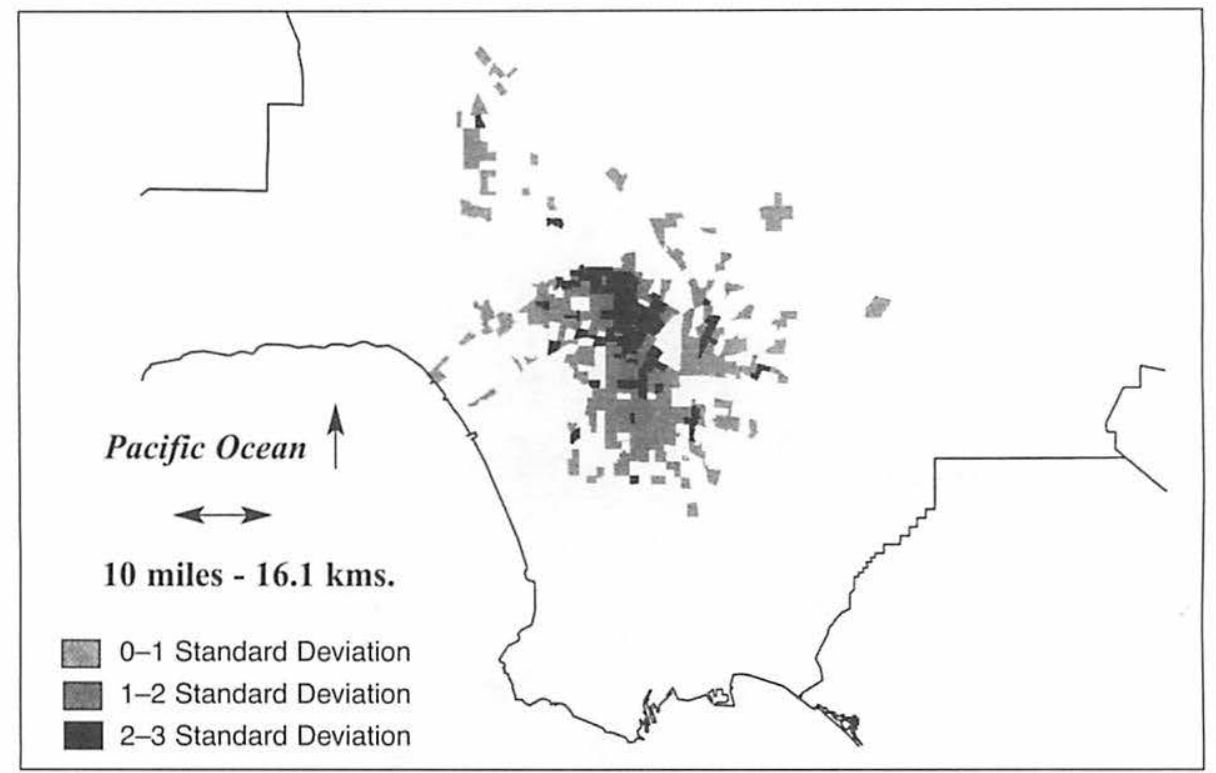

Source: MTA Ride Check Database.

Figure 3. Los Angeles County MTA bus boardings/square mile

The proxy variable used to visualize transit demand was the number of patrons onboard vehicles by time period and location. Transit supply was assessed through the number of seats offered by time period and location. These variables were summarized by 20 -minute and census tract data for the entire day from the geocoded bus stops for each line. The ratio of the patrons onboard to the number of seats offered is known as the "load ratio." Load ratios below 0.5 indicate locations and time periods where smaller vehicles (22-seat vans or shuttle buses) can be used to satisfy demand, since almost all MTA buses have an average of 43 seats. This is shown in Figure 4 for the peak direction of the lines.

These figures show the concentrated load ratios of the lines by census tract. The centers of these figures, which picture the downtown area, are where the load ratios are highest. This can be displayed with a three-dimensional graphic that takes into account the individualized route and its load ratio height. It can then be seen that lines traversing these areas are heavily crowded in one direction, and that the western portion of the county is the result of severe overcrowding on just one to three buses. 


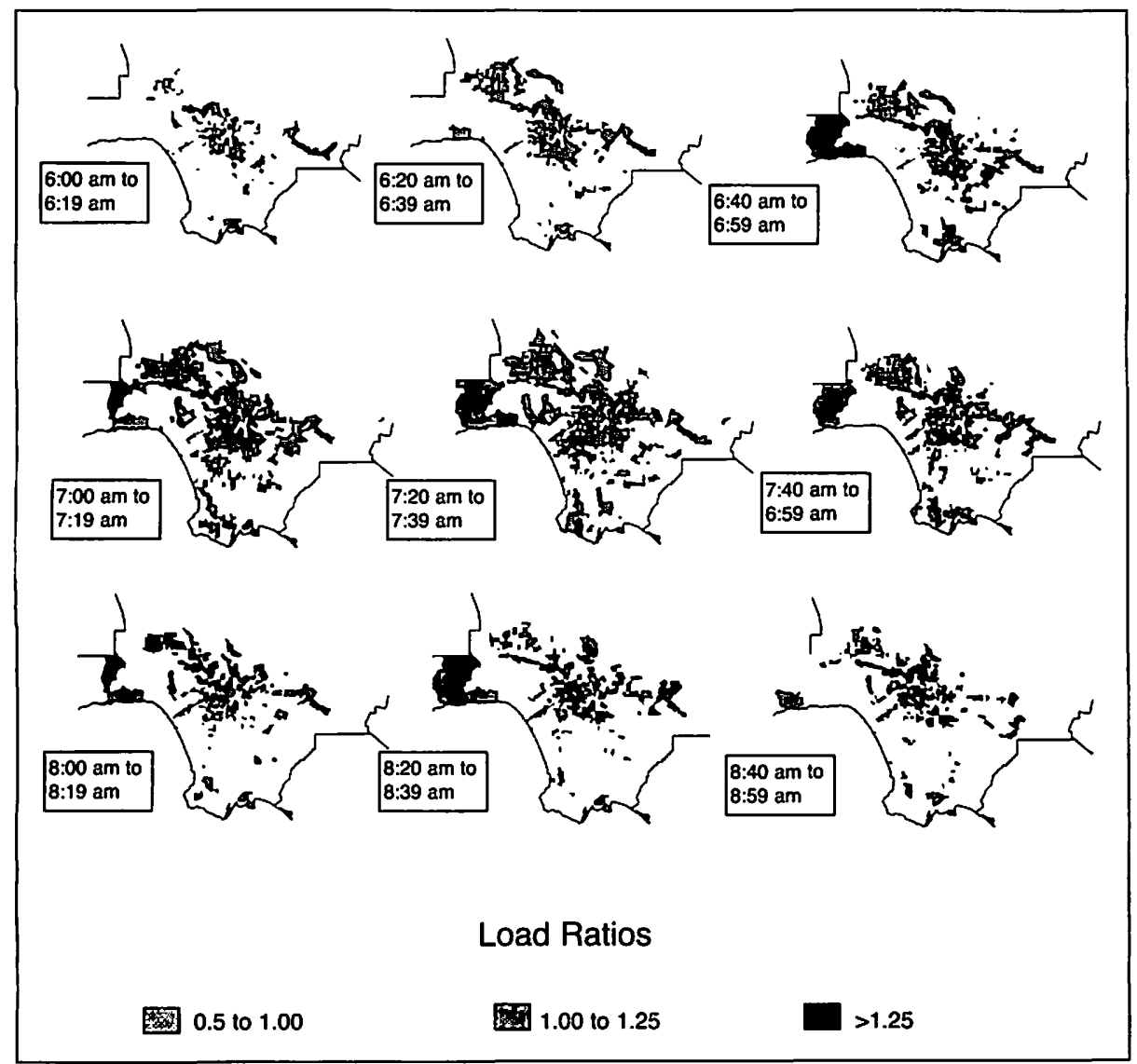

Figure 4. Average Load Ratios-average weeklay A.M. peak direction

The temporal pockets of overcrowding on major streets seen in the route visualizations can be abated by trippers that do not run the entire route length or by jitney/van service. The latter was done in the past on streets where overcrowding currently occurs (Teal and Nemer 1986). Conversely, population density and land-use patterns in certain areas do not support traditional transit service, yet there are unmet travel needs that could be accommodated with shuttles, vans, or taxis.

Poor vehicle utilization can be caused by several factors. On some routes, more service is offered than time-of-day demand warrants. Other routes have heavy demand in one direction but much less in the other, yet the vehicles complete round-trips. In certain areas, there are community circulators that take 
away the demand for shorter length trips. Another possible cause for underutilized vehicles is infrequent service that is lightly used. Creative scheduling strategies, like interlining and turn-backs which are done at the MTA, can be visualized with this methodology. The analysis needs to incorporate the ridership information of the municipal operators to be complete since they offer overlapping service at different prices.

\section{Conclusions}

The temporal GIS presented in this article can be used to assess the effectiveness and efficiency of transportation options at the regional, transit agency, and route level. The method uses off-the-shelf software and it is immediately useful to transit agencies with ride-check information. The end-products of the methodology provide the tools necessary to inform elected officials, who fund transportation programs, and the public on current transit usage and to generate support for creative public transportation policies. The application of the methodology elsewhere and the sharing of the analytical results are encouraged.

\section{Further Research}

The methodology presented here uses off-the-shelf software to visualize transit system performance with preexisting data. There is a need for an integrated software product connected to a Global Positioning Satellite (GPS) transponder collecting real-time data from transit vehicles in a continuous fashion. The enormous amount of data collected by these devices needs to be filtered to produce the visualizations presented here. These can serve as prototypes for product results.

The software would integrate AVLs, automatic passenger counters, and automated fare collection through the GPS, and depict the transaction outputs as a temporal GIS. Issues such as hardware compatibility and open connectivity standards for emerging technologies need to be addressed. As an example, the AVL portion of the hardware could be tied to computer-aided dispatch to maximize efficiency. This product could serve as the basis for establishing specifications that could advance a standard for the transit industry. 


\section{Acknowledgments}

The authors wish to thank Julian Burke, chief executive officer of the MTA; James de la Loza, executive officer for countywide planning; and James McLaughlin, director of transit planning, for their support. An appreciation is extended to Thomas Amiya, Mauro Arteaga, Kathy Hesseltine, and Devang Parikh for their technical assistance. Six anonymous reviewers are thanked for their constructive suggestions. The opinions contained in this article are solely those of the authors and do not represent the official view of the Los Angeles County MTA.

\section{Endnote}

1. The MTA statistics were obtained from the annual ridership data in effect from June 1999.

\section{References}

American Public Transit Association. 2000. APTA 2000 transit fact book. APTA, Washington DC, p. 111.

Chrisman, Nicholas. 1997. Exploring Geographic Information Systems. John Wiley \& Sons, NY, p. 5.

City of Los Angeles Planning Department. 1995. Citywide general plan frameworksocioeconomic impact assessment report. City of Los Angeles, p. 26.

Draper, N. R., and H. Smith. 1981. Applied regression analysis. John Wiley \& Sons, NY, p. 8.

Teal, Roger F., and Terry Nemer. 1986. Privatization of urban transit: The Los Angeles jitney experience. Transportation 13. Martinus Nijhoff Publishers, Dordrecht, Holland, p. 5-22.

U.S. Census Bureau and U.S. Department of Commerce from World almanac and book of facts 1995. Funk \& Wagnalls Corporation, Mahwah, NJ, p. 840. 


\section{About the Authors}

ANibal A. Galíndez (galindeza@hotmail.com) is a transportation project manager in the transit planning unit of the countywide planning division at the Metropolitan Transportation Authority. He is currently involved in data mining, ITS, and the examination of variables for their inclusion into a regional planning network. He holds a master's degree in operations research/applied statistics from the University of Miami.

RiCardo Mireles-Córdova (rmc@magi.net) is an information services director in the facilities planning division of the Los Angeles Unified School District. He holds a bachelor's degree in anthropology from Columbia University. He is presently engaged in the development of web-based information tools. 


\title{
Evaluation of Garden State Parkway Alternate Bus Routing Field Operational Test
}

\author{
Kaan Ozbay, Tilanka Karunaratne, and Trefor Williams \\ Department of Civil and Environmental Engineering, Rutgers University \\ Diogenes Feldhaus and Mohsen Jafari \\ Department of Industrial Engineering, Rutgers University
}

\begin{abstract}
$\overline{\text { Abstract }}$
This study evaluates the effectiveness of the New Jersey Garden State Parkway (GSP) Alternate Bus Routing (ABR) system, an Advanced Public Transportation System (APTS). The GSP ABR Field Operational Test (FOT), which was conducted on a small portion of the parkway, was mainly concerned with real-time routing of New Jersey Transit (NJT) buses traveling the GSP to a parallel alternate route to avoid congestion on the parkway.

One of the most important features of this FOT is the use of NJT buses as probe vehicles that provide real-time travel-time information to the bus routing algorithm. The use of probe vehicles for network surveillance increases the attractiveness of similar systems that can be deployed over larger networks where infrastructure-based surveillance can be prohibitively expensive. The functional evaluation of GSP ABR includes the collection and analysis of data from various sources including traffic sensors, probe vehicles, and surveys conducted among transit bus operators and system users.
\end{abstract}

During the official testing period in 1997, the GSP ABR system produced accurate diversion messages, which proved the reliability of the system. However, the rela- 
tively short length of the alternate route, U.S. Route 9, and similar traffic patterns observed on both routes did not give the evaluation team the opportunity to observe scenarios where statistically significant travel-time improvements exist. This result prevented the evaluation team from reaching conclusive recommendations in terms of the effectiveness of this FOT. However, the survey results show that both transit bus operators and ABR system operators believe the system can be very beneficial if implemented in a different network.

From a policy point of view, the general conclusions of the functional tests presented along with a list of lessons learned can be used in the effective design of future FOTs in the area of APTS.

\section{Introduction}

One of the most efficient ways to understand and assess the effectiveness of Intelligent Transportation Systems (ITS) in improving the existing transportation system is through the implementation of FOTs. FOTs are projects aimed at deploying promising ITS technologies in relatively small-scale networks. Evaluation of these FOTs is an integral part of the overall tests, because the major goal for the limited deployment of ITS technologies is to assess the effectiveness of the deployed ITS technology and draw general conclusions that can be used to ensure success of future large-scale ITS deployment projects. Currently, most ITS FOTs deal with passenger vehicles and related infrastructure. However, public transportation can be equally impacted by the use of advanced technologies recently introduced in the context of ITS. To better understand possible effects of advanced ITS technologies on public transit, real-world field implementation of these technologies and subsequent evaluation of their effectiveness is needed.

The GSP ABR FOT project is concerned with real-time routing of NJT buses to avoid congested highway stretches along the test corridor shown in Figure 1. This is similar to the real-time traffic diversion concept implemented by incident management crews to reroute traffic around the closed highway link as a result of a traffic accident (Ozbay and Kachroo 1999). In this project, however, the diversion recommendation is limited to participating NJT buses; the other vehicles are not given any diversion messages. Based on the diversion 


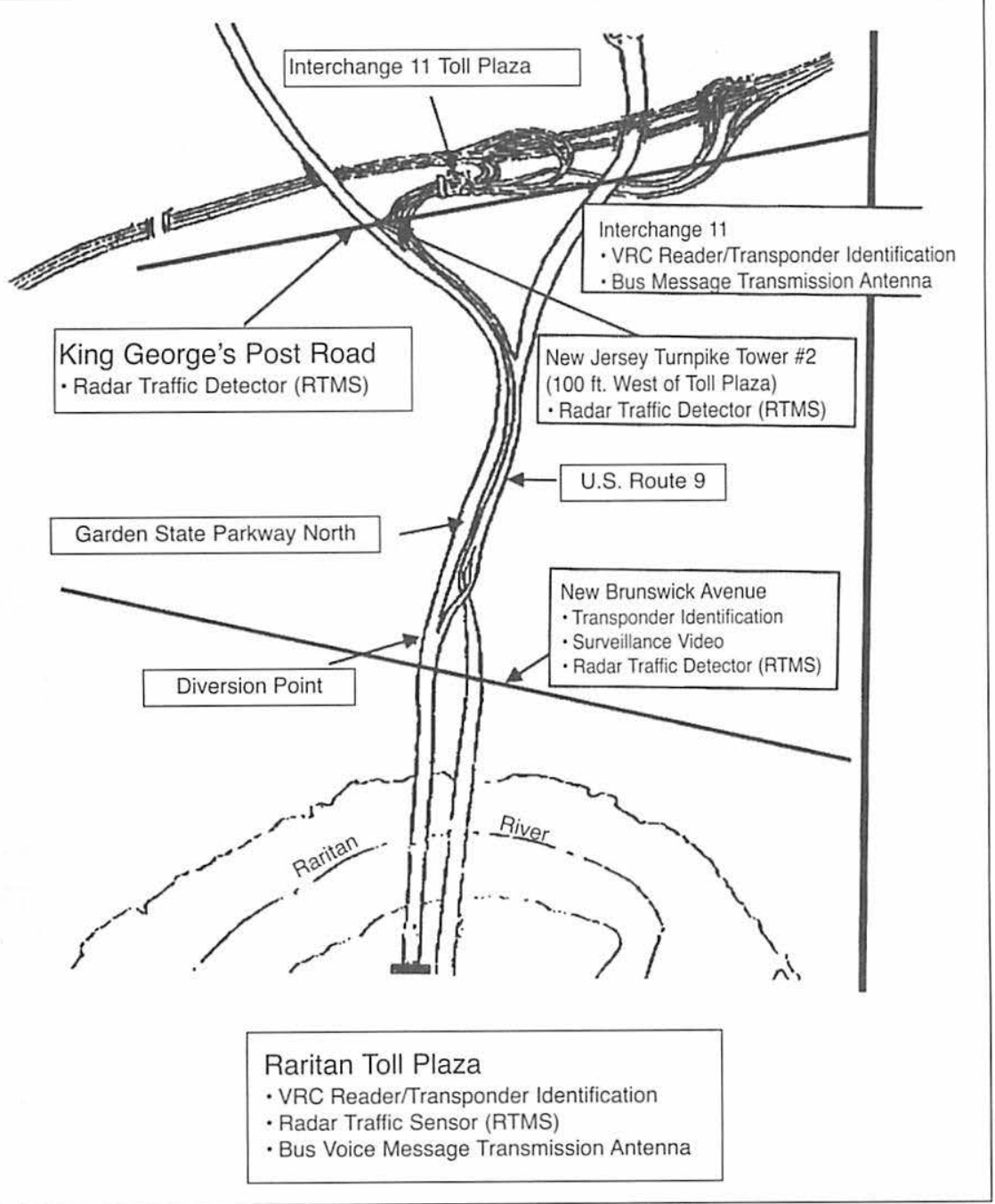

Source: Based on U.S. Department of Transportation (DOT) Federal Highway Administration (FHWA), 1966.

Figure 1. GSP ABR network

recommendation generated by the GSP ABR system, NJT buses are routed in real time to an alternate route, U.S. 9.

This article has three main objectives:

1) to describe the FOT and the plan developed specifically to evaluate the deployment of this APTs; 
2)to present the evaluation results of this unique advanced public transit FOT performed in one of the most heavily congested areas of the United States; and

3)to present a list of general conclusions and lessons learned that can be used as a future guide for the implementation of similar ITS projects in the context of public transit systems.

\section{Project Overview}

The ABR project on the GSP is an operational field test designed to improve the efficiency of NJT buses traveling the parkway and to reduce the commuting time of bus passengers. The system is expected to accomplish these goals by transmitting real-time routing diversion messages directly to the NJT buses heading north toward New York City at the entrance of the project location at the Raritan Toll Plaza.

Figure 1 represents the layout of the ABR system network. The route guidance system obtains real-time traffic information from road sensors and probe buses and makes a decision regarding whether diversion from the GSP to the alternate route is warranted. If the answer is positive, the diversion message is broadcast to incoming NJT buses through annunciators installed in the buses.

The project was planned as a two-phase effort. During the first phase, 50 NJT buses equipped with Automatic Vehicle Identification (AVI) transponders and audio annunciators acted as probe vehicles. Based on the results of the Phase 1 evaluation, a decision was made regarding implementation of Phase 2, which required the instrumentation of the remaining $350 \mathrm{NJT}$ buses. Thus, the results of Phase 1's evaluation played an important role in determining if it was feasible to continue with the implementation of Phase 2.

The GSP ABR project, which can be identified as an ITS FOT, was designed to satisfy six national goals for ITS projects identified by the FHWA (U.S. DOT 1996):

1) improve the safety of the nation's surface transportation system;

2) increase the operational efficiency and capacity of the surface transportation system;

3) reduce environmental costs associated with traffic congestion; 
4)enhance present and future productivity;

5)enhance the personal mobility and convenience and comfort of the surface transportation system; and

6)create an environment in which the development and deployment of ITS can flourish.

Based on these goals, the evaluation team identified three major goals for this project:

1) enhance system performance by reducing NJT bus travel time during the morning rush hour by transmitting real-time diversion information directly to participating NJT buses;

2)ensure GSP ABR system reliability in terms of routing decisions that depend, in turn, on the reliability of traffic sensors, proven vehicle data, and the routing algorithm; and

3)ensure user acceptance by proving to the users (i.e., limited-case transit operators) that the GSPABR will enhance the mobility of the existing system.

Table 1 shows the relationship of the goals of the ABR project to the national ITS goals.

\section{The GSP ABR Demonstration Project}

This FOT involved three transportation agencies: NJT, New Jersey Highway Authority, and TRANSCOM, which is a partnership of a number of agencies in New Jersey and New York.

\begin{tabular}{|c|c|c|c|c|c|c|}
\hline \multicolumn{7}{|c|}{$\begin{array}{c}\text { Table } 1 \\
\text { Relationship between ITS Goals and ABR Goals }\end{array}$} \\
\hline ITS Goals & $\begin{array}{l}\text { Improve } \\
\text { Safety }\end{array}$ & $\begin{array}{l}\text { Increase } \\
\text { Efficiency }\end{array}$ & $\begin{array}{c}\text { Reduce } \\
\text { Environmental } \\
\text { Costs }\end{array}$ & $\begin{array}{l}\text { Enhance } \\
\text { Productivity }\end{array}$ & $\begin{array}{l}\text { Enhance } \\
\text { Personal } \\
\text { Mobility }\end{array}$ & $\begin{array}{c}\text { Promote } \\
\text { ITS }\end{array}$ \\
\hline $\begin{array}{c}\text { System } \\
\text { Performance }\end{array}$ & $\sqrt{ }$ & $\sqrt{ }$ & $\sqrt{ }$ & $\checkmark$ & $\sqrt{ }$ & $\sqrt{ }$ \\
\hline $\begin{array}{c}\text { System } \\
\text { Reliability }\end{array}$ & $\sqrt{ }$ & & & & & $\checkmark$ \\
\hline User Acceptance & & $\sqrt{ }$ & & $\sqrt{ }$ & $\sqrt{ }$ & $\checkmark$ \\
\hline
\end{tabular}


This ABR FOT was located between GSP milepost 125.4 and New Jersey Turnpike interchange-11 (NJT-11) shown in Figure 1. The main goal of the ABR project was the development of a bus routing system that provides realtime alternate routing information to NJT buses traveling northbound on the GSP. In the absence of diversion messages, all the NJT buses used the GSP, the primary route according to the ABR system. However, in the event of excessive congestion on the GSP, NJT buses were diverted to the secondary route. Table 2 summarizes the functional capabilities of the GSP ABR system.

The GSP ABR system physical architecture (shown in Figure 2) was comprised of these components installed at locations in the test network shown in Figure 1:

- Remote Traffic Microwave Sensors (RTMS),

- VRC transponder/reader,

- audio annunciators, and

- surveillance camera.

\section{Functional Analysis of the System}

Functional analysis measures the performance of the individual system components as well as the performance of the complete integrated system. The evaluation tests developed in this FOT are briefly explained in Table 3. Table 4 shows the relationship between the evaluation tests developed and the major goals of this FOT.

\section{Data Sources}

Data for the ABR project was obtained from two main sources, Rutgers University instrumented vehicle and ABR system traffic sensors.

\section{Rutgers University Instrumented Vehicle Data}

Two vehicles instrumented with AVI tags were used by Rutgers University to collect independent travel-time data along the study site on the GSP and U.S. 9. Experimental configuration of a Rutgers instrumented vehicle and its relationship to the rest of the GSP ABR system is shown in Figure 3. The instrumented vehicle had all the equipment that the NJT buses had. This configuration was needed to ensure proper testing of the hardware functions of the system. 
Table 2

\section{Functional Capabilities of Data Processing Centers of the ABR System}

Raritan Toll Plaza-Mile Post 125.4

- RTMS sensor-GSP data monitored

- VRC reader

- Bus message transmission antenna

- Radio communications between TOC and equipment at Raritan Toll Plaza

- Inner roadway has 3 lanes; outer roadway has 4 lanes

- Equipment is placed and installed on the variable message sign

New Brunswick Avenue-Mile Post 128.4

-Surveillance camera

.RTMS sensor-U.S. 9 and GSP data monitored

.VRC transponder

-Equipment is mounted on southern face of the New Brunswick Avenue overpass

- Radar and VCR transponder cover all 5 inner lanes of GSP and all 4 outer lanes of U.S. 9

-Radio communications with TOC and New Brunswick Avenue overpass

King George's Post Road-Mile Post 129.1

-RTMS radar traffic data-GSP and U.S. 9 data monitored

- Radar is mounted at the overpass abutment to give complementary traffic information

-Detector covers both ramps from U.S. 9 to New Jersey Turmpike and the outer lanes of GSP that feed the

- ramp to the turnpike

-Ramps from U.S. 9-3 lanes

.GSP north lanes- 5 lanes

New Jersey Turnpike Tower \# 2-100 ft. West of the Toll Plaza

-RTMS radar traffic detector is mounted at the tower-monitors GSP and U.S. 9

.GSP and U.S. 9 merges at this point

New Jersey Turnpike Sign Structure-2500 ft. East of the Toll Plaza

-VRC reader

- Bus message transmission antenna

- Sign structure at the northbound New Jersey Turnpike entrance ramp

-VCR beacon mounted over the signAll 3 lanes of the ramp are covered by the VCR transponder

New Jersey Turnpike Headquarters-New Brunswick

- Send bus messages-at exit 11 only

- Summary of traffic data and reports

- Ability to view surveillance video from the camera placed at New Brunswick Avenue

New Jersey Transit Operations-Maplewood

- Bus message override

- Summary of traffic data and reports

- Ability to view surveillance video from the camera placed at New Brunswick Avenue

TRANSCOM Jersey City

- Ability to view surveillance video from the camera placed at New Brunswick Avenue

New Jersey Transit Operations-Maplewood

- Connect all above-cited sites

- Recording of voice messages

- Display traffic data

- Generate statistical reports

- Analyze real-time traffic data

- Determine optimum advisory message

- Ability to override messages

- Ability to control camera at New Brunswick A venue

Source: Based on information provided by Hughes Electronics, 1995.

Vol. 3, No. 4, 2001 


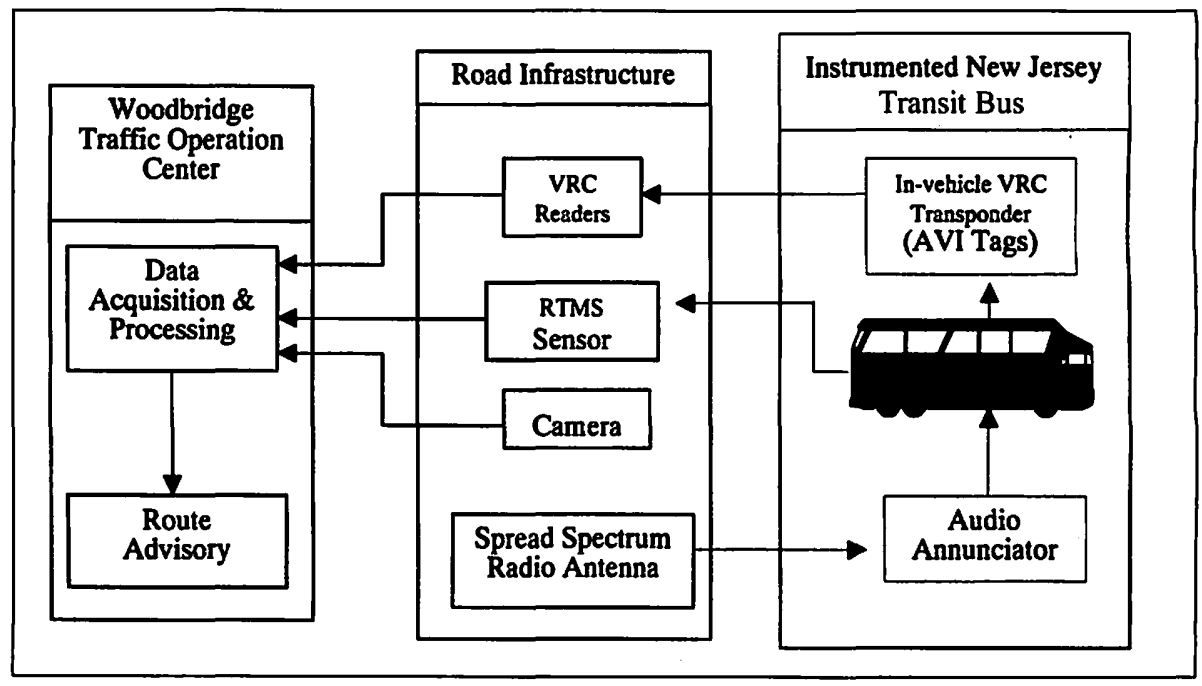

Figure 2. System architecture of ABR project

Data were obtained during the peak rush-hour periods (6:30-9:00 A.M.) when a diversion condition was most likely to occur. The instrumented vehicles were used to perform synchronized parallel runs to determine travel-time differences between the primary (GSP) and alternate route (U.S. 9). The two test vehicles entered the Raritan Toll Plaza on the GSP simultaneously, then separated at the diversion point, and met at the end of each run after NJT-11 at the New Jersey Turnpike. Both drivers completed travel logs after each run, and included the test time (synchronized with the ABR system) and length of travel times for each predetermined station point along the route. Travel-time data were compared with ABR system output to evaluate system travel-time data accuracy.

The transponders in the test vehicles were turned on once a day for a complete run for (1) testing the messaging function of the system and (2) testing the accuracy of the "tagged" travel times obtained by the system. Transponders were not turned on during all the test runs to avoid the risk of introducing bias to the traveltime estimation of the ABR system algorithm due to the additional probe data.

\section{ABR System Data}

The operator at the traffic operation center at the New Jersey Highway Authority provided the following information daily for the 6:00-9:00 A.M. time period: 


\section{Table 3}

\section{Evaluation Test Numbers, Names, Symbols, and Descriptions}

\begin{tabular}{c|c|c}
\hline $\begin{array}{c}\text { Test } \\
\text { Number }\end{array}$ & Test Name & Test Description \\
\hline Functional & Testing
\end{tabular}

\begin{tabular}{|l|l|l|}
\hline FPT-01 & Bus Routing & $\begin{array}{l}\text { Verifies that the routing system is functioning properly under a } \\
\text { range of conditions. }\end{array}$ \\
\hline FPT-02 & Audio Messaging & $\begin{array}{l}\text { Verifies that the audio messages received by the bus drivers } \\
\text { are comprehensible. }\end{array}$ \\
\hline FPT-04 & $\begin{array}{l}\text { Traffic-Volume Data } \\
\text { Accuracy }\end{array}$ & $\begin{array}{l}\text { Verifies that the traffic volume collected by the system is } \\
\text { accurate to a given degree of accuracy. }\end{array}$ \\
\hline FPT-05 & $\begin{array}{l}\text { Travel-Time Data } \\
\text { Accuracy }\end{array}$ & $\begin{array}{l}\text { Verifies that the travel-time data collected by the automatic } \\
\text { system is accurate to a given degree of accuracy. }\end{array}$ \\
\hline System-Wide Performance Testing \\
\hline SW-01 & $\begin{array}{l}\text { Bus Travel-Time } \\
\text { Reduction }\end{array}$ & $\begin{array}{l}\text { Will analyze and determine the reduction (if any) in bus travel } \\
\text { time due to the automatic traffic management system. If } \\
\text { possible, this test should take into account a wide range of } \\
\text { possible scenarios reflecting normal traffic conditions, high- } \\
\text { peak (e.g., during holidays) conditions. }\end{array}$ \\
\hline SW-03 & $\begin{array}{l}\text { Consumer } \\
\text { Satisfaction }\end{array}$ & $\begin{array}{l}\text { Will analyze and determine consumer satisfaction due to better } \\
\text { bus routing and reduced travel time. }\end{array}$ \\
\hline
\end{tabular}

\begin{tabular}{|c|c|c|}
\hline \multicolumn{3}{|c|}{$\begin{array}{c}\text { Table } 4 \\
\text { Relationship between Evaluation Tests and ABR Goals }\end{array}$} \\
\hline Goal 1 & Evaluate System Performance & Tests \\
\hline 1. & Assess reduction in bus travel time due to routing change. & SW-01 \\
\hline 2. & Assess algorithm capability of selecting the correct route. & SW-01 \\
\hline Goal 2 & Evaluate System Reliability & \\
\hline 3. & Assess traffic-volume data collected by the system. & FPT-04 \\
\hline 4. & Assess travel-time data collected by the system. & FPT-05 \\
\hline Goal 3 & Evaluate User Acceptance & \\
\hline 5. & Assess quality of the audio messages. & FPT-02 \\
\hline 6. & Assess acceptance of the routing information by the users. & SW-03 \\
\hline 7. & Assess the best audio message to transmit. & FPT-02 \\
\hline
\end{tabular}




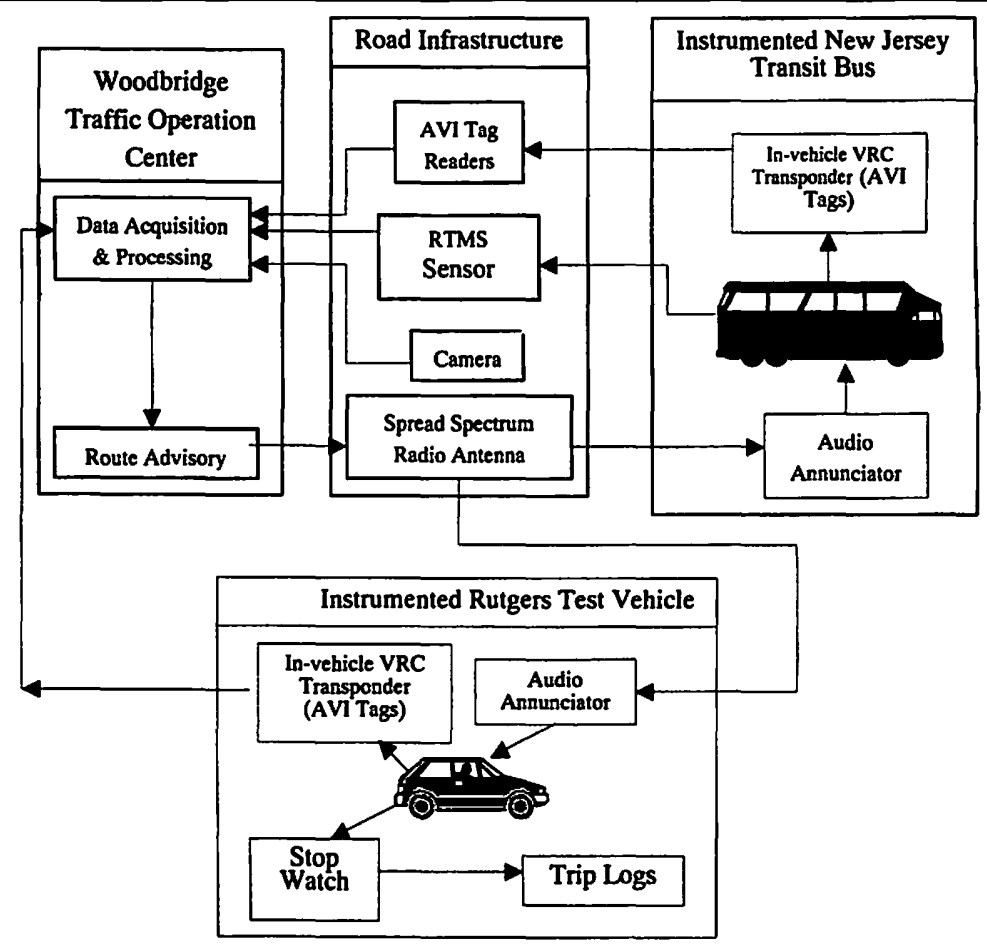

Figure 3. Experimental configuration of instrumented Rutgers test vehicle in the overall context of the GSP bus routing project

- Detector Data. Detector data included the RTMS output for average speed, occupancy, and volume data for each location aggregated over each 30 -second interval.

- Tag Data. AVI tag data provided travel-time information of the NJT buses. These data contained current time, location, bus identity number, route choice, total trip time for each bus, and the current routing message generated by the ABR system.

- System Log Data. Log data consisted of four-minute summaries of the ABR system output. The data included estimated travel times for GSP and U.S. 9; station delays; and five-minute aggregated volume, occupancy, and speed data.

- Video Output. Traffic conditions at New Brunswick Avenue were videotaped from 6:30-9:00 A.M. daily. Apart from enabling visual access to the system from the traffic operations center, these video images were used for traffic volume data accuracy testing. 


\section{Data Collection and Analysis}

The following sections describe the data collection and analysis methods used in this study.

\section{Evaluation of Operation of RTMS Traffic Sensors (FTP-04-Traffic-Volume Data Test)}

A summary of the sample traffic volume data test, which evaluated the accuracy of radar sensors, is shown in Table 5. RTMS have been independently evaluated by the manufacturer as part of other FOTs. However, the evaluation team and participating agencies decided to test the accuracy of the traffic detectors under the existing operating conditions. This test was designed to identify any problems specific to this network and traffic conditions. Thus, the evaluation team used volume counts as the testing criteria because of the relative ease of collecting dependable ground truth volume data. Traffic volume counts were performed at New Brunswick Avenue using video camera images obtained from the traffic operation center. Specifying an alpha value of 5 percent, the true mean, with a confidence of 95 percent, was placed in the following interval of $[0,15.4691]$. Since the confidence interval does cover zero, values do not supply enough evidence to affirm that the Rutgers volume counts versus the system volume counts had different means. According to the collected data, the ABR system had a smaller average volume value than the real average volume value, assuming the Rutgers counts represented the real val-

\begin{tabular}{|c|c|}
\hline \multicolumn{2}{|c|}{$\begin{array}{c}\text { Table } 5 \\
\text { Summary of Sample Volume Count Data } \\
\text { Volume Counting Differences between Rutgers and ABR System }\end{array}$} \\
\hline Date of Volume Data Collection (from 6:50 A.M.-8:20 A.M.) & November 25, 1997 \\
\hline $\begin{array}{l}\text { Average of difference of volume counts: } \\
\text { Volume(Rutgers)-Volume (System) }\end{array}$ & 3.55 \\
\hline $\begin{array}{l}\text { Maximum value of difference of volume counts: } \\
\text { Volume(Rutgers)-Volume (System) }\end{array}$ & 20 \\
\hline $\begin{array}{l}\text { Minimum value of difference of volume counts: } \\
\text { Volume(Rutgers) - Volume (System) }\end{array}$ & -15 \\
\hline Total Volume (Rutgers) & 5653 \\
\hline Total Volume (System) & 5024 \\
\hline $\begin{array}{l}\text { Standard deviation of difference of volume counts: } \\
\text { Volume(Rutgers)-Volume(System) }\end{array}$ & 6.05 \\
\hline Number of observation points & 177 \\
\hline \% Total Difference & $11.12 \%$ \\
\hline
\end{tabular}


ues. The real volume was found to be, on average, 11.1266 percent larger than the volume counts supplied by the ABR system. A detector calibration procedure helped to reduce the difference between the real and system volume counts. Also the radar manual stated that errors up to \pm 5 percent are acceptable for the RTMS counts. This test concluded that both the system and the evaluation team's volume counts did not have a statistically significant difference of means based on the results of the t-test and thus the data collected by RTMS were considered statistically accurate.

\section{Evaluation of the Integrated ABR System's Accuracy (FPT-05-Travel-Time Data Accuracy Test, FTP-01-Bus Routing Test)}

The evaluation of the integrated ABR system's accuracy was performed effectively by analyzing the impact of the integrated system's main output, namely, "the routing decisions." If the routing decisions are appropriate for most of the traffic patterns experienced in the system, the integrated ABR system can be considered accurate. The ABR system's accuracy was evaluated using two tests:

1)FPT-05-Travel-Time Accuracy Test: Travel times calculated by the ABR system for the two routes had to be accurate to generate reliable and precise diversion messages since the major requirement for the generation of a diversion message was the presence of significant traveltime difference between the GSP and U.S. 9. The ground truth data for this test were collected using Rutgers test vehicles traveling on the two alternate routes.

2)FTP-01-Bus Routing Test: The main purpose of this test was to evaluate if the ABR system bus routing algorithm generated reliable and accurate routing advisories based on the travel-time estimations of the $A B R$ system. The ABR bus routing algorithm generated diversion messages and sent them to buses traveling across the project section only if:

- the difference between the system estimated trip time at the GSP and U.S. 9 was larger than a preestablished threshold value (set at four minutes),

- the trip time at the GSP was greater than a preestablished threshold value (set at five minutes), or 
- the diversion message was not overridden by the system operators.

The travel-time accuracy test (FPT-05) was based on the testing of the differences in travel times estimated by the ABR system and actual travel times observed by the Rutgers test vehicles. These travel times were route travel times at any given time "t" and ABR system used point travel-time measurements in combination with probe vehicle (bus) travel times to estimate travel times on both routes. Thus, the Rutgers team decided to use instrumented test vehicles to measure actual travel times on both routes and compare these measurements with $\mathrm{ABR}$ system route travel-time estimates.

These ground truth route travel-time data were collected by the Rutgers evaluation team using two instrumented vehicles to conduct synchronized, parallel runs on the GSP and U.S. 9 from 6:30 A.M. to 9:00 A.M. to analyze the travel-time estimation process. Travel-time data from the Rutgers vehicle was compared with the ABR system travel-time estimates. Trip times were calculated based on these equations.

$T T(G S P)=$ Time $($ ICT/GSP)-Time $($ RAR/GSP $)$

$T T$ (US9) $=$ Time(ICT/US9) - Time(RAR/US9)

where:

TT (GSP) $=$ travel time for the Rutgers vehicle traveling on the GSP.

TT (US9) = travel time for the Rutgers vehicle traveling on U.S. 9.

Time $(\mathrm{ICT} /$ route $)=$ time the Rutgers vehicle crossed the radar placed at NJT-11. The /route indicates which route was taken (GSP or U.S. 9).

Time $(\mathrm{RAR} /$ route $)=$ time the Rutgers vehicle crossed the radar placed before the Raritan Toll Plaza. The /route indicates which route was taken (GSP or U.S. 9).

The system estimates travel times every four minutes. Each estimate is valid until another travel-time estimation is computed by the system.

Table 6 summarizes both route travel times estimated by the GSP ABR system and measured by the Rutgers test vehicles. The system's general trend was to underestimate the travel times with a reasonable order of magnitude. 
The difference in travel times given by the system and by actual travel times can be reasonably modeled as a normal distribution. Additionally, the system showed more variability when comparing estimated and actual travel times at U.S. 9 than the GSP, according to analysis of the standard deviation of the travel-time differences.

\begin{tabular}{|cccc|}
\hline \multicolumn{5}{|c|}{ Table 6} \\
\multicolumn{2}{|c|}{ Summary of Travel-Time Differences (in seconds) (November 25, 1997) } \\
\hline Route & \multirow{2}{*}{ Mean Rutgers Travel Time } & $\begin{array}{c}\text { Mean System Travel Time } \\
\text { (seconds) }\end{array}$ & $\begin{array}{c}\text { Differences } \\
\text { (seconds) }\end{array}$ \\
\hline GSP & & 382 & 123 \\
U.S.9 & 505 & 337 & 179 \\
\hline
\end{tabular}

\section{Evaluation of In-Vehicle Operations}

The NJT buses that were part of the ABR project were equipped with onboard transponders and annunciators. These devices provided direct communication to the equipped buses to transmit route guidance messages. Similar devices have been used in other ITS projects, and the proper functionality of these onboard devices are crucial to ensure the complete link between the central computer system (responsible for the decision-making process) and the bus operator (agent responsible for the implementation of the diversion instructions).

The evaluation of in-vehicle operations encompasses the analysis of message quality sent to participating buses. These issues were investigated for a complete evaluation of the quality messages:

- length and time of message sending,

- clarity of messages,

- location the message is transmitted, and

- external facts affecting the messages quality.

The length and time of message sending was analyzed through the use of a customer satisfaction survey. According to the sample of bus operators that filled out the questionnaire, the length and time of message sending did not achieve excellent marks, therefore leaving room for further improvement.

The audio message test (FTP-02) was performed by activating the transponders on the instrumented vehicles during test runs to verify that mes- 
sages could be received at normal highway speeds at the Raritan Toll Plaza and NJT-11. When transponder tests were conducted using Rutgers test vehicles, the initial message was heard at the proper location, right before the Raritan Toll Plaza. The message was also heard clearly under a variety of weather conditions, such as clear and rainy. The intensity of the volume and clarity of the message were acceptable during the test vehicle runs.

According to audio message testing results conducted by the Rutgers evaluation team, the length, time, and road position of messages sent were found to be adequate for the project purposes. However, the results of the questionnaire from the bus operators indicated that the system requires further improvement. This difference is due to the fact that bus operators that were new or not familiar with the GSP ABR study had difficulty understanding the diversion messages. They were sometimes also surprised with the message, sent just before the Raritan Toll Plaza. However, the simple capability of repeating the messages by pressing a button on the transponders could have solved this problem without any major changes to the system.

\section{Evaluation of the Integrated ABR System Performance}

The GSP ABR system consists of several components that perform specific functions. The evaluation of the integrated system was performed during the official testing period to test the system's:

- capability to produce effective diversion messages that reduce NJT bus travel times;

- ability to be understood and interact with its users, namely, bus drivers and operators; and

- capability of creating a positive perception among users regarding the system outputs, such as quality of messages and number of useful diversion messages issued.

Two major testing activities were conducted during morning rush hours at a maximum level of system requirements:

1) SW-01-Bus Travel-Time Reduction Test. System output was used to conduct the "bus travel-time" reduction test. 
2) SW-03-Consumer Satisfaction Test. Surveying was chosen as the major tool to conduct the consumer satisfaction test. Both bus drivers and system operators were surveyed to understand their perception of the ABR technology. The surveys were also useful in identifying areas of improvement for the system.

\section{Bus Travel-Time Reduction Test (SW-01)}

This test was performed by analyzing the system's output of diversion messages. During the testing days, system diversion messages, advising the use of the alternate route (U.S. 9), were issued. The occurrence and the time they affected a tagged vehicle traveling in the system were collected and the results were summarized and analyzed.

A summary of diversion messages compiled during the testing period showed that no diversion message, except one on December 11, 1997, lasted more than 15 minutes (Ozbay et al. 1998). The real length of the diversion message is a multiple of 4 minutes because the system issues new diversion messages at this rate. The effective length of a diversion message is equal to or smaller than a multiple of 4 minutes and may be used as a measurement of system performance because it also counts the rate that buses enter the system. This rate is proportional to the number of participating buses in the project. Table 7 gives a summary of diversion messages generated by the system during the testing period. The relatively low number of diversion messages during the testing period makes it difficult to draw conclusions regarding this issue. Given the traffic and network conditions of the ABR system, it was found that the probability of a diversion was very low (Table 8). This result limited the usefulness of the GSP ABR system in terms of understanding the effects of real-time bus routing because there were not too many cases where diversion of NJT buses from the GSP to U.S. 9 was warranted.

Table 7 shows that the most important factor for the system to be effective is its capability of transmitting the diversion message to the buses at the right time and at the right place. For example, although there were nine buses traveling during the time period when the diversion message was broadcast by the system, only three buses received the message. This might be partly due to 
the fact that they were not at the right location at the right time. Thus, it is extremely important to choose the best locations and most effective timing for disseminating diversion messages to the buses.

\section{Consumer Satisfaction Test (SW-03)}

This test was designed to measure the success of implementing a new technology that basically depends on user acceptance. Therefore, customer satisfaction is an important aspect of the integrated system evaluation. The main users of the ABR system are the NJT bus operators and the system operators who monitor the system. Customer satisfaction surveys were conducted in two parts: one set of surveys was designed for bus operators and the other for system operators.

\section{Summary of Survey Results Conducted among Bus Operators}

Twenty-one NJT bus operators were surveyed and interviewed on December 11, 1997, the final week of official testing at the Howell garage. The survey was designed to query bus operators in three areas: message transmission, routing information, and equipment.

The analysis of the surveys revealed several important points:

- All of the operators were familiar with the alternate route (U.S. 9).

- Sixty-three percent of the operators did not find the diversion messages clear, while 47 percent of the operators thought the sound quality could be improved by increasing the volume. Sixty-eight percent of the drivers replayed the diversion message.

\begin{tabular}{|c|c|c|c|}
\hline \multicolumn{3}{|c|}{ Summary of Diversion Messages } \\
\hline Date & $\begin{array}{c}\text { No. of Tagged } \\
\text { Vehicles that } \\
\text { Diverted }\end{array}$ & $\begin{array}{c}\text { No. of Tagged Vehicles in the } \\
\text { System during the Diversion } \\
\text { Message }\end{array}$ & $\begin{array}{c}\text { No. of Tagged Vehicles that the } \\
\text { Message was Transmitted to at Raritan } \\
\text { Toll Plaza }\end{array}$ \\
\hline $11 / 17 / 97$ & 2 & 9 & 3 \\
\hline $11 / 18 / 97$ & 0 & 1 & 0 \\
\hline $11 / 20 / 97$ & 3 & 11 & 5 \\
\hline $11 / 25 / 97$ & 1 & 6 & 6 \\
\hline $12 / 11 / 97$ & 0 & 5 & 1 \\
\hline $12 / 12 / 97$ & 0 & 4 & 0 \\
\hline $12 / 15 / 97$ & 1 & 3 & 1 \\
\hline $12 / 16 / 97$ & 0 & 2 & 0 \\
\hline $12 / 17 / 97$ & 1 & 2 & 1 \\
\hline
\end{tabular}




\section{Table 8}

Summary of Travel-Time Differences on GSP and U.S. 9 (in seconds) (Travel-Time Difference $=$ TravelTime_GSP- TravelTime_US 9)

\begin{tabular}{|c|c|c|c|}
\hline Date & $\begin{array}{c}\text { No. of Tagged } \\
\text { vehicles that } \\
\text { Diverted }\end{array}$ & $\begin{array}{c}\text { No. of the Tagged Vehicles } \\
\text { in the System during the } \\
\text { Diversion Message }\end{array}$ & $\begin{array}{c}\text { No. of Tagged Vehicles that the } \\
\text { Messages was transmitted to at } \\
\text { Raritan Toll Plaza }\end{array}$ \\
\hline $11 / 17 / 97$ & 2 & 9 & 3 \\
\hline $11 / 18 / 97$ & 0 & 1 & 0 \\
\hline $11 / 20 / 97$ & 3 & 11 & 5 \\
\hline $11 / 25 / 97$ & 1 & 6 & 6 \\
\hline $12 / 11 / 97$ & 0 & 5 & 1 \\
\hline $12 / 12 / 97$ & 0 & 4 & 0 \\
\hline $12 / 15 / 97$ & 1 & 3 & 1 \\
\hline $12 / 16 / 97$ & 0 & 2 & 0 \\
\hline $12 / 17 / 97$ & 1 & 2 & 1 \\
\hline
\end{tabular}

- Sixty-seven percent of the drivers were optimistic that the ABR system would improve travel time, while 47 percent believed that the alternate route provided an advantage after the diversion instruction.

- Eighty percent of the drivers thought the diversion message was accurate.

- Sixty percent of the bus drivers agreed that the ABR system saves travel time.

- Twenty-five percent of the drivers diverted to U.S. 9 when the diversion message instructed the operators to stay on the GSP.

- Eighty-five percent of the operators agreed that the equipment was functioning effectively and installed correctly.

\section{Summary of Survey Results Conducted among System Operators}

The system operators of the ABR project who monitor the GSP ABR system from the traffic operation center in Maplewood were also surveyed. The operator survey form consisted of three main sections: routing information, software management, and equipment. The conclusions of the survey, conducted among three system operators, are summarized below.

Routing Information. All three operators believed the system's diversion decisions were almost correct. Two operators stated that they overrode the sys- 
tem's diversion message once because they felt the diversion was not warranted. They also agreed that the alternate route did not save any time at all. The operators unanimously agreed that the system could have potentially provided useful information if the alternate route had been different. They also all agreed that the ABR system can be enhanced by improving the performance of the existing camera and adding new cameras.

Software Management. The software operation training and information provided by the software developers were rated as adequate. The volume, speed, and occupancy information displayed by the software were also found satisfactory by the system operators.

Equipment. There was a difference of opinion among the three operators regarding the functioning of the surveillance camera. One operator rated most of the camera functions as perfect while another operator rated them as barely adequate or poor. The third operator rated all camera functions as average or adequate.

\section{Conclusions}

Based on the results of the evaluation, two important conclusions specific to this FOT are evident:

1) Similarity of travel times on both routes (Table 8). Even if one route gets congested, the other route gets quickly congested, too, due to the drivers switching to the alternate route. This, in turn, limits the usefulness of the ABR system by eliminating the possibility of directing NJT buses to the uncongested route. During morning travel-time data collection, the locations on the GSP and U.S. 9 that were affected during the rush hour were found before the Raritan Toll Plaza, Driscoll Bridge, and NJT-11 tollbooth.

2) The ABR system used tag data upon the completion of a trip. Thus, diversion decisions were based on this completed run, using basically the system conditions that existed 5 to 10 minutes before the bus entered the system. Therefore, when the next bus received a route diversion message, this trip-time information may not have reflected the "actual" realtime system conditions. This problem can be remedied by modifying the 
$\mathrm{ABR}$ system to receive bus travel times at intermediate locations and not just at the end of the trip.

\section{Lessons Learned}

Several more general conclusions based on the system-specific conclusions and evaluation results can be used in the design of future successful APTS FOTs.

- Network and traffic conditions play an important role in the successful testing and evaluation of any ITS technology. Therefore, site selection for any FOT is of great importance. In this study, the selected network was too small and thus the travel-time differences between the two alternate routes were not statistically significant. This limited the usefulness of the FOT in terms of assessing the effectiveness of the system. This could have been easily identified as a potential problem if a simulation study had been performed prior to the initiation of the actual field study.

- Hardware and equipment problems are almost always site specific. The accuracy of sensors depends heavily on the appropriate installation and maintenance of the equipment. For example, RTMS that are widely used at other places had several problems in this FOT, mainly due to installation and site-specific problems.

- Hardware was the source of most of the major problems in this project. Due to the equipment and possibly some algorithmic estimation problems for the testing days, travel-time estimations of the ABR system were different than the ground truth travel times collected by the evaluation team. This type of equipment problem can seriously reduce the effectiveness of a real-time system. Operating conditions also play an important role in the successful implementation of even proven technologies such as annunciators used in this project. Messages were clear when tested by the test vehicles. However, 63 percent of the operators did not find the diversion message clear, while 47 percent of the operators thought the sound quality could be improved by increasing the volume. Sixty-eight percent of the drivers replayed the diversion message. 
- System users are usually open to new ITS technologies. However, the actual performance of the system plays an important role in ensuring the acceptance of the system by its users in the long term. Another important point is the need for involving system users before and during the implementation of any new ITS system and making sure that the system effectively responds to the needs of the actual users.

- The project team decided not to pursue the second phase of the project, which involved instrumentation of 350 NJT buses. The limitation of the test network in terms of travel-time differences between the two routes played an important role in this decision.

\section{Acknowledgments}

This project has been partially funded by a grant from the New Jersey Highway Authority. The contents of this article reflect the views of the authors who are fully responsible for the facts, accuracy of the data, and conclusions presented in the article and do not necessarily reflect those of NJHA and other organizations involved in this study.

\section{References}

Gardener-Rowe Systems. 1995. Single Point Diversion Strategy for the New Jersey Garden State Parkway.

Hughes Electronics. 1995. Alternate Bus Routing Project Functional Specification, Garden State Parkway Pilot System. Hughes Electronics.

Ozbay, K., M. Jafari, D. Feldhaus, T. Karunaratne, and T. P. Williams. 1998.

Evaluation of Garden State Alternate Bus Routing Project. Final Report.

Piscataway, NJ: Rutgers Intelligent Transportation Systems (RITS) laboratory, Rutgers University.

Ozbay, K., and P. Kachroo. 1999. Incident management for Intelligent Transportation Systems. Norwood, MA: Artech House Publishers.

U.S. Department of Transportation, Federal Highway Administration. 1996. Alternate Bus Routing: New Jersey Parkway. Project Overview Presentation, Washington DC. 
U.S. Department of Transportation. 1995. National ITS plan. First Edition, Volumes I and II. Washington, DC: U.S. Department of Transportation, ITS America.

\section{About the Authors}

KAAN OZBAY (kaan@rci.rutgers.edu) is an assistant professor at Rutgers University Department of Civil and Environmental Engineering.

Diogenes Feldhaus (dfeldhau@embraco.com.br) was a graduate student at Rutgers University Department of Industrial Engineering.

Tilanka Karunaratne was a graduate student at Rutgers University Department of Civil and Environmental Engineering.

MoHSEN JAFARI (jafari@rci.rutgers.edu) is an associate professor at Rutgers University Department of Industrial Engineering.

TREFOR Williams (tpw@rci.rutgers.edu) is an associate professor at Rutgers University Department of Civil and Environmental Engineering. 
